\title{
Bayesian Inference for Hospital Quality in a Selection Model
}

\author{
John Geweke \\ Departments of Economics and Statistics \\ University of Iowa \\ john-geweke@uiowa.edu \\ Gautam Gowrisankaran \\ Department of Economics \\ Harvard University, \\ Federal Reserve Bank of San Francisco, \\ and NBER \\ gautam_gowrisankaran@nber.org \\ Robert J. Town \\ School of Public Health \\ University of Minnesota \\ rjtown@umn.edu
}

July, 2002

\begin{abstract}
This paper develops new econometric methods to infer hospital quality in a model with discrete dependent variables and non-random selection. Mortality rates in patient discharge records are widely used to infer hospital quality. However, hospital admission is not random and some hospitals may attract patients with greater unobserved severity of illness than others. In this situation the assumption of random admission leads to spurious inference about hospital quality. This study controls for hospital selection using a model in which distance between the patient's residence and alternative hospitals are key exogenous variables. Bayesian inference in this model is feasible using a Markov chain Monte Carlo posterior simulator, and attaches posterior probabilities to quality comparisons between individual hospitals and groups of hospitals. The study uses data on 74,848 Medicare patients admitted to 114 hospitals in Los Angeles County from 1989 through 1992 with a diagnosis of pneumonia. It finds the smallest and largest hospitals to be of the highest quality. There is strong evidence of dependence between the unobserved severity of illness and the assignment of patients to hospitals, whereby patients with a high unobserved severity of illness are disproportionately admitted to high quality hospitals. Consequently a conventional probit model leads to inferences about quality markedly different than those in this study's selection model.
\end{abstract}

We thank Pat Bajari, Lanier Benkard, Richard Blundell, Gary Chamberlain, Mike Chernew, Tom Holmes, Steven Stern, anonymous referees and seminar participants at Duke, FRB Chicago, Georgetown, Harvard/MIT, Iowa, Michigan, Princeton, Stanford, UC Davis, Irvine and Riverside, Virginia, Yale, the Econometric Society Seventh World Congress and the Society of Economic Dynamics 1999 Annual Meetings for helpful comments. Any remaining errors are the sole responsibility of the authors. The first author acknowledges support from NSF grant SBR-9819444 and the second author acknowledges support from the University of Minnesota Supercomputer Institute. The views expressed herein do not represent those of the Federal Reserve System, the Federal Reserve Bank of San Francisco or of any other institution. 


\section{Introduction}

This paper develops new econometric methods to estimate hospital quality and other models with discrete dependent variables and non-random selection. Assessing the quality of care in hospitals is an important problem for public policy and a challenge for applied econometrics. ${ }^{1}$ Policy changes in Medicare reimbursement rates and the rise of managed care as well as technological innovations have affected hospital incentives, and through that, hospital quality ${ }^{2}$ These quality changes have large welfare effects and hence the potential for large deadweight losses.

Hospital patient discharge databases provide several indicators plausibly associated with hospital quality. Since they cover large numbers of patients and hospitals and are much less expensive to obtain and access than other sources of information, they have been widely used in comparisons of hospital quality. Mortality has been the most popular indicator of hospital quality in the literature: it is unambiguously defined and its link with quality of care is so strong as to be tautological. 4

In this widely used framework, the conceptual experiment that reveals hospital quality is hospital-specific mortality rates following random assignment of a population of patients to hospitals. Patients, however, are not randomly assigned to hospitals. Patients or their physicians are likely to choose hospitals based on factors such as location, convenience and their severity of illness. If assignment were nonrandom, but random conditional on observed characteristics, then conventional dichotomous outcome models could be used to infer the outcome of the conceptual experiment from the available data. However, discharge data contain only crude summaries of medically pertinent information and hence many aspects of the severity of illness are unobserved. Thus, the assumption of random conditional assignment is not tenable and patients with the same observed characteristics are not equally likely to be admitted to all hospitals. For

\footnotetext{
1 "As described by a leading study, "Quality of care is the degree to which health services for individuals and populations increase the likelihood of desired health outcomes and are consistent with current professional knowledge...," Lohr (1990, p. 4).

${ }^{2}$ See Cutler (1995), Kessler and McClellan (2000), McClellan and Noguchi (1998) for studies of the effects on medical outcomes of Medicare policy, the impact of managed care and the impacts of technological change, respectively.

${ }^{3}$ For instance, if changes in Medicare policies cause hospitals to reduced their pneumonia mortality rates by one percentage point, this would translate to over 6,000 lives saved annually in the U.S.

${ }^{4}$ Strictly speaking mortality is an indicator of hospital mediocrity; mortality is an inverse indicator of quality. Subsequently we provide a precise definition of hospital quality in the context of the model developed in this study.
} 
instance, if patients with high unobserved severity of illness select high quality hospitals, then observed mortality rates for high quality hospitals will be inconsistent and upwardly biased measures of mortality from the conceptual experiment. This will be true even after controlling for observed measures of severity of illness. Conventional statistical methods that ignore unobserved severity will produce misleading inferences about hospital quality. This has led prominent medical experts to make a pessimistic assessment of the usefulness of discharge data in assessing hospital quality.

Recent work by Gowrisankaran and Town (1999) developed a framework to control for the non-random assignment of patients. This work modeled mortality as a function of indicator variables for each hospital and patient discharge information. The authors treat mortality as continuous and directly apply linear instrumental variables methods. The identifying assumption is that a patient's mortality is not affected by how far that patient's residence is from alternative hospitals. Combined with the demonstrable fact that patients are more likely to choose hospitals that are closer to home, other things equal, the conventional conditions for consistency of instrumental variables estimation in a linear model are satisfied. Conceptually, the estimator would predict hospital A to be of higher quality than hospital B if patients residing near hospital A have lower mortality than patients residing near hospital B, after controlling for their medical and demographic characteristics.

The difficulty with this approach is that because the outcome variable, mortality, is dichotomous, any internally consistent model of hospital quality and choice must be nonlinear. This paper develops a logically coherent model designed to infer the outcome of the conceptual experiment that randomly assigns patients to hospitals, given data that has non-random patient assignment. ${ }^{6}$ Inference with this model is challenging because the amount of information per observation is small. ${ }^{\square}$ This paper develops an approach to inference in this model that is practical with the large data sets required to extract signal from noise in hospital patient discharge databases. This approach is potentially applicable to a wide range of policy evaluations of

\footnotetext{
${ }^{5}$ Leading medical researchers, including Iezzoni et al. (1996), and government studies (US GAO (1994)) have both argued that discharge databases are problematic, for this reason.

${ }^{6}$ Though the methods of Gowrisankaran and Town (1999) are much simpler than the ones developed in this paper, there is no formal statistical model that rationalizes their approach.

${ }^{7}$ Simple measures of fit always indicate that most variation in mortality cannot be ascribed to covariates. Even if all the difference in mortality rates were attributable to quality, the variation in these rates is small.
} 
economic interest where the outcome variable is dichotomous.

The model developed here incorporates hospital choice and mortality as endogenous variables and fixed hospital and patient characteristics as exogenous variables. Hospital choice is described by a multinomial probit model and mortality by a binary probit model. The mortality model includes indicator variables for each hospital to accommodate hospital specific differences in quality as well as demographic variables and observed disease characteristics. The mortality model is structural in the sense that it predicts outcomes given alternative assignments of patients to hospitals including random assignment. The multinomial probit model is a reduced form relationship that provides probabilities of hospital choice conditional on observed covariates that are a function of demographic characteristics and distance of the hospital from the patient's home. The random component in the binary probit model includes unobserved severity of illness and is permitted to be correlated with the random component in the multinomial choice model. If, after controlling for the observed covariates in the hospital choice model, patients with high unobserved severity of illness are more likely to be admitted to hospital A than patients with low unobserved severity, this will imply a positive correlation between the shock in the mortality equation and the shock in the hospital A choice equation.

We estimate this selection model using Bayesian inference from data on 74,848 Medicare patients admitted to 114 hospital in Los Angeles County during 1989 to 1992 with a diagnosis of pneumonia. By transforming the integration problem posed by the latent variables into a simulation problem, our approach to inference computes estimates orders of magnitude faster than the method of maximum likelihood. This makes inference feasible for this type of

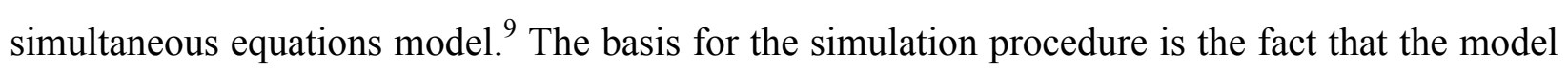
is similar to the conventional linear simultaneous equation model conditional on latent variables. Using Markov-chain Monte Carlo (MCMC) techniques, we iteratively simulate latent variable values conditional on data and parameters, and parameters conditional on data and latent variables. The second step is computationally similar to classical instrumental variables,

\footnotetext{
${ }^{8}$ Examples include the effect of school performance based on graduation rates, of prison rehabilitation programs based on recidivism rates, of job training programs based on the incidence of harassment complaints, and many medical outcome evaluations.

${ }^{9}$ Maximum likelihood evaluation for one parameter vector for one individual would require evaluating the joint density of the mortality and hospital choice outcome for that individual. Given that we have 114 endogenous variables and that the mortality error and hospital choice error are correlated, this would take several minutes on a fast supercomputer. Multiplied by a data set of roughly 75,000 patients (necessary because of the small signal to noise ratio), it would take months to evaluate the likelihood for a single parameter vector.
} 
differing principally in the appearance of the discrete hospital choice in the mortality probit equation, which does not pose a problem The simulation methods simultaneously recover the joint posterior distribution of parameters and latent variables. ${ }^{10}$ Albert and Chib (1993) used this approach in the binary probit model and Geweke, Keane and Runkle (1997) extended them to the multinomial probit model. The methods developed here extend this approach to a new class of models.

We use these methods to address the motivating policy questions directly. First, to what extent is hospital quality associated with observed characteristics of hospitals, such as size and ownership status? Second, with what degree of confidence can it be said that one hospital is of higher quality than another? We model hospital quality using hierarchical priors. This approach, which combines some characteristics of classical fixed- and random-effects models, specifies the quality of each hospital as a separate parameter, but assigns a more important role to the data in determining whether these parameters are similar for hospitals with similar observable characteristics, relative to a normal prior. Our approach provides an efficient method for extracting the signal from the noise, which is particularly important given this type of data.

The remainder of the paper is organized as follows. Section 2 provides the specification of the model and methods for inference, with some details relegated to an appendix. The database is described in Section 3. Section 4 presents findings on hospital quality and the role of nonrandom admission to hospitals. Section 5 concludes. Five appendices are available in the working paper version of this paper. 1 Appendix A1 details the construction of the prior, Appendix A2 details the likelihood function and computation, Appendix A3 gives evidence on the numerical accuracy of our Markov chain Monte Carlo (MCMC)) algorithm, Appendix A4 provides posterior rankings for the hospitals in our data set, and Appendix A5 provides robustness results with alternative priors.

\section{The Model}

The central component of the model is a structural probit equation, in which the probability of mortality is a function of the hospital to which a patient is admitted, the observed

\footnotetext{
${ }^{10}$ Surveys that discuss convergence to the posterior include Chib and Greenberg (1996), Geweke (1997) and Geweke (1999).
} 
severity of the patient's illness, and the observed demographic characteristics of the patient. The objective is to learn about the way the hospital to which the patient is admitted influences the probability of mortality in this equation. A multinomial probit model of hospital admission supplements the mortality model, to permit non-random assignment of patients to hospitals. This section describes, in turn, the specification of the model, the prior distribution of the model parameters, and methods to recover the posterior distribution of these parameters.

\subsection{Model specification}

Let $i=1, \ldots, n$ index the patients in the sample, and let $j=1, \ldots, J$ index hospitals in the sample. There are two groups of exogenous variables in the model. The $k \times 1$ vector $x_{i}$ consists of individual characteristics of patient $i$ that may affect mortality, including indicators for age, race, sex, and disease stage, and measures of income. The $q \times 1$ vector $z_{i j}$, which consists of characteristics specific to the combination of individual $i$ and hospital $j$, includes distance between the home of patient $i$ and hospital $j$ and interactions of distance with observable patient characteristics. The specifics of these variables are given in Section 3.

There are two sets of endogenous variables in the model. The mortality indicator $m_{i}$ is 1 if the patient dies in the hospital within ten days of admission and is 0 otherwise. The $J \times 1$ indicator vector $c_{i}$ has $j$ 'th entry 1 if patient $i$ is admitted to hospital $j$, and 0 otherwise.

To present the structural mortality equation, let $\varepsilon_{i}(i=1, \ldots, n)$ be independent $\mathrm{N}\left(0, \sigma^{2}\right)$ random variables conditional on the exogenous variables. The mortality probit $m_{i}^{*}$ is a latent random variable,

$$
m_{i}^{*}=c_{i}^{\prime} \beta+x_{i}^{\prime} \gamma+\varepsilon_{i} .
$$

The mortality indicator $m_{i}=1$ if $m_{i}^{*}>0$ and $m_{i}=0$ if $m_{i}^{*} \leq 0$. The structural interpretation of (1) is that if patient $i$ were randomly assigned to hospital $j$, then $m_{i}^{*}=\beta_{j}+x_{i}^{\prime} \gamma+\varepsilon_{i}$ and consequently $P\left(m_{i}=1\right)=\Phi\left(\left(\beta_{j}+x_{i}^{\prime} \gamma\right) / \sigma\right)$. Note that the parameters $\beta$ and $\sigma$ are jointly unidentified in (1) because they can be scaled by the same arbitrary positive

\footnotetext{
${ }^{11}$ See the NBER working paper Geweke, Gowrisankaran and Town (2001).
} 
constant without changing the behavior of $m_{i}$. In the conventional probit model this problem is avoided by setting $\sigma=1$. We return to this matter in the context of the complete model below.

If $c_{i}$ were in fact independent of $\varepsilon_{i}$ - as it would be if patients were randomly assigned to hospitals, for example - then $c_{i}$ would be exogenous in (1). After resolution of the above identification issue this model would conform with the conventional textbook specification of the binary probit model. However, it is likely that in observed data, $c_{i}$ depends in part on $\varepsilon_{i}$ : the admission of patient $i$ to hospital $j$ takes into account information that is correlated with $\varepsilon_{i}$. The conventional probit model is then misspecified.

To develop a more plausible model of hospital choice, we assume that patients become infected with one of the many bacterial or viral agents that can cause pneumonia and it has been determined that they are sufficiently ill to benefit from inpatient treatment. At that point the patient (or the patient's agent) selects from the set of $J$ hospitals the hospital to which the patient will be admitted. The actual choice decision will be a complex function of many factors, such as severity of illness, characteristics of the hospital, the patient's primary care physician, etc. One important observable influence on choice is distance: previous research has shown that the farther a patient is from a hospital, the less likely is the patient to be admitted to that hospital, other observables constant.

To present the reduced form model of hospital choice define the $J \times q$ matrix $\tilde{Z}_{i}$, $\tilde{Z}_{i}=\left[z_{i 1}, z_{i 2}, \ldots, z_{i J}\right]^{\prime}$. Let the $J \times 1$ vectors $\tilde{\eta}_{i} \sim N(0, \tilde{\Sigma})(i=1, \ldots, n)$ be mutually independent conditional on the exogenous variables, and let $\tilde{\rho}_{j}, j=1, \ldots, J$ denote the correlation between $\varepsilon_{i}$ and $\tilde{\eta}_{i j}$. Define the $J \times 1$ hospital choice latent vector multinomial probit $\tilde{c}_{i}^{*}=\left(\tilde{c}_{i 1}^{*}, \ldots, \tilde{c}_{i J}^{*}\right)^{\prime}$ as (2) $\tilde{c}_{i}^{*}=\tilde{Z}_{i} \alpha+\tilde{\eta}_{i}$.

The choice indicator vector $c_{i}=\left(c_{i 1}, \ldots, c_{i J}\right)^{\prime}$ has entry $c_{i j}=1$ if $\tilde{c}_{i j}^{*} \geq \tilde{c}_{i k}^{*}(k=1, \ldots, J)$ and $c_{i j}=0$ otherwise. As above with (1), the parameters $\alpha$ and $\tilde{\Sigma}$ are jointly unidentified since scaling $\alpha$ by any positive constant and $\tilde{\Sigma}$ by the square of that constant leaves the distribution of

\footnotetext{
${ }^{12}$ See Luft et al. (1990) and Burns and Wholey (1992).
} 
$c_{i}$ conditional on $Z_{i}$ unaffected. We return to this matter in the context of the prior distribution in Section 2.2.

As is customary in models with $J$ choices, it is easier to work with $J-1$ latent utilities, and normalize the $J$ th utility to 0 . Accordingly, we define the $(J-1) \times q$ matrix $Z_{i}=\left[\tilde{z}_{i 1}-\tilde{z}_{i J}, \tilde{z}_{i 2}-\tilde{z}_{i J}, \ldots, \tilde{z}_{i, J-1}-\tilde{z}_{i J}\right]^{\prime}$, the $(J-1) \times 1$ vectors $\eta_{i}=\left[\tilde{\eta}_{i 1}-\tilde{\eta}_{i J}, \ldots, \tilde{\eta}_{i, J-1}-\tilde{\eta}_{i J}\right]^{\prime}$ and $c_{i}^{*}=\left[\tilde{c}_{i 1}^{*}-\tilde{c}_{i J}^{*}, \ldots, \tilde{c}_{i, J-1}^{*}-\tilde{c}_{i J}^{*}\right]^{\prime}$, and the $(J-1) \times(J-1)$ matrix $\Sigma=\operatorname{var}\left(\eta_{i}\right)$. Note that

$$
c_{i}^{*}=Z_{i} \alpha+\eta_{i} .
$$

If the unobserved severity of illness affects hospital choice, the mortality and choice error terms will be correlated. Let $\rho_{j}$ denote the correlation between $\varepsilon_{i}$ and $\eta_{i j}(j=1, \ldots, J-1)$. The larger is $\rho_{j}$, the more likely is a patient with a high unobserved severity of illness $\left(\varepsilon_{i}\right)$ to be admitted to hospital $j$. Thus we shall refer to $\rho_{j}$ as the hospital $j$ severity correlation. The hospital severity correlations are a useful way to characterize severity of illness by hospital since they are independent of the scale of $\varepsilon_{i}$ which we know from 1 ) is unidentified.

Now, we can write the variance of the joint error terms as:

$$
\operatorname{var}\left(\varepsilon_{i}, \eta_{i}^{\prime}\right)=\left[\begin{array}{cc}
\sigma^{2} & \pi^{\prime} \\
\pi & \Sigma
\end{array}\right]
$$

where $\pi$ is a $(J-1) \times 1$ vector with $\pi_{j}=\rho_{j} \sigma \Sigma_{j j}^{1 / 2}$.

To permit unobserved severity of illness to affect hospital choice in any way consistent with the model, the only restriction we place on $\pi$ is that $\operatorname{var}\left(\varepsilon_{i}, \eta_{i}^{\prime}\right)$ be positive definite. Since this implies complicated restrictions on $\pi$, a more graceful treatment is to work with the population regression of the shock $\varepsilon_{i}$ in $(1)$ on the shock vector $\eta_{i}$ in (3),

$$
\varepsilon_{i}=\eta_{i}^{\prime} \delta+\zeta_{i} ; \operatorname{cov}\left(\eta_{i}, \zeta_{i}\right)=0
$$

In this regression $\delta$ is a $(J-1) \times 1$ parameter vector and the scale of $\varepsilon_{i}$ is normalized by $\operatorname{var}\left(\zeta_{i}\right)=1$. This specification simultaneously resolves the identification problem due to the scaling in (1) and incorporates all permissible values of $\pi=\Sigma \delta$ in (4) 
With this reparametrization, the variance of the shock in the mortality probit equation is $\sigma^{2}=\delta \Sigma \delta+1$, and the correlation between $\varepsilon_{i}$ and $\eta_{i j}$ is

$$
\rho_{j}=\left(\sum_{k=1}^{J-1} \delta_{k} \Sigma_{k j}\right) /\left[\Sigma_{j j}(\delta \Sigma \delta+1)\right]^{1 / 2} .
$$

In the hypothetical experiment in which patient $i$ is admitted to hospital $j$ by means of a random assignment $c_{i}, \mathrm{P}\left(m_{i}=1 \mid x_{i}\right)=\Phi\left[\left(c_{i}^{\prime} \beta+\mathbf{x}_{i}^{\prime} \gamma\right) /(\delta \Sigma \delta+1)^{1 / 2}\right]$. We shall refer to

$$
q_{j}=-\beta_{j} /(\delta \Sigma \delta+1)^{1 / 2}
$$

as the hospital $j$ quality probit. Differences in these probits across hospitals may be used to address quality comparisons for individual hospitals. In the conventional probit model with normalization $\sigma=1$, the hospital $j$ quality probit is $q_{j}^{*}=-\beta_{j}$. To compare groups of hospitals, define $q_{G}=\sum_{j \in G} \omega_{j} q_{j}$, where $G$ is the group of interest and the weight $\omega_{j}$ is proportional to the number of patients admitted to hospital $j$; define $\rho_{G}$ and $q_{G}^{*}$ analogously.

\subsection{Prior distributions}

The number of free parameters in $\Sigma$ is $J(J-1) / 2-1$, that is, 6,441 in our sample with $J=114$ hospitals. We make one major simplification, that $\tilde{\Sigma}=I_{J}$, so that after differencing, $\Sigma=I_{J-1}+e_{J-1} e_{J-1}^{\prime}$, where $e_{n}$ denotes an $n \times 1$ vector of units. We introduce some evidence on the plausibility of this assumption in Section 4.4. Estimating these parameters would increase the computation time by orders of magnitude and also complicate our MCMC simulation algorithm.

We choose independent prior distributions for the parameter vectors, $\alpha, \delta, \gamma$, and $\beta$ so as to include all reasonable parameter values well within their support. We discuss specific aspects of these priors here. 14

First, we utilize a variance component structure and a hierarchical prior to specify that hospital qualities are similar ex ante while allowing the data to determine the degree of similarity ex post. Each hospital, $i$, is in one of four ownership categories, $j$, and one of for size categories,

\footnotetext{
${ }^{13}$ Keane (1992) shows that $\Sigma$ is the source of irregularity in the multinomial probit likelihood function.

${ }^{14}$ Appendix A1 of the Working Paper version of this paper (Geweke, Gowrisankaran and Town (2001)) contains detailed descriptions of all the priors.
} 
$k$, detailed in Section 3.2. If hospital $i$ is of ownership category $j$ and size category $k$, then decompose $\beta_{i}=\beta_{1}+p_{j}+s_{k}+u_{i}$. The prior distributions of the components $\beta_{1}, p_{1}, \ldots, p_{4}, s_{1}, \cdots, s_{4}$ and $u_{1}, \ldots, u_{114}$ are jointly Gaussian, mean zero, and mutually independent. The common term $\beta_{1}$ has standard deviation 3 (essentially a flat prior). The other components have variances $\tau_{p}^{2}, \tau_{s}^{2}$ and $\tau_{u}^{2}$, respectively, grouped together in the vector $\tau^{\prime}=\left(\tau_{p}^{2}, \tau_{s}^{2}, \tau_{u}^{2}\right)$. Given $\tau$, the prior specifies that hospital quality is more strongly correlated between hospitals that share the same size or ownership specification. However, we employ a hierarchical prior distribution with the variance terms having independent prior distributions $1.25 / \tau_{j}^{2} \sim \chi^{2}(5)(j=p, s, u)$ in the standard probit model.

Second, since $\eta_{i j}=\tilde{\eta}_{i j}-\tilde{\eta}_{i J}$, an iid prior on $\delta$ implies a prior on $\tilde{\rho}$ that is not exchangeable with respect to the $J^{\text {th }}$ hospital, which is undesirable since the numbering of hospitals is arbitrary. We use the prior $\delta \sim N\left(0, \sigma_{\delta}^{2} \Sigma^{-1}\right)$ with $\sigma_{\delta}=0.196$, which implies an exchangeable and diffuse prior for $\tilde{\rho}$.

Third, the priors for the selection model need to be carefully scaled relative to the conventional probit model to account for the different values of $\sigma$ across the models. From (5), $\sigma^{2}=\delta \Sigma \delta+1$ in the selection model, but $\sigma=1$ in the probit model. Since $\delta \sim N\left(0, \sigma_{\delta}^{2} \Sigma^{-1}\right)$ it follows that $\delta \Sigma \delta+1 \sim \sigma_{\delta}^{2} \chi^{2}(J-1)+1$ and $\mathrm{E}(\delta \Sigma \delta+1)=\sigma_{\delta}^{2}(J-1)+1$. Thus, in the hierarchical hospital quality prior in the selection model, $1.25\left[\sigma_{\delta}^{2}(J-1)+1\right] / \tau_{j}^{2} \sim \chi^{2}(5)$. Similarly, we scale the selection model prior standard deviations for $\beta_{1}$ and $\gamma$ by $\left[\sigma_{\delta}^{2}(J-1)+1\right]^{1 / 2}$ relative to the probit model.

The choice of the prior distributions of $\alpha$ and $\gamma$ is relatively straightforward. As with $\beta$ and $\delta$ the governing principle is that reasonable values be well within the support of the prior distribution, and care must be taken to maintain the same scale in the probit and selection models. With respect to the last consideration note in particular that the impact of covariates in

\footnotetext{
${ }^{15}$ The centered $99 \%$ prior credible interval for each $\tau_{j}^{2}$ is $(.22,1.7)$. Robustness of our results with respect to variation in these and other priors is summarized in Section 4.4 and detailed in Appendix A5.
} 
the selection model, corresponding to $\gamma$ in the probit model is $\gamma /(\delta \Sigma \delta+1)^{1 / 2}$ in the selection model by means of the same reasoning leading to (7).

\subsection{Inference}

The observed data are $\left(x_{i}, Z_{i}, c_{i}, m_{i}, i=1, \ldots, n\right)$, which can be abbreviated as $y$. The model contains latent variables $\left(m_{i}^{*}, c_{i}^{*}, i=1, \ldots, n\right)$, which can be abbreviated $y^{*}$. The parameter vectors are $\alpha, \beta, \gamma$ and $\delta$, which can be collected in the vector $\theta$. The model specified in

Section 2.1 provides $\mathrm{p}\left(y, y^{*} \mid \theta\right)$ and the prior distributions in Section 2.2 provide $\mathrm{p}(\theta)$. Explicit expressions for these densities are given in Appendix A2. From Bayes rule, the distribution of the unobservables $y^{*}$ and $\theta$ conditional on the data and model specification is

$$
\mathrm{p}\left(y^{*}, \theta \mid y\right)=\mathrm{p}(\theta) \mathrm{p}\left(y, y^{*} \mid \theta\right) / \mathrm{p}(y) \propto \mathrm{p}(\theta) \mathrm{p}\left(y, y^{*} \mid \theta\right) .
$$

The objective is to obtain the posterior distribution of functions such as the hospital quality probits $q_{j}$, and $\Phi\left(-q_{j}+x_{i}^{\prime} \gamma\right)$, the probability of mortality under random hospital admission of a patient with observed characteristics $x_{i}$ to hospital $j$. This objective requires integrating a highly nonlinear function over millions of dimensions, most of which correspond to latent variables. This cannot be accomplished analytically.

The parameter vector and latent variables can be partitioned into groups, such that the posterior distribution of any one group conditional on all the others is of a single, easily recognized form that is easy to simulate. Details of the partition are given in Appendix A2. The problem is then well suited to attack by execution of a Gibbs sampling algorithm (Gelfand and Smith, 1990; Geweke, 1999). In this approach, each group of parameters and latent variables is simulated conditional on all the others. Following each pass through the entire vector of latent variables and parameters, all parameter values are recorded in a file.

As detailed in Appendix A2, the Gibbs sampling algorithm is ergodic and its unique limiting distribution is the posterior distribution. Therefore, dependent draws from the posterior distribution of any function of the parameters $\mathrm{g}(\theta)$ can be made by computing the value of $g$

\footnotetext{
${ }^{16}$ Appendix A1 documents further details of this prior distribution including the reasoning leading to the choice $\sigma_{\delta}=0.196$.
} 
corresponding to the recorded parameter values, after discarding initial iterations of the Gibbs sampling algorithm to allow for convergence. We used parallel computing methods and a supercomputer, exploiting the fact that in each iteration of the Gibbs sampling algorithm the latent variables $\left(m_{i}^{*}, c_{i}^{*}, i=1, \ldots, n\right)$ are conditionally independent across individuals. The iterations themselves are executed serially. The results reported in Section 4 are based on every $10^{\text {th }}$ draw from 19,000 successive iterations (a total of 1900 draws), after discarding 1,000 burnin iterations based on convergence diagnostics. For comparison purposes, we apply the same procedures to a conventional probit model for mortality, using the Gibbs sampling algorithm described in Albert and Chib (1993). Appendix A3 provides details on the numerical accuracy of our Gibbs sampling algorithm.

\section{The Data}

The primary source of data for this study is the Version B Discharge Data from the State of California Office of Statewide Health Planning and Development. These data provide records for all patients discharged from any California acute-care hospital during the years 1989 through 1992. We confine our attention to patients who were over 65 at the time of admission. During this time period, the vast majority of patients over 65 were covered by traditional Medicare feefor-service insurance, which has standardized hospitalization benefits. We confine our attention to Los Angeles County. A large metropolitan area is best suited to our purposes, because it has a large base of patients and contains multiple hospitals in every size and ownership class. We limit our study to a single disease, because there is evidence that the relation between mortality and covariates is disease specific. ${ }^{\square}$ We choose pneumonia in particular for three reasons. First, it is a common disease $\frac{18}{18}$ that provides the large sample needed to draw inferences about hospital quality. Second, in-hospital death is a relatively frequent outcome for pneumonia patients, which makes it a relevant disease to examine through the medium of hospital discharge records. Third,

\footnotetext{
${ }^{17}$ See Wray et al. (1997)

${ }^{18}$ Pneumonia and influenza alone constitute the sixth leading cause of death in the US, and the fourth leading cause of death for those over 65 (National Center for Health Statistics, 1996). Pneumonia is also the leading cause of death among patients with nosocomial (hospital acquired) infections (Pennington, 1994).
} 
there is independent evidence that an appropriately adjusted in-hospital mortality rate for pneumonia is correlated with the quality of in-hospital care.

The secondary source of data is the Annual Survey of Hospitals Database published by the American Hospital Association (AHA). Among other information, the AHA data contain the addresses, ownership status, and size of each hospital in our sample.

\subsection{Sample construction}

The sample was selected through a process of eliminating patients from the 1989-1992 Version B Discharge Data. The first qualification for selection is that the patient live in a Los Angeles County zip code, be admitted to a Los Angeles County hospital and be over 65 at the time of admission.

The second qualification is that one of the five ICD-9-CM disease codes specified in the discharge data be 48.1, 48.2, 48.5, 48.6, or 48.38, as suggested by Iezzoni et al. (1996) to define pneumonia.

The third qualification is that the source of admission must be either routine, or from the emergency room. This eliminates patients transferred into the hospital from another medical facility, or admitted from an intermediate care or skilled nursing facility. To the extent that placement in these facilities is correlated with unobserved disease severity, and to the extent that such facilities may be systematically located near higher quality hospitals, the key assumption that distance from the hospital is exogenous in our model would be violated. This step eliminates approximately 23 percent of the patients from the sample.

The fourth qualification is that the patient be admitted to a hospital with at least 80 admissions for pneumonia in our data set. This screen reduces $J$ and thereby computation time. Its potential to introduce sample selection bias is limited by the fact that it eliminates fewer than one per cent of the patients.

\subsection{Variable construction}

The covariate vector $x_{i}$ in the mortality probit equations contains an indicator for each year, demographic variables and indicators of disease severity. Most of the demographic variables are constructed from the discharge records. These are four age indicators $(70-74,75-79$,

\footnotetext{
${ }^{19}$ See Keeler et al. (1990) and McGarvey and Harper (1993).
} 
80-84, and 85 or older), an indicator for female, and indicators for black, Hispanic, Native American and Asian respectively. The discharge records contain no information on socioeconomic status. As a proxy for the patient's household income, we use the mean 1990 census household income for households with the same zip code, race, and age class as the patient. 20

Indicators of disease severity in $x_{i}$ are constructed from the admission disease staging information contained in the discharge records. Disease staging has been shown to be as good as some risk adjustment data based on chart review of medical records. ${ }^{21}$ Since some of the 13 stages have very few patients, we aggregated stages into five groups: stage 1.1, stages 1.3 through 2.3 , stages 3.1 through 3.6 , stage 3.7 , and stage 3.8. Indicator variables for all but stage 1.1 are included in $x_{i}$.

The indicator for mortality, $m_{i}$, is set to 1 if the patient died in the hospital within ten days of admission; otherwise $m_{i}=0$. The horizon for mortality is limited to ten days, because beyond this point hospitals sometimes transfer terminally ill patients to other facilities, and this decision appears to vary considerably by hospital. To control for differential patient transfer, Gowrisankaran and Town (1999) used a hazard model as an alternative to the 10-day inpatient mortality, but found little difference between the two specifications. In two separate studies of heart disease patients, McClellan, McNeil and Newhouse (1994) and McClellan and Staiger (1999b), find that there is a very strong correlation between 7-day mortality and 30-day mortality rates across hospitals. 2

Table 1 provides a summary of the distribution of demographic characteristics and disease severity in the sample, together with mortality rates. Within each age group the composition of the sample by race and sex closely reflects the demographics of Los Angeles County. Older individuals enter the sample in greater proportion to their numbers in the population than do younger ones. Within each age group three-quarters of the sample is

\footnotetext{
${ }^{20}$ The census provides only two relevant age categories, $65-74$ and 75+, instead of four. Thus, we aggregated the discharge data age categories to this level. Additionally, the census provides income only within cells. To find the mean income, we took the mean value for each cell as the income for each household in that cell. For the highest cell, $\$ 100,000$ or more, we assumed a mean income of $\$ 140,000$. Income is measured in units of $\$ 100,000$ and income squared in units of billions of dollars squared.

${ }^{21}$ See Thomas and Ashcroft (1991). Iezzoni et al. (1996) showed excellent agreement of disease stage with the ratings of other systems.

${ }^{22}$ As caveats, note that heart disease is very different from pneumonia and that these studies examine mortality, not inpatient mortality.
} 
classified in the least severe disease stage. Mortality rates increase gradually with age, increase sharply with disease stage, are a little higher for men than for women, and are lower for Asians and Hispanics than for whites or blacks.

The covariate matrix $Z_{i}$ contains variables specific to the combination of patient $i$ and each hospital. The additional information in $Z_{i}$ not contained in $x_{i}$ is the distance of the patient's home from each hospital. The discharge data include patient zip codes and the AHA data include hospital zip codes. The Census TIGER database provides the latitude and longitude of the centroid of each zip code. Given these, standard great circle trigonometric formulas provide the

distance between each patient home and hospital. ${ }^{2.3}$ The five variables in $Z_{i}$ are distance (in hundreds of kilometers); distance-squared; the product of distance and an age indicator (1 for 6569, 2 for 70-74, 3 for 75-79, 4 for 80-84, 5 for 85+); the product of distance and disease stage $(1.1, \ldots, 3.8)$; and the product of distance and income (in units of $\$ 100,000)$.

The prior distribution and subsequent analyses require the size and ownership status of each hospital. This information was obtained from the AHA survey, and is summarized in Table 2. We specified private teaching, public (operated by Los Angeles county) other not-for-profit and for-profit hospitals as four mutually exclusive ownership categories.

While mortality rates differ slightly by ownership category none of the differences are significant at conventional levels. The same is true by size category. Contrasts in mortality rates are stronger between cross-classified cells in Table 2. For example, the mean of the cells private, not-for-profit with $151-200$ beds (11.11\%) and private, for-profit with 201-300 beds (10.54\%) are significantly greater than the overall mean at the $5 \%$ level.

\section{Findings}

The model set forth in Section 2 applied to the data described in Section 3 yields evidence on systematic differences in quality across hospitals, provides insight into the interaction between hospital choice and hospital quality, and suggests quality orderings among hospitals. This section summarizes these findings. 


\subsection{Patient mortality and hospital choice}

Table 3 presents the posterior means and standard deviations of some parameters and functions of parameters in the selection and standard probit models. Table 3 details $q_{G}, \rho_{G}$, $\gamma /(\delta \Sigma \delta+1)^{1 / 2}$ and $\tau^{2} /(\delta \Sigma \delta+1)$ for the selection model and $\gamma, q_{G}^{*}$ and $\tau^{2}$ for the probit model. 24

The mortality equation has three groups of covariates: demographics, disease severity, and hospital indicators. In the case of the demographic and disease severity covariates, coefficient posterior means in the selection and probit models are similar to each other, and closely reflect the mortality rates presented in Table 1. Posterior standard deviations indicate substantial information about differences in mortality probabilities across demographic group.

In the case of the hospital quality probits, there are greater and more interesting differences between the selection model, the probit model, and the raw data. Both the probit model and the raw data (Table 2) do not draw any sharp distinctions in hospital quality by size or ownership class. However, the selection model finds sharp distinctions by size. This suggests that controls for both observed and unobserved severity of illness are important.

The posterior means of the hyperparameters $\tau_{j}^{2}$ carry forward the substantial uncertainty about hospital qualities in the prior distribution, combined with the information in the data. The prior mean of each $\tau_{j}^{2}$ is 0.41 . In the case of the four ownership components $p_{j}$ and size components $s_{k}$ the data combine with the prior to lower the posterior mean to 0.21 . In the case of the 114 individual hospital components $u_{i}$ the data provide more information about the common variance and lower the posterior mean to 0.037 .25

Posterior means and standard deviations of the choice covariate coefficient vector $\alpha$ show that, as expected, distance is an important factor in describing the hospital of admission.

\footnotetext{
${ }^{23}$ For zip codes that contain more than one hospital, we used address-level latitude and longitude data from the Census TIGER database, which stores the geographic location of every block corner and will interpolate from that to find the latitude and longitude of any address.

${ }^{24}$ The normalization of $\gamma$ and $\tau^{2}$ facilitates comparison between the two models.

${ }^{25}$ The mean of an inverted gamma distribution for $\tau^{2}$ of the form $s^{2} / \tau^{2} \sim \chi^{2}(v)$ is $\mathrm{E}\left(\tau^{2}\right)=s^{2} /(v-2)$. If the prior were conjugate then the posterior mean of each $\tau_{j}^{2}$ would be $\left(1.25+d^{2}\right) /(n+3)$, where $d^{2}$ is the sum of squares due to $p_{j}, s_{k}$ or $u_{i}$ and $n=4$ in the first two cases and $n=114$ in the last. The lower bound on the posterior mean would then be $1.25 /(n+3)$, or 0.18 in the first two cases and 0.011 in the last case.
} 
The posterior mean of -13.65 implies that a hospital that is 20 kilometers farther from a patient's home than another has a normalized probit that is $13.65 \times 0.2 / \sqrt{2} \approx 2$ units lower. The quadratic term in the equation is highly significant, but since distances are at most 100 kilometers within Los Angeles County, its substantive effect is not great. Interactions of distance with age and severity both have negative coefficients with posterior standard deviations small relative to their posterior means. Given that age class varies between 1 and 5 and observed severity varies between 1.1 and 3.8, the posterior mean of the distance coefficient varies between -14.44 and 17.08, with distance decreasing in age and observed severity of illness. The reason for this is likely due to the increased cost and difficulty of transport for severely ill patients. Patients in zip codes with higher average income are more likely to be admitted to nearby hospitals.

Table 4 provides explicit posterior probabilities for hospital group quality comparisons using the selection model and also lists the mean and standard deviation of the posterior probability of mortality at each type of hospital given a 10\% mortality (roughly the sample mean) at other types. There are sharp differences based on hospital size (Panel A). The posterior probability that the group hospital quality probit for the largest-hospital group exceeds that of the smallest-hospital group is 0.71 , and the posterior probability that it is greater than that of the other two size groups exceeds 0.95 . The posterior probability that the smallest-hospital group quality probit exceeds that of the second-smallest group similarly exceeds 0.95 . This is reflected in a mortality rate of $11.7 \%$ for the $150-200$ bed category given a mortality rate of $10 \%$ for the smallest size of hospital.

These findings are in rough agreement with the literature. A study by Keeler et al. (1992), which examined the relationship between hospital quality and size using a very detailed and expensive data set that included pneumonia patients along with patients with other, more complex diagnoses, found that hospital quality increases with bed size. However, in their study they did not allow for a nonlinear relationship between hospital size and morality rates, thus they could not uncover the U-shaped relationship between hospital quality and size that we do. Successful pneumonia treatments are linked to identifying the pathogen responsible for the infection and administering the appropriate antibacterial agent early in the progression of the disease, and subsequently monitoring and adjusting the dosage of the drug (Rello and Valles (1998), Pennington (1994), McGarvey and Harper (1993)). There is evidence that smaller hospitals may be better at the timely administration of antibiotics (Fine et al. (1998)) which may 
explain why we observe that they have better outcomes. Furthermore, since small hospitals are likely to treat a disproportionate number of pneumonia patients relative to more technically challenging illnesses $\frac{26}{2}$ they may also develop expertise in this disease. That, in turn, may overcome advantages that medium-sized hospitals may have in other dimensions, such as laboratory facilities.

There are less sharp differences in the selection model based on ownership (Panel B). Overall, private teaching hospitals have the highest quality, public hospital have the lowest quality, and other hospitals are in the middle. However, from the posterior standard deviations of the mortality rates it is evident that there are no definitive comparisons among ownership categories.

There is debate in health policy circles regarding the role that for-profit hospitals should play in the U.S. health system (Gray (1991), Sloan (2000)). Some have argued that private, notfor-profit hospitals may better serve the public interest because they are more likely to provide better care. Our results indicate that for the treatment of pneumonia in older patients and the hospitals in our sample, there is no evidence of this. Keeler et al. (1992) also found public hospitals in large cities to be of lower quality, while the difference in quality between for-profit and not-for-profit hospitals is less pronounced. McClellan and Staiger (1999a) conclude that the quality difference in for-profit and not-for-profit hospitals is small and if anything for-profits likely provide better care in the treatment of heart attacks. Private teaching hospitals, which are generally viewed as providing superior care (Keeler et al. (1992)), do appear to offer significantly higher quality according to the selection model.

\subsection{Selection and selection bias}

We present some statistics on the relationship between the posterior means of $q_{j}, q_{j}^{*}$ and $\rho_{j}$ across the 114 hospitals in Table 5. These statistics allow us to uncover the importance of selection and the relationship between selection and quality.

\footnotetext{
${ }^{26}$ Performing a simple multinomial logit regression of Southern California patients, we found that pneumonia patients were more likely to be admitted to smaller hospitals than were hospital patients generally. In contrast, acute myocardial infarction (heart attack) patients were more likely to be admitted to larger hospitals than the average hospital patient. Unlike pneumonia treatments, acute myocardial infarction treatments often include high-technology surgery such as cardiac catheterization, angioplasty or bypass.
} 
We start by analyzing the quantitative importance of selection in influencing patient mortality. In the simple probit model, the variance in unobserved disease severity $\varepsilon_{i}$ is normalized to be 1 . From the posterior means of the coefficients on observed disease severity in the model (Table 3) and the distribution of observed patient characteristics in the population (Table 1), one may approximate the variance in the contribution of observed demographics and disease severity to the mortality probit: it is about 0.45 . The variance in the mortality probit due to variation in hospital quality is about 0.013 (Table 5 Panel A), much smaller than the variance due to unobserved severity of illness, which is normalized to 1 . This decomposition of variance is about the same in the selection model - variation in hospital quality is slightly higher (Table 5) but it is still quite small relative to disease severity.

In the selection model the variation in unobserved disease severity is decomposed into a component that is independent of the hospital assignment process $\left(\zeta_{i}\right.$ from $\left.(5)\right)$ with variance 1 , and a component that is a function of the hospital assignment probits, $\eta_{i}^{\prime} \delta$ (also from (5)). The variance of the latter term, $\delta \Sigma \delta$, has a posterior mean of 8.7, which is much larger than the independent component. This constitutes strong evidence against random assignment of patients, and suggests that the simple probit model provides misleading inferences about hospital quality.

Since patient selection is important, we are interested in understanding the relationship between selection and quality. Table 5 Panel A reveals a positive relationship between the posterior means of $q_{j}$ and $\rho_{j}$ : the correlation between posterior means is 0.517 (Panel A) and a simple least squares regression of the posterior means of the $\rho_{j}$ on the posterior means of the $q_{j}$ shows a slope coefficient of 0.183 that is significantly positive ( $t$ of over 6 ). ${ }^{\text {. }}$ Thus, hospitals with higher quality (higher $q_{j}$ ) have a greater propensity to be selected by patients with greater unobserved disease severity (higher $\varepsilon_{j}$ ). This is also reflected in Table 3, which shows similar patterns of $q_{G}$ and $\rho_{G}$ across types of hospitals.

In any selection model, conditional on observed characteristics (including observed severity), the observed mortality rate for each hospital will be decomposed into a hospital quality

\footnotetext{
${ }^{27}$ Since results in Table 5 are based on posterior means, they do not take into account dispersion in the posterior. To account for this dispersion, one can examine the sample relation between $q_{j}, q_{j}^{*}$ and $\rho_{j}$ as a function of the parameters, and consider the posterior uncertainty associated with this relationship. This would yield values of Table 5 for each draw from the posterior simulator. One can then compute the mean value across the draws. This method yields similar results.
} 
component and an unobserved severity component. Panel $\mathrm{C}$ of Table 5 shows that in this relationship hospital quality $q_{j}^{*}$ in the probit model is well described as a linear function of hospital quality $q_{j}$ and severity correlation $\rho_{j}$ in the selection model. From the regression relation reported in panel $\mathrm{C}$ of Table 5 , it is clear that variation in hospital severity correlation substantially drives variation in inferred hospital quality $q_{j}^{*}$ in the probit model. From the regressions in panels $\mathrm{B}$ and $\mathrm{C}$, one can infer the slope coefficient of .712 (=.905-1.553×.124) in panel D. Thus, variation in hospital severity correlation accounts for a substantial portion of the variation in hospital mortality rates in the selection model, whereas in the simple probit model this variation must be attributed to quality differences.

\subsection{Ordering by quality}

The model and approach to inference described in Section 2 provide the complete posterior distribution of all the parameters in the model, and any functions of these parameters. In particular, corresponding to the parameter values in any iteration of the Gibbs sampling algorithm, it is a simple matter to compute the corresponding hospital quality probits $q_{j}$. The 1900 draws used to obtain the posterior moments reported in this section therefore also provide 1900 draws from the joint distribution of the hospital quality probits $q_{j}$. Pairwise comparisons between hospitals are then straightforward. For example, for two hospitals $j$ and $k$, the numerical approximation to the posterior probability that $q_{j}>q_{k}$ is the fraction of iterations in which $q_{j}>q_{k}$, and the joint distribution of $q_{j}$ and $q_{k}$ could easily be plotted.

Comparing all 114 hospitals simultaneously is more challenging. A formal approach to ordering hospitals by quality would begin with a loss function for orderings. Suppose the 114element vector of quality ranks is $\mathbf{r}$, and the estimated quality rank vector is $\hat{\mathbf{r}}$. If the loss function is $(\hat{\mathbf{r}}-\mathbf{r})^{\prime} \mathbf{A}(\mathbf{r}-\hat{\mathbf{r}})$, where $\mathbf{A}$ is a positive definite matrix, then $\hat{\mathbf{r}}$ should be the posterior mean of $\mathbf{r}^{28}$ This estimate may, in turn, be approximated numerically by sorting hospital qualities $q_{j}$ in each iteration of the Gibbs sampler, finding the corresponding rank for each hospital, and then averaging the ranks across all iterations. The resulting estimated ranks $\hat{r}_{j}$ are

\footnotetext{
${ }^{28}$ See, for example, Bernardo and Smith (1994, Section 5.1.5), for this standard result, as well as the one on medians used in the next paragraph.
} 
generally not integers. If the loss function were $\sum_{j=1}^{117} a_{j}\left|\hat{r}_{j}-r_{j}\right|$, where all $a_{j}>0$, then $\hat{r}_{j}$ should be the median of the posterior distribution of $r_{j}$, which in turn is an integer (with probability one).

Appendix A4 provides rankings based on both loss functions. The choice of loss function turns out not to have a large effect on the orderings of relative quality. The rankings produced by these alternative loss functions are similar. The posterior distributions of $\mathbf{r}$ and of the hospital qualities convey the uncertainty associated with the rankings. For most pairwise combinations of hospitals in the top and bottom quartiles, the posterior that the quality of the former exceeds the latter is rarely less than 0.8 and exceeds 0.9 more often than not. An approximate rule of thumb for the accuracy of rankings is that if a hospital is ranked at quantile $x$ then the posterior probability that its true rank is above the median is also $x$. Appendix A4 provides all the rankings and several aspects of their joint posterior distribution.

\subsection{Specification and robustness}

A key assumption in the selection model is that the distances between the patients' homes and the 114 hospitals in the sample constitute variables that may be used to control for the nonrandom assignment patients to hospitals. Because of the nonlinear relationship between the endogenous variables (hospital choice) in the mortality equation and the instruments, this relationship was modeled explicitly. Table 3 reveals an indisputably strong link between the measures in $Z$ and the choice of hospital. For instance, distance and its square explain about 30\% of the variance of the probits. The findings are in accord with the literature. 29

The further assumption that distances from hospitals to patients are uncorrelated with unobserved disease severity cannot be examined so directly. One plausible alternative is that there remain geographic variations in unobserved disease severity after accounting for the observed covariates listed in the first two panels of Table 3. We examined this possibility from three angles. First, in a conventional probit model for mortality using the observed covariates, hospital choice dummies and patient zip code dummies, the zip code dummies are insignificant. Second, the same is true if dummies for nearest hospital replace zip code dummies. In both equations, the coefficients on the hospital choice dummies are jointly significant in the presence of the zip code dummies. Finally, we conducted a more direct examination by retrieving the 
unobserved disease severity component from the mortality probit equation in each iteration of the MCMC algorithm. In the regression of this component on zip code dummies and the other regressors, the dummies were jointly insignificant in every iteration. All these findings are consistent with the absence of any unobserved geographic component of disease severity.

Given the large number of endogenous variables in the selection model, quite a few assumptions about functional form were required. The dimensionality of the problem is perhaps most evident in the 6,440 potentially independent free parameters in $\Sigma$, the prior variance matrix in the multinomial hospital assignment model. The selection model takes the extreme step of assuming that shocks to the probits in this model are iid normal before differencing (Section 2.2). If this assumption is reasonable, then the $113 \times 1$ vectors of posterior shocks $\eta_{i}(i=1, \ldots, n)$, which may be retrieved in each iteration of the MCMC algorithm, should be consistent with the specification $\Sigma=\mathbf{I}_{J-1}+\mathbf{e}_{J-1} \mathbf{e}_{J-1}^{\prime}$. If it is not - for example, if patients with certain characteristics all choose from one small group of hospitals - then this will be evidenced by a constructed covariance matrix $\mathbf{S}=(n-1)^{-1} \sum_{i=1}^{n}\left(\eta_{i}-\bar{\eta}\right)\left(\eta_{i}-\bar{\eta}\right)^{\prime}$ being substantially different from $\Sigma$. A conventional goodness of fit test, carried out at the $5 \%$ level, rejects the null hypothesis in slightly over half the iterations of the MCMC algorithm. We conclude that there may well be misspecification of the covariance structure in the multinomial hospital assignment covariance matrix, but it is probably not severe. Due to the large number of parameters in $\Sigma$, information about the covariance structure beyond the data would be required to deal constructively with this potential misspecification.

The sensitivity of findings to the specification of the prior distribution can be examined in a number of ways. To convey the nature of the sensitivity we set up three further variants of the selection model. Variant A effectively eliminates the instruments from the entire model, by scaling the prior standard deviations of the coefficient vector $\alpha$ in the multinomial hospital assignment model by the factor $10^{-6}$. This variant leaves only the functional form to identify the hospital-specific parameters in the mortality equation. Variant B scales the prior standard deviations of $\alpha$ in the original selection model downward by a factor of 5 and $\tau^{2}$ downward by a factor of 25. Variant C is like Variant B except that prior standard deviations are increased by a

\footnotetext{
${ }^{29}$ See Luft et al. (1990) and Gowrisankaran and Town (1999).
} 
factor of 5 relative to the base model. Thus, variants $\mathrm{B}$ and $\mathrm{C}$ provide alternative priors that are plausible from the perspective of the subjective prior in the base selection model.

Appendix A5 provides a detailed set of results for each of these prior distributions. As one might expect, coefficients on covariates in the mortality probit equation show very little sensitivity to the choice from among the four prior distributions. The same is true in the hospital choice multinomial probit model, with the obvious exception of prior A. The findings about hospital mortality (Section 4.1) are the same in variants B and C as in the base selection model: quality is a "U" shaped function of size; private teaching hospitals have the highest and public hospitals the lowest quality with differences in this dimension remaining small. By contrast variant A shows little effect of size, or ownership, and the point estimates display neither the "U" shape for size nor the ownership ranking of the base model. The correlations between hospital quality posterior means in the base selection model and variants $\mathrm{B}$ and $\mathrm{C}$ are both 0.80 . By contrast, the correlation between hospital quality posterior means in the base selection model and variant $\mathrm{A}$ is only 0.34. We conclude that reasonable variants on the prior produce distinct but insubstantial differences, whereas elimination of the instruments from the model has strong and substantial effects.

\section{Conclusion}

This study has extended existing econometric methods in order to measure hospital quality using the experience of patients admitted to hospitals in nonrandom fashion. Using discharge records for almost 75,000 older pneumonia patients from 114 hospitals in Los Angeles County, we find evidence of differences in quality between hospitals of different size and ownership classifications. The smallest and largest hospitals exhibit higher quality than other hospitals. We also detect substantial differences in quality for a sizable minority of individual hospitals.

As an important by-product, our methods produce information about the hospital admissions process. Patients with greater unobserved severity of illness tend, overall, to be admitted to hospitals of higher quality. Consequently more conventional methods that ignore nonrandom admission, when applied to this data set, tend to lower the inferred quality of good hospitals and raise that of poor ones, relative to our findings. We find that variation across 
individual hospitals in the unobserved severity of illness is at least as great as variation in quality, and that this variation accounts for most of the large discrepancy between inference about hospital quality in our model and with more conventional methods.

The procedures used here are at the current frontier of intensive computational methods in econometrics. A supercomputer and several days of computing were required to obtain the results reported here. Recent and imminent innovations in numerical methods and computing technology should sharply reduce the real costs of these procedures in the near term. Given the policy importance of assessing quality of care in hospitals, we believe there is a significant return to further investment in these methods and their application to similar questions in health policy and related fields. 
Table 1

Frequency and mortality rates by age, disease stage, racial and sex categories

\begin{tabular}{|c|c|c|c|c|c|c|c|}
\hline \multirow{2}{*}{\multicolumn{2}{|c|}{$\begin{array}{c}\text { Severity and } \\
\text { Demographic } \\
\text { Categories }\end{array}$}} & \multicolumn{5}{|c|}{ Age Categories } & \multirow{3}{*}{$\begin{array}{c}\text { Row } \\
\text { Totals } \\
56,217 \\
6.94 \\
\end{array}$} \\
\hline & & \multirow{2}{*}{$\begin{array}{c}\begin{array}{c}65-69 \\
\text { years }\end{array} \\
8,409 \\
5.01 \\
\end{array}$} & \multirow{2}{*}{$\begin{array}{c}70-74 \\
\text { years } \\
10,254 \\
5.09\end{array}$} & \multirow{2}{*}{$\begin{array}{c}75-79 \\
\text { years } \\
11,524 \\
5.83 \\
\end{array}$} & \multirow{2}{*}{$\begin{array}{c}80-84 \\
\text { years } \\
11,168 \\
5.82\end{array}$} & \multirow{2}{*}{$\begin{array}{c}\text { Over } 84 \\
\text { years } \\
14,864 \\
10.18\end{array}$} & \\
\hline \multirow{5}{*}{ 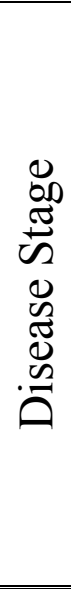 } & $\begin{array}{c}\text { Disease } \\
\text { Stage } 1.1\end{array}$ & & & & & & \\
\hline & $\begin{array}{c}\text { Disease } \\
\text { Stage 1.3- } \\
2.3 \\
\end{array}$ & $\begin{array}{l}846 \\
5.91\end{array}$ & $\begin{array}{c}1,021 \\
5.97\end{array}$ & $\begin{array}{c}1,017 \\
6.88\end{array}$ & $\begin{array}{c}912 \\
10.09\end{array}$ & $\begin{array}{l}1,069 \\
10.20\end{array}$ & $\begin{array}{c}4,865 \\
7.85\end{array}$ \\
\hline & $\begin{array}{c}\text { Disease } \\
\text { Stage } 3.1- \\
3.6 \\
\end{array}$ & $\begin{array}{c}670 \\
12.69\end{array}$ & $\begin{array}{c}769 \\
12.87\end{array}$ & $\begin{array}{l}1,018 \\
14.83\end{array}$ & $\begin{array}{c}973 \\
16.07\end{array}$ & $\begin{array}{l}1,478 \\
21.99\end{array}$ & $\begin{array}{l}4,908 \\
16.70\end{array}$ \\
\hline & $\begin{array}{c}\text { Disease } \\
\text { Stage } 3.7\end{array}$ & $\begin{array}{l}1,350 \\
15.33\end{array}$ & $\begin{array}{l}1,598 \\
14.77\end{array}$ & $\begin{array}{l}1,707 \\
16.81\end{array}$ & $\begin{array}{l}1,381 \\
22.13\end{array}$ & $\begin{array}{l}1,664 \\
28.18\end{array}$ & $\begin{array}{l}7,700 \\
19.56\end{array}$ \\
\hline & $\begin{array}{c}\text { Disease } \\
\text { Stage } 3.8\end{array}$ & $\begin{array}{c}156 \\
45.51\end{array}$ & $\begin{array}{c}228 \\
42.10\end{array}$ & $\begin{array}{c}218 \\
44.03\end{array}$ & $\begin{array}{c}239 \\
56.49\end{array}$ & $\begin{array}{c}317 \\
53.94\end{array}$ & $\begin{array}{l}1,158 \\
49.14\end{array}$ \\
\hline \multirow{5}{*}{$\begin{array}{l}\mathbb{E} \\
\mathbb{E} \\
\tilde{1}\end{array}$} & White & $\begin{array}{c}7,100 \\
7.20\end{array}$ & $\begin{array}{c}9,301 \\
7.68 \\
\end{array}$ & $\begin{array}{c}10,796 \\
8.75\end{array}$ & $\begin{array}{c}10,542 \\
10.44\end{array}$ & $\begin{array}{c}14,256 \\
13.89\end{array}$ & $\begin{array}{c}51,995 \\
10.10 \\
\end{array}$ \\
\hline & Black & $\begin{array}{c}1,498 \\
9.74\end{array}$ & $\begin{array}{l}1,405 \\
8.61\end{array}$ & $\begin{array}{c}1,295 \\
7.80 \\
\end{array}$ & $\begin{array}{l}1,207 \\
10.60\end{array}$ & $\begin{array}{l}1,433 \\
13.32 \\
\end{array}$ & $\begin{array}{l}6,919 \\
10.04\end{array}$ \\
\hline & Hispanic & $\begin{array}{c}2,013 \\
6.31\end{array}$ & $\begin{array}{c}2,032 \\
5.41\end{array}$ & $\begin{array}{c}1,941 \\
6.85\end{array}$ & $\begin{array}{l}1,978 \\
7.79\end{array}$ & $\begin{array}{l}2,709 \\
11.04\end{array}$ & $\begin{array}{c}10,830 \\
7.70\end{array}$ \\
\hline & Asian & $\begin{array}{l}794 \\
6.17\end{array}$ & $\begin{array}{c}1,106 \\
6.06\end{array}$ & $\begin{array}{c}1,129 \\
6.38\end{array}$ & $\begin{array}{l}930 \\
8.27\end{array}$ & $\begin{array}{c}971 \\
11.33\end{array}$ & $\begin{array}{c}4,990 \\
7.59\end{array}$ \\
\hline & $\begin{array}{c}\text { Native } \\
\text { American }\end{array}$ & $\begin{array}{c}24 \\
4.17\end{array}$ & $\begin{array}{c}26 \\
7.69\end{array}$ & $\begin{array}{c}25 \\
8.00\end{array}$ & $\begin{array}{c}16 \\
37.50\end{array}$ & $\begin{array}{c}23 \\
26.09 \\
\end{array}$ & $\begin{array}{c}114 \\
14.91\end{array}$ \\
\hline \multirow{2}{*}{$\underset{\infty}{凶}$} & Female & $\begin{array}{c}5,335 \\
6.61\end{array}$ & $\begin{array}{c}7,010 \\
6.22\end{array}$ & $\begin{array}{c}8,116 \\
7.34\end{array}$ & $\begin{array}{c}7,955 \\
9.25\end{array}$ & $\begin{array}{c}12,092 \\
13.24\end{array}$ & $\begin{array}{c}40,899 \\
9.14\end{array}$ \\
\hline & Male & $\begin{array}{l}5,703 \\
8.12 \\
\end{array}$ & $\begin{array}{l}6,860 \\
8.42 \\
\end{array}$ & $\begin{array}{c}7,368 \\
9.23 \\
\end{array}$ & $\begin{array}{l}6,718 \\
10.87 \\
\end{array}$ & $\begin{array}{l}7,300 \\
13.51 \\
\end{array}$ & $\begin{array}{c}33,949 \\
10.12 \\
\end{array}$ \\
\hline \multicolumn{2}{|c|}{ Column Totals } & $\begin{array}{c}11,429 \\
7.30\end{array}$ & $\begin{array}{c}13,387 \\
7.31\end{array}$ & $\begin{array}{c}15,484 \\
8.24\end{array}$ & $\begin{array}{c}14,673 \\
9.99\end{array}$ & $\begin{array}{c}19,392 \\
13.34\end{array}$ & $\begin{array}{c}74,848 \\
9.59\end{array}$ \\
\hline
\end{tabular}

The first number in each cell is the cell frequency, and the second number is the mortality rate in that cell. 
Table 2

Hospital frequency, patients treated, and mortality by hospital classification

\begin{tabular}{|c||c|c|c|c|c|}
\hline & $\begin{array}{c}150 \text { Beds or } \\
\text { Less }\end{array}$ & $\begin{array}{c}151-200 \\
\text { Beds }\end{array}$ & $\begin{array}{c}201-300 \\
\text { Beds }\end{array}$ & $\begin{array}{c}\text { Over 300 } \\
\text { Beds }\end{array}$ & Row Totals \\
\hline \hline \multirow{2}{*}{ Private, Not- } & 9 & 4 & 18 & 19 & 50 \\
for-Profit & 4,741 & 2,369 & 15,526 & 21,545 & 44,181 \\
& 9.17 & 11.11 & 9.42 & 9.71 & 9.62 \\
\hline \multirow{2}{*}{ Private, For- } & 32 & 15 & 7 & 1 & 55 \\
profit & 9,792 & 6,627 & 4,412 & 973 & 21,804 \\
& 9.24 & 9.57 & 10.54 & 10.48 & 9.66 \\
\hline Private & & & & 5 & 5 \\
Teaching & 0 & 0 & 0 & 6,802 & 6,802 \\
& & & & 9.17 & 9.17 \\
\hline & & & 1 & 3 & 4 \\
Public & 0 & 0 & 232 & 1,829 & 2,061 \\
& & & 8.62 & 9.57 & 9.46 \\
\hline \hline \multirow{2}{*}{ Column } & 41 & 19 & 26 & 28 & 114 \\
Totals & 14,533 & 8,996 & 20,170 & 31,149 & 74,848 \\
& 9.22 & 9.97 & 9.65 & 9.61 & 9.59 \\
\hline
\end{tabular}

The first number in each cell is the number of hospitals in that category, the second number is the total number of pneumonia patients discharged from hospitals in that cell, and the third number is the mortality rate (patient weighted) for patients who were discharged from hospitals in that cell. 
Table 3

Posterior means and standard deviations

\begin{tabular}{|c|c|c|c|c|c|c|}
\hline & Coefficient & \multicolumn{3}{|c|}{ Selection model } & \multicolumn{2}{|c|}{ Probit model } \\
\hline & & \multicolumn{3}{|c|}{$\gamma /(\delta \Sigma \delta+1)^{1 / 2}$} & \multicolumn{2}{|c|}{$\gamma$} \\
\hline \multirow{11}{*}{ 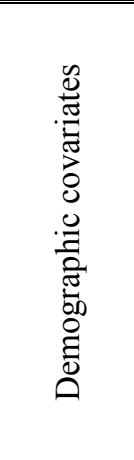 } & Age 70-74 & $\begin{array}{l}-0.009 \\
0.65\end{array}$ & \multicolumn{2}{|c|}{$(0.024)$} & $2-0.008$ & $\begin{array}{l}(0.025) \\
\end{array}$ \\
\hline & Age $75-79$ & & \multicolumn{2}{|c|}{$(0.023)$} & 0.068 & $(0.025)$ \\
\hline & Age 80-84 & 0.184 & \multicolumn{2}{|c|}{$(0.023)$} & 0.187 & $(0.024)$ \\
\hline & Age $>84$ & 0.369 & \multicolumn{2}{|c|}{$(0.022)$} & 0.374 & $(0.023)$ \\
\hline & Female & \multirow{2}{*}{$\begin{array}{l}-0.087 \\
-0.020\end{array}$} & \multicolumn{2}{|c|}{$(0.013)$} & -0.087 & $(0.013)$ \\
\hline & Black & & \multicolumn{2}{|c|}{$(0.028)$} & -0.025 & $(0.028)$ \\
\hline & Hispanic & -0.12 & \multicolumn{2}{|c|}{$(0.022)$} & -0.126 & $(0.023)$ \\
\hline & Native & 0.152 & \multicolumn{2}{|c|}{$(0.13)$} & 0.168 & $(0.134)$ \\
\hline & Asian & -0.091 & \multicolumn{2}{|c|}{$(0.030)$} & -0.091 & $(0.031)$ \\
\hline & Income & 0.223 & \multicolumn{2}{|c|}{$(0.207)$} & 0.253 & $(0.201)$ \\
\hline & Income $^{\wedge} 2$ & -0.028 & \multicolumn{2}{|c|}{$(0.024)$} & -0.030 & $(0.024)$ \\
\hline \multirow{6}{*}{ 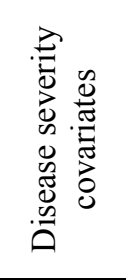 } & & \multicolumn{3}{|c|}{$\gamma /(\delta \Sigma \delta+1)^{1 / 2}$} & & \\
\hline & Emergency admit & 0.180 & & & 0.181 & $\overline{(0.016)}$ \\
\hline & Disease stages 1.3-2.3 & 0.089 & & & 0.089 & $(0.028)$ \\
\hline & Disease stages 3.1-3.6 & 0.493 & & & 0.496 & $(0.023)$ \\
\hline & Disease stage 3.7 & 0.635 & & & 0.640 & $(0.018)$ \\
\hline & Disease stage 3.8 & 1.396 & & & 1.412 & $(0.037)$ \\
\hline & & $q_{G}$ & & & & \\
\hline 吾斈 & 150 beds or less & $\overline{(0.021)}$ & 0.001 & $\overline{(0.022)}$ & 0.007 & $\overline{(0.012)}$ \\
\hline$\ddot{\vec{\sigma}} \tilde{D}$ & 151 to 200 beds & $(0.032)$ & -0.017 & $(0.024)$ & -0.032 & $(0.018)$ \\
\hline$\overline{0}=0$ & 201 to 300 beds & $(0.027)$ & -0.010 & $(0.032)$ & -0.003 & $(0.013)$ \\
\hline 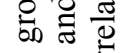 & Over 300 beds & $(0.019)$ & 0.022 & $(0.023)$ & 0.004 & $(0.012)$ \\
\hline$\underline{.50}$ & Private, not for profit & $(0.018)$ & 0.003 & $(0.026)$ & -0.001 & $(0.009)$ \\
\hline क्त & Private, for profit & $(0.015)$ & 0.008 & $(0.024)$ & -0.008 & $(0.009)$ \\
\hline & Private Teaching & $(0.041)$ & 0.006 & $(0.023)$ & 0.021 & $(0.023)$ \\
\hline & Public & $(0.089)$ & -0.017 & $(0.038)$ & -0.017 & $(0.041)$ \\
\hline & & $\tau^{2} /(\delta$ & $+1)$ & & & \\
\hline. $\bar{\Xi}$ & Size & 0.20 & & & 0.21 & $(0.15)$ \\
\hline & Ownership & 0.20 & & & 0.21 & $(0.15)$ \\
\hline & Individual Hospital & 0.037 & $(0.1$ & 62) & 0.030 & $(0.0048)$ \\
\hline & & & & & & \\
\hline & Distance & -13.65 & & & & \\
\hline 0 & Distance $^{2}$ & 12.43 & & & & \\
\hline$\sqrt{\pi} \cdot \frac{\pi}{\pi}$ & Distance $\times$ Age & -0.45 & & & & \\
\hline क्षे & Distance $\times$ Severity & -0.31 & & & & \\
\hline & $\begin{array}{c}10^{-5} \times \text { Distance } \\
\times \text { Income }\end{array}$ & -0.974 & & 58) & & \\
\hline
\end{tabular}

Specifications also include indicators for each year. 


\section{Table 4}

Posterior probability comparisons of group hospital quality probits, selection model

\begin{tabular}{|c|c|c|c|c|}
\hline & \multicolumn{4}{|c|}{ A. Hospitals grouped by size } \\
\hline & $\leq 150$ beds & $151-200$ beds & 201-300 beds & $>300$ beds \\
\hline$\leq 150$ beds & $0.10^{--}$ & $\begin{array}{c}1 \% \\
0.086(0.007)\end{array}$ & $\begin{array}{c}16 \% \\
0.089(0.007)\end{array}$ & $\begin{array}{c}71 \% \\
0.104(0.006)\end{array}$ \\
\hline $151-200$ beds & $\begin{array}{c}99 \% \\
0.117(0.009)\end{array}$ & $0.10(--)$ & $\begin{array}{c}82 \% \\
0.109(0.009)\end{array}$ & $\begin{array}{c}100 \% \\
0.121(0.007)\end{array}$ \\
\hline $201-300$ beds & $\begin{array}{c}84 \% \\
0.108(0.007)\end{array}$ & $\begin{array}{c}18 \% \\
0.093(0.008)\end{array}$ & $0.10_{(--)}^{--}$ & $\begin{array}{c}98 \% \\
0.112(0.006)\end{array}$ \\
\hline \multirow[t]{3}{*}{$>300$ beds } & $\begin{array}{c}29 \% \\
0.097(0.006)\end{array}$ & $\begin{array}{c}0 \% \\
0.083(0.006)\end{array}$ & $\begin{array}{c}2 \% \\
0.090(0.005)\end{array}$ & $0.10(--)$ \\
\hline & \multicolumn{4}{|c|}{ B. Hospitals grouped by ownership classification } \\
\hline & $\begin{array}{c}\text { Private } \\
\text { not-for-profit }\end{array}$ & $\begin{array}{c}\text { Private } \\
\text { for-profit }\end{array}$ & $\begin{array}{l}\text { Private } \\
\text { teaching }\end{array}$ & Public \\
\hline $\begin{array}{c}\text { Private } \\
\text { not-for-profit }\end{array}$ & 0.10 (--) & $\begin{array}{c}54 \% \\
0.101(0.005)\end{array}$ & $\begin{array}{c}60 \% \\
0.103(0.008)\end{array}$ & $\begin{array}{c}23 \% \\
0.088(0.015)\end{array}$ \\
\hline $\begin{array}{l}\text { Private } \\
\text { for-profit }\end{array}$ & $\begin{array}{c}46 \% \\
0.10(0.005)\end{array}$ & $0.10(--)$ & $\begin{array}{c}56 \% \\
0.103(0.009)\end{array}$ & $\begin{array}{c}20 \% \\
0.088(0.014)\end{array}$ \\
\hline $\begin{array}{l}\text { Private } \\
\text { teaching }\end{array}$ & $\begin{array}{c}40 \% \\
0.098(0.008)\end{array}$ & $\begin{array}{c}44 \% \\
0.099(0.009)\end{array}$ & $0.10^{--}$ & $\begin{array}{c}22 \% \\
0.087(0.017)\end{array}$ \\
\hline Public & $\begin{array}{c}77 \% \\
0.116(0.019)\end{array}$ & $\begin{array}{c}80 \% \\
0.116(0.018)\end{array}$ & $\begin{array}{c}78 \% \\
0.118(0.022)\end{array}$ & $0 . \overline{0_{(--}}$ \\
\hline
\end{tabular}

The first number in each cell is the posterior probability that the group quality probit $q_{G}$ in the column category exceeds $q_{G}$ in the row category, and the second number is the posterior mean probability of mortality in the row category given a $10 \%$ probability of mortality in the column category, with the posterior standard deviation of this statistic in parentheses. 


\section{Table 5}

Relations between hospital quality probits and severity correlations in the sample

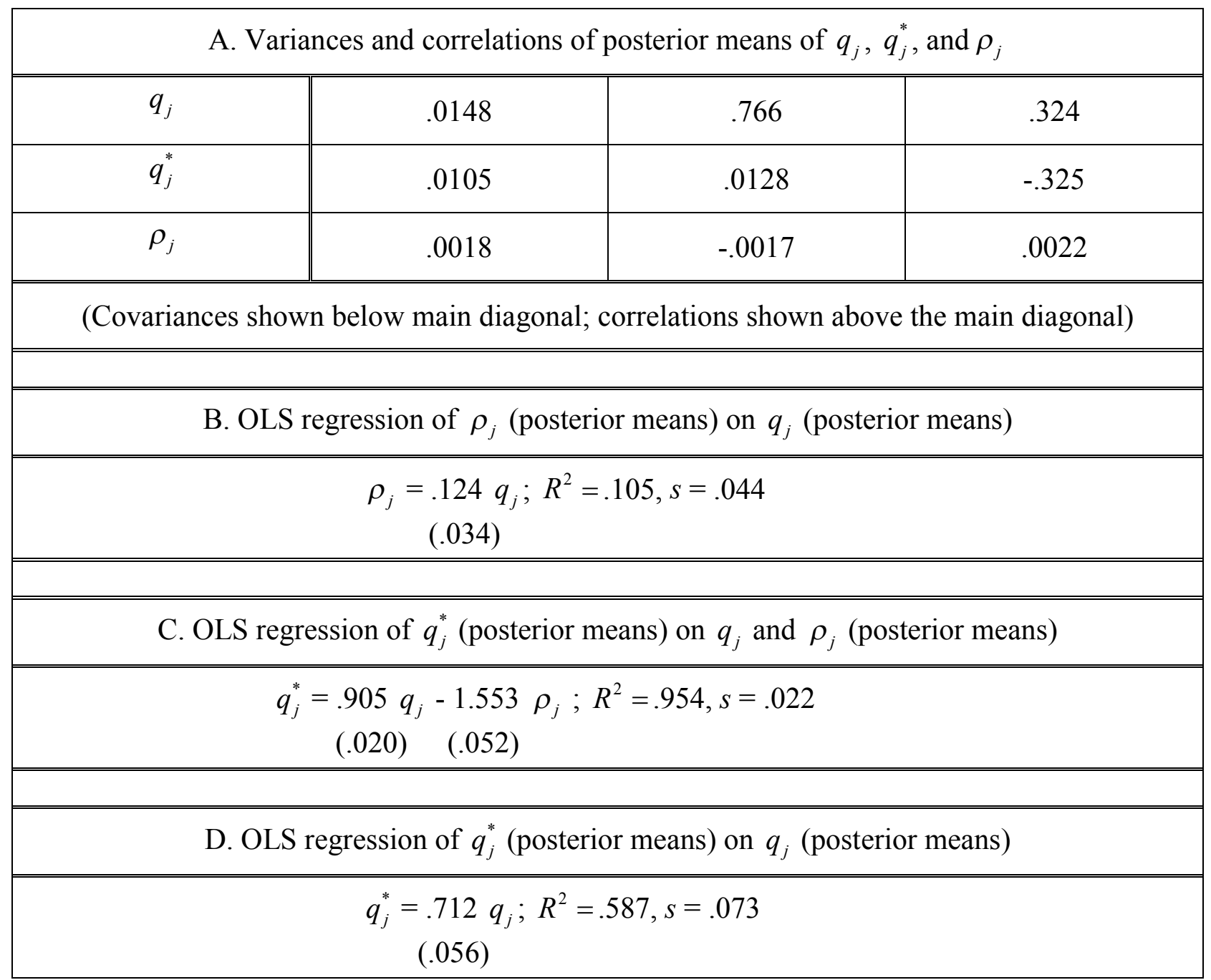




\section{References}

Albert and Chib, 1993, "Bayesian Analysis of Binary and Polychotomous Response Data," Journal of the American Statistical Association, 422, 669-79.

Bernardo and Smith (1994), Bayesian Theory. Chichester: John Wiley and Sons.

Burns L, Wholey D., 1992, "The Impact of Physician Characteristics in Conditional Choice Models for Hospital Care," Journal of Health Economics 11, 43-62.

Chib, S., and Greenberg, 1996, "Markov Chain Monte Carlo Simulation Methods in Econometrics," Econometric Theory, 12, 409-31.

Cutler, D. M., 1995, "The Incidence of Adverse Medical Outcomes Under Prospective Payment," Econometrica, 63(1): 29-50.

Fine, J.M., J.D. Scinto, D.H. Galusha, M.K. Petrillo, T.P. Meehan, 1998, "Patient and Hospital Characteristics Associated with Timely Care of Elderly Patients Hospitalized with Pneumonia: Results from the Medicare Quality Indication System Pneumonia Module," Abstract Book, Association of Health Services Research, 15.

Gelfand, A.E., and A.F.M. Smith, 1990, "Sampling Based Approaches to Calculating Marginal Densities," Journal of the American Statistical Association 85: 398-409.

Geweke, J., 1997, "Posterior Simulators in Econometrics," in D. Kreps and K.F Wallis (eds.), Advances in Economics and Econometrics: Theory and Applications, vol. III. Cambridge: Cambridge University Press, 128-165.

Geweke, J., 1999, "Using Simulation Methods for Bayesian Econometric Models: Inference, Development and Communication," (with discussion and rejoinder) Econometric Reviews 18: 1-126.

Geweke, J., G. Gowrisankaran and R.J. Town, 2001, “Bayesian Inference for Hospital Quality in a Selection Model," Cambridge, MA: NBER Working Paper 8497.

Geweke, J., M. Keane and D. Runkle, 1997, "Statistical Inference in the Multinomial, Multiperiod Probit Model," Journal of Econometrics, 80, 125-65.

Gowrisankaran, G., and R.J. Town, 1999, "Estimating the Quality of Care in Hospitals Using Instrumental Variables," Journal of Health Economics 18, 747-67.

Gray, B., 1991, The Profit Motive and Patient Care, Cambridge, MA: Harvard University Press.

Iezzoni, L.I., 1997, Risk Adjustment for Measuring Health Care Outcomes, Ann Arbor, MI: Health Administration Press, $2^{\text {nd }}$ Edition., 
Iezzoni, L.I. et al., 1996, "Severity Measurement Methods and Judging Hospital Death Rates for Pneumonia," Medical Care, 34(1): 11-28.

Keane, M.P., 1992, "A Note on Identification in the Multinomial Probit Model," Journal of Business and Economic Statistics, 10, 193-200.

Keeler, E. B., K.L. Kahn, D. Draper, M.J. Sherwood, L.V. Rubenstein, E.J. Reinisch, J. Kosecoff, and R.H. Brook, 1990, "Changes in Sickness at Admission Following the Introduction of the Prospective Payment System." Journal of the American Medical Association, 264, 1962-68.

Keeler, E. B., et al., 1992, "Hospital Characteristics and Quality of Care." Journal of the American Medical Association, 268 (13): 1709-14.

Kessler, D. and McClellan, 2000, “Is Hospital Competition Socially Wasteful?" Quarterly Journal of Economics, 115 (2): 577-615.

Lohr, K.N., ed., 1990, Medicare: A Strategy for Quality Assurance. Volume I. Washington DC: National Academy Press.

Luft, H., et al., 1990, “Does Quality Influence Choice of Hospital?” Journal of the American Medical Association 263, 2899-2906.

McClellan M, B. McNeil, and J. Newhouse, 1994, "Does More Intensive Treatment of Acute Myocardial Infarction in the Elderly Reduce Mortality?" Journal of the American Medical Association. 272, 859-866.

McClellan, M. and H. Noguchi, 1998, "Technological Change in Heart-Disease Treatment: Does High Tech Mean Low Value," American Economic Review (Papers and Proceedings), 88 (2): 90-96.

McClellan M., and D. Staiger, 1999a, "Comparing Hospital Quality at For-Profit and Not-ForProfit Hospitals,” NBER Working Paper 7324.

McClellan M., and D. Staiger, 1999b, "The Quality of Health Care Providers," NBER Working Paper 7327.

McGarvey, R. and J. Harper, 1993, "Pneumonia Mortality Reduction and Quality Improvement in a Community Hospital," Quality Review Bulletin, 19, 124-30.

National Center for Health Statistics (1996). Available on the Internet at http://www.cdc.gov/nchswww/nchshome.htm.

Pennington, J., 1994, Respiratory Infections: Diagnosis and Management, New York: Raven Press, $3{ }^{\text {rd }}$ edition. 
Rello, J. and J. Valles, 1998, "Mortality as an Outcome in Hospital-Acquired Pneumonia," Infection Control and Hospital Epidemiology, 19(10): 795-7.

Sloan, F., 2000, "Not-for-profit Ownership and Hospital Behavior," in A. J. Culyer and J.P. Newhouse, ed., The Handbook of Health Economics, Volume 1, Amsterdam: Elsevier Science.

Thomas, J.W. and M.L.F. Ashcroft, 1991, "Measuring Severity of Illness: Six Severity Systems and their Ability to Explain Cost-variations," Inquiry, 28, 39-55.

United States General Accounting Office, 1994, "Report Cards" Are Useful But Significant Issues Need to be Addressed. (GAO/HEHS-94-219) Washington, DC: United States General Accounting Office.

Wray, N. J. Hollingsworth, N. Petersen, and C. Ashton, 1997, "Case-Mix Adjustment Using Administrative Databases: A Paradigm to Guide Future Research," Medical Care Research and Review, 54, 326-356. 


\title{
Bayesian Inference for Hospital Quality in a Selection Model: Appendices
}

\author{
John Geweke, john-geweke@uiowa.edu \\ Gautam Gowrisankaran, gautam_gowrisankaran@nber.org \\ Robert J. Town, rjtown@umn.edu \\ July, 2002
}

\section{Appendix A1: Construction of prior distributions}

This appendix describes in detail the construction of the prior distributions used in the selection model. The notation in this appendix is the same as in the paper.

\section{A1.1 Prior distributions for $\alpha$ (selection model)}

There are five coefficients in the vector $\alpha$ in the hospital multinomial choice model (2) corresponding to the five covariates: distance from patient $i$ 's home to hospital $j$, the square of this distance, and the product of distance with age, disease stage, and income respectively. The priors for the five coefficients are independent, each Gaussian with mean zero and a specified standard deviation.

To construct these standard deviations, we took a random subsample of 1,000 patients and constructed the covariate vectors $\mathbf{z}_{i j}(i=1, \ldots, 1000 ; j=1, \ldots, 114)$ of the multinomial choice model. For each of the five covariates we found a value of the coefficient such that if all other coefficients are zero then the joint probability that the patient goes to one of the 27 hospitals farthest away is 0.003 . We verified that these values resulted in the probabilities of the patient going to the nearest hospital being between 0.1 and 0.2 . These resulted in coefficient values of $6,-12,-4,-5$ and -35 for the respective covariates (ordered as in Table 4, bottom panel).

The prior standard deviations are therefore set to 6,12, 4, 5 and 35, respectively. Since the mean of all distributions is zero, the prior is centered about independence of hospital choice from the covariates. But it is sufficiently inclusive that it renders reasonable what we regard as $a$ priori reasonable effects of the covariates on hospital choices. 


\section{A1.2 Prior distribution for $\delta$ (selection model)}

We begin with the probit equation (2) of the hospital choice model before differencing,

$$
\tilde{\mathbf{c}}_{i}^{*}=\tilde{\mathbf{Z}}_{i} \alpha+\tilde{\eta}_{i} ; \quad \tilde{\eta}_{i} \sim N\left(\mathbf{0}, \mathbf{I}_{J}\right)
$$

Express the correlation between $\tilde{\eta}_{i}$ and the shock $\varepsilon_{i}$ to the mortality equation (1) by means of the linear projection

$$
\varepsilon_{i}=\sum_{j=1}^{J} \tilde{\delta_{i}} \tilde{\eta}_{i j}+\tilde{\zeta}_{i} ; \quad \tilde{\zeta}_{i} \sim N(0,1)
$$

This equation corresponds to (5) in the paper; we return to this correspondence below.

Suppose that in the system (A1.1)-(A1.2) our prior distribution for $\tilde{\delta}$ is

$$
\tilde{\delta} \sim N\left(0, \underline{h}_{\tilde{\delta}}^{-1} \mathbf{I}_{J}\right)
$$

In (A1.3) the priors are independent and exchangeable across hospitals. The corresponding correlation between $\varepsilon_{i}$ and $\tilde{\eta}_{i}$ is $\tilde{\rho}_{j}=\tilde{\delta}_{j} /\left(\tilde{\delta}^{\prime} \tilde{\delta}+1\right)^{1 / 2}$. Since the distribution in (A1.3) is symmetric about zero, the prior correlation between the parameters $\tilde{\rho}_{j}$ and $\tilde{\rho}_{k}$ is zero.

As explained between (2) and (3) in the paper, normalizing $\tilde{c}_{J}^{*}=0$ leads to

$$
\mathbf{c}_{i}^{*}=\mathbf{Z}_{i} \alpha+\eta_{i}, \quad \eta_{i} \sim N(\mathbf{0}, \Sigma), \quad \sum=\mathbf{I}_{J-1}+\mathbf{e}_{J-1} \mathbf{e}_{J-1}^{\prime}
$$

which is (3) in the paper. Express the linear projection of $\varepsilon_{i}$ on $\eta_{i}$ as

$$
\varepsilon_{i}=\sum_{j=1}^{J-1} \delta_{j}^{*} \eta_{i j}+\zeta_{i}^{*}
$$

The asterisks in this equation reflects the fact that $\operatorname{var}\left(\zeta_{i}^{*}\right) \neq 1$ whereas $\operatorname{var}\left(\zeta_{i}\right)=1$ in (5). The next step is to derive $\delta^{*}=\left(\delta_{1}^{*}, \ldots, \delta_{J-1}^{*}\right)^{\prime}$ and $\operatorname{var}\left(\zeta_{i}^{*}\right)$.

From (A1.4), and then from (A1.1)-(A1.2),

$\delta^{*}=\left[\operatorname{var}\left(\eta_{i}\right)\right]^{-1} \operatorname{cov}\left(\eta_{i}, \varepsilon_{i}\right)=\left[\operatorname{var}\left(\eta_{i}\right)\right]^{-1} \operatorname{cov}\left(\tilde{\eta}_{(-J)}-\mathbf{e}_{J-1} \tilde{\eta}_{J}, \varepsilon_{i}\right)=\Sigma^{-1}\left(\tilde{\delta}_{(-J)}-\mathbf{e}_{J-1} \tilde{\delta}_{J}\right)$.

(In this expression, the subscript " $J$ " denotes the last element of the $J \times 1$ vector, and the subscript " $(-J)$ " denotes the first $J-1$ elements of the $J \times 1$ vector.) Since the prior distribution of $\tilde{\delta}$ is (A1.3), the prior distribution of $\delta^{*}$ is also normal, with mean zero and variance 


$$
\operatorname{var}\left(\delta^{*}\right)=\Sigma^{-1} \operatorname{var}\left(\tilde{\delta}_{(-J)}-\mathbf{e}_{J-1} \tilde{\delta}_{J}\right) \Sigma^{-1}
$$

Since

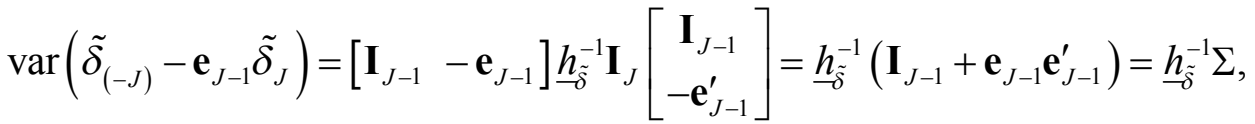

$$
\begin{aligned}
& \operatorname{var}\left(\delta^{*}\right)=\underline{h}_{\tilde{\delta}}^{-1} \Sigma^{-1}=\underline{h}_{\tilde{\delta}}\left(\mathbf{I}_{J-1}-J^{-1} \mathbf{e}_{J-1} \mathbf{e}_{J-1}^{\prime}\right) .
\end{aligned}
$$

Because $\operatorname{var}\left(\zeta_{i}^{*}\right) \neq 1$ whereas $\operatorname{var}\left(\zeta_{i}\right)=1$ in (5), $\delta^{*}$ differs from $\delta$ by a scale factor. The prior for $\delta$ will have mean zero and variance proportional to (A1.6). To obtain the factor of proportionality, scale $\delta^{*}$ by $\left[\operatorname{var}\left(\zeta_{i}^{*}\right)\right]^{-1}$ to obtain $\operatorname{var}(\delta)$. By the usual population regression formulas, $\operatorname{var}\left(\zeta_{i}^{*}\right)=\operatorname{var}\left(\varepsilon_{i}\right)-\delta^{*^{\prime}} \Sigma \delta^{*}$. From (A1.5),

$$
\begin{aligned}
& \delta^{*^{\prime}} \Sigma \delta^{*}=\tilde{\delta}^{\prime}\left[\begin{array}{c}
\mathbf{I}_{J-1} \\
-\mathbf{e}_{J-1}^{\prime}
\end{array}\right] \Sigma^{-1}\left[\begin{array}{ll}
\mathbf{I}_{J-1} & -\mathbf{e}_{J-1}
\end{array}\right] \tilde{\delta} \\
& =\tilde{\delta}^{\prime}\left[\begin{array}{c}
\mathbf{I}_{J-1} \\
-\mathbf{e}_{J-1}^{\prime}
\end{array}\right]\left[\mathbf{I}_{J-1}-J^{-1} \mathbf{e}_{J-1} \mathbf{e}_{J-1}^{\prime}\right]\left[\begin{array}{ll}
\mathbf{I}_{J-1} & -\mathbf{e}_{J-1}
\end{array}\right] \tilde{\delta} \\
& =\tilde{\delta}^{\prime}\left[\begin{array}{cc}
\mathbf{I}_{J-1}-J^{-1} \mathbf{e}_{J-1} \mathbf{e}_{J-1}^{\prime} & -J^{-1} \mathbf{e}_{J-1} \\
-J^{-1} \mathbf{e}_{J-1}^{\prime} & 1-J^{-1}
\end{array}\right] \tilde{\delta}=\tilde{\delta}^{\prime}\left(\mathbf{I}_{J}-J^{-1} \mathbf{e}_{J} \mathbf{e}_{J}^{\prime}\right) \tilde{\delta}=\tilde{\delta} \Sigma^{-1} \tilde{\delta} .
\end{aligned}
$$

Hence from (A1.2) and (A1.7),

$$
\operatorname{var}\left(\zeta_{i}^{*}\right)=\tilde{\delta}^{\prime} \tilde{\delta}+1-\tilde{\delta}^{\prime}\left(\mathbf{I}_{J}-J^{-1} \mathbf{e}_{J} \mathbf{e}_{J}^{\prime}\right) \tilde{\delta}=J^{-1}\left(\mathbf{e}_{J}^{\prime} \tilde{\delta}\right)^{2}+1=J^{-1}\left(\sum_{j=1}^{J} \tilde{\delta}_{j}\right)^{2}+1
$$

Thus $\tilde{\delta} \sim N\left(\mathbf{0}, \underline{h}_{\tilde{\delta}}^{-1} \mathbf{I}_{T}\right)$ implies the prior expectation $\underline{h}_{\tilde{\delta}}^{-1}+1$ for $\operatorname{var}\left(\zeta_{i}^{*}\right)$. This leads to the appropriate normalization for (A1.6),

$$
\operatorname{var}(\delta)=\left(\frac{\underline{h}_{\tilde{\delta}}^{-1}}{\underline{h}_{\tilde{\delta}}^{-1}+1}\right) \Sigma^{-1}=\left(1+\underline{h}_{\tilde{\delta}}\right)^{-1} \Sigma^{-1} .
$$

Since $\operatorname{var}\left(\zeta_{i}^{*}\right)$ involves $\tilde{\delta}$, the implied distribution for $\tilde{\delta}$ under the normalization $\operatorname{var}\left(\zeta_{i}\right)=1$ of (5) is not Gaussian. We therefore conjecture a Gaussian prior distribution for $\delta$, and then examine whether it is in fact similar to the non-Gaussian prior implied by (A1.3) and (5). From (A1.3) and (A1.8), the prior expectation of $\operatorname{var}\left(\zeta_{i}^{*}\right)$ is $1+\underline{h}_{\tilde{\delta}}^{-1}$. Our conjectured Gaussian distribution for $\delta$ is therefore 


$$
\delta \sim N\left(0, \sigma_{\delta}^{2} \Sigma^{-1}\right) \text {, with } \sigma_{\delta}^{2}=\left(1+\underline{h}_{\tilde{\delta}}\right)^{-1} .
$$

A series of numerical experiments showed that the non-Gaussian prior implied by (A1.3) and (A1.5), and the Gaussian prior (A1.9), give essentially identical moments for the correlations $\tilde{\rho}_{j}$ and $\rho_{j}$, for the same values of $\underline{h}_{\delta}$. Table A1 shows the relationships between $\underline{h}_{\delta}$ and some

moments of $\tilde{\rho}_{j}$ and $\rho_{j}$. (In Table A1, $\tilde{R}^{2}=\tilde{\delta^{\prime}} \tilde{\delta} /\left(\tilde{\delta}^{\prime} \tilde{\delta}+1\right)$, the fraction of variance in the mortality shock explained by the hospital choice probits in (A1.2); $R^{2}=\delta^{\prime} \delta /\left(\delta^{\prime} \delta+1\right)$, the fraction of variance in the mortality shock explained by the hospital choice probits in (5).)

Observe that as the standard deviation in the elements of $\tilde{\delta}, \underline{h}_{\delta}^{-1 / 2}$, increases, $R^{2}$ and $\tilde{R}^{2}$ increase; that this must happen is obvious from (A1.2) and (5). But the correlations $\rho_{j}$ and $\tilde{\rho}_{j}$ do not increase significantly beyond $\underline{h}_{\delta}^{-1 / 2}=.08$. This is due to the large number of hospitals, and the symmetry of the prior in $\delta$. For the work reported in this paper, we chose $\underline{h}_{\delta}^{-1 / 2}=0.2$, or equivalently, $\sigma_{\delta}=0.196$.

\section{A1.3 Prior distributions for $\beta$}

The variance component structure in the prior for $\beta$ described in the text can be used to simplify the coding of the algorithm detailed in Appendix A2. Let $\mathbf{W}$ be a $J \times(J+9)$ matrix of hospital characteristics. Let the first column of $\mathbf{W}$ be entirely units, columns 2 through 5 dichotomous variables for the four ownership categories, and columns 6 through 9 dichotomous variables for the four size categories. Redefine $\beta$ to be the $(J+9) \times 1$ vector of corresponding coefficients. The priors for the components of this vector are mutually independent, with $\beta_{1} \sim N\left(0,3^{2}\right)$. The hierarchical prior distribution for $\beta_{2}, \ldots, \beta_{J+9}$ is

$$
\begin{array}{ll}
\underline{s}_{p}^{2} / \tau_{p}^{2} \sim \chi^{2}\left(\underline{v}_{p}\right), & \beta_{j} \sim N\left(0, \tau_{p}^{2}\right)(j=2,3,4,5) ; \\
\underline{s}_{s}^{2} / \tau_{s}^{2} \sim \chi^{2}\left(\underline{v}_{s}\right), \quad \beta_{j} \sim N\left(0, \tau_{s}^{2}\right)(j=6,7,8,9) ; \\
\underline{s}_{u}^{2} / \tau_{u}^{2} \sim \chi^{2}\left(\underline{v}_{u}\right), \quad \beta_{j} \sim N\left(0, \tau_{u}^{2}\right)(j=10, \ldots, J+9) .
\end{array}
$$

In the prior distribution used in the paper, $\underline{s}_{p}^{2}=\underline{s}_{s}^{2}=\underline{s}_{u}^{2}=1.25$ for the conventional probit model with $\sigma=1$. As discussed in Section 2.2, the variances in the selection model are scaled by 
$\left[\sigma_{\delta}^{2}(J-1)+1\right]=5.35$, so that $\underline{s}_{p}^{2}=\underline{s}_{s}^{2}=\underline{s}_{u}^{2}=6.68$. For both models $\underline{v}_{p}=\underline{v}_{s}=\underline{v}_{u}=5$. It is readily verified that the prior distribution of $\mathbf{W} \beta$ is the same as the prior distribution of $\beta$ described in the text. The elements of the $(J+9) \times 1$ vector $\beta$ have proper prior distributions, and the posterior distribution of $\mathbf{W} \beta$ is exactly the same as that of $\beta$ described in the text.

\section{A1.3 Prior distributions for $\gamma$}

The demographic covariates $x_{i}$ are of two types: dichotomous variables, and two continuous variables (income and its square). The coefficients $\gamma_{i}$ of the dichotomous variables are independent in the prior, all with standard deviation 0.5 in the conventional probit model with $\sigma=1$. The coefficients on income and its square (call them $\gamma_{1}$ and $\gamma_{2}$ ) are derived from the independent priors

$$
\begin{gathered}
\gamma_{1} \bar{y}+\gamma_{2} \bar{y}^{2} \sim N\left(0,0.25^{2}\right), \\
\gamma_{1}(2 \bar{y})^{2}+\gamma_{2}(2 \bar{y})^{2} \sim N\left(0,0.25^{2}\right) .
\end{gathered}
$$

Substituting for average income $\bar{y}$, scaling $y$ by $10^{-5}$ and $y^{2}$ by $10^{-9}$ (as was done in variable construction) yields prior variances of 3.603 and 0.1437 for $\gamma_{1}$ and $\gamma_{2}$, respectively, and a prior covariance of -0.7026 . As discussed in Section 2.2, these coefficients are scaled by $\left[\sigma_{\delta}^{2}(J-1)+1\right]^{1 / 2}=2.31$ for the selection model relative to these values.

\section{Appendix A2: Details of distributions and computations}

This appendix describes in detail the prior and data distributions used in the selection model, and the probit model. The notation in this appendix is the same as in the paper.

\section{A2.1 Notation}

The notation in this appendix is the same as in the paper. We collect all the definitions here for reference, and introduce some additional useful notation. Indexing:

$$
i=1, \ldots, n \quad \text { Patients in sample }
$$




$$
j=1, \ldots, J \quad \text { Hospitals in Los Angeles County, California }
$$

Observed variables:

$$
\begin{array}{ll}
m_{i} & \text { Mortality indicator, } 1 \text { if patient dies, else } 0 \\
\mathbf{c}_{i}: J \times 1 & \text { Hospital choice indicator, } c_{i j}=1 \text { if } i \text { chooses } j, \text { else } 0 \\
\mathbf{x}_{i}: k \times 1 & \text { Individual characteristics affecting mortality } \\
\mathbf{Z}_{i}:(J-1) \times q & \text { Individual characteristics affecting hospital choice } \\
\mathbf{W}: J \times(J+9) & \text { Matrix of hospital characteristics } \\
\mathbf{u}_{i}^{\prime} \equiv\left(\mathbf{c}_{i}^{\prime} \mathbf{W}, \mathbf{x}_{i}^{\prime}\right) &
\end{array}
$$

Latent variables

$$
\begin{array}{ll}
m_{i}^{*} & \text { Mortality probit } \\
\mathbf{c}_{i}^{*}:(J-1) \times 1 & \text { Hospital choice probit }
\end{array}
$$

Miscellaneous:
$\chi_{S}(z)$
Indicator function, $\chi_{S}(z)=1$ if $z \in S$, else 0
$\mathbf{e}_{n}: n \times 1$
$\mathbf{e}_{n}^{\prime}=(1, \ldots, 1)$

\section{A2.2 Model}

The model for the latent variables and observables is:

$$
\begin{aligned}
& \mathbf{c}_{i}^{*}=\mathbf{Z}_{i} \alpha+\eta_{i}, \quad c_{i J}^{*} \equiv 0 \\
& c_{i j}=\prod_{\ell=1}^{J} \chi_{[0, \infty)}\left(c_{i j}^{*}-c_{i \ell}^{*}\right) \\
& m_{i}^{*}=\mathbf{c}_{i}^{\prime} \mathbf{W} \beta+\mathbf{x}_{i}^{\prime} \gamma+\eta_{i}^{\prime} \delta+\zeta_{i} \\
& m_{i}=\chi_{[0, \infty)}\left(m_{i}^{*}\right) \\
& \left(\begin{array}{l}
\eta_{i} \\
\zeta_{i}
\end{array}\right) \stackrel{I I D}{\sim} \mathrm{N}\left(\mathbf{0},\left[\begin{array}{cc}
\Sigma & \mathbf{0} \\
\mathbf{0}^{\prime} & 1
\end{array}\right]\right) ; \Sigma=\mathbf{I}_{J-1}+\mathbf{e}_{(J-1)} \mathbf{e}_{(J-1)}^{\prime} \\
& \tau \equiv\left(\tau_{p}^{2}, \tau_{s}^{2}, \tau_{u}^{2}\right)^{\prime}, \lambda^{\prime} \equiv\left(\beta^{\prime}, \gamma^{\prime}\right), v^{\prime} \equiv\left(\lambda^{\prime}, \delta^{\prime}\right)
\end{aligned}
$$

\section{A2.3 Prior distribution}


As motivated in the text the prior distribution consists of three, independent components: $\underline{s}_{j}^{2} / \tau_{j}^{2} \sim \chi^{2}\left(\underline{v}_{j}\right)(j=p, s, u)$ and $\lambda \mid \tau \sim \mathrm{N}\left(\underline{\lambda}, \underline{\mathbf{H}}_{\lambda}(\tau)^{-1}\right) ; \delta \sim \mathrm{N}\left(\underline{\delta}, \underline{\mathbf{H}}_{\delta}^{-1}\right) ; \alpha \sim \mathrm{N}\left(\underline{\alpha}, \underline{\mathbf{H}}_{\alpha}^{-1}\right)$. Hence the prior density is

$$
\begin{aligned}
& \mathrm{p}(\lambda, \delta, \alpha, \tau)=\prod_{j=p, s, u}\left\{\left[2^{\underline{v}_{j} / 2} \Gamma\left(\underline{v}_{j} / 2\right)\right]^{-1}\left(\underline{s}_{j}^{2}\right)^{\underline{v}_{j} / 2}\left(\tau_{j}^{2}\right)^{-\left(\underline{v}_{j}+2\right) / 2} \exp \left(-\underline{s}_{j}^{2} / 2 \tau_{j}^{2}\right)\right\} \\
& \cdot(2 \pi)^{-(r+k+J+q-1) / 2}\left|\underline{\mathbf{H}}_{\lambda}(\tau)\right|^{1 / 2}\left|\underline{\mathbf{H}}_{\delta}\right|^{1 / 2}\left|\underline{\mathbf{H}}_{\alpha}\right|^{1 / 2} \\
& \quad \cdot \exp \left\{-.5\left[(\lambda-\underline{\lambda})^{\prime} \underline{\mathbf{H}}_{\lambda}(\tau)(\lambda-\underline{\lambda})+(\delta-\underline{\delta})^{\prime} \underline{\mathbf{H}}_{\delta}(\delta-\underline{\delta})+(\alpha-\underline{\alpha})^{\prime} \underline{\mathbf{H}}_{\alpha}(\alpha-\underline{\alpha})\right]\right\} .
\end{aligned}
$$

\section{A2.4 Distribution of observables and latent variables}

To derive the joint density of the observable data and latent variables for individual $I$, let $\Phi_{i} \equiv\left\{\mathbf{Z}_{i}, \mathbf{W}, \alpha, \lambda, \delta, \Sigma\right\}$. Then

$$
\begin{aligned}
& \mathrm{p}\left(\mathbf{c}_{i}^{*}, \mathbf{c}_{i}, \mathbf{m}_{i}^{*}, \mathbf{m}_{i} \mid \Phi_{i}\right)=\mathrm{p}\left(\mathbf{c}_{i}^{*} \mid \Phi_{i}\right) \mathrm{p}\left(\mathbf{c}_{i} \mid \mathbf{c}_{i}^{*}, \Phi_{i}\right) \mathrm{p}\left(m_{i}^{*} \mid \mathbf{c}_{i}, \mathbf{c}_{i}^{*}, \Phi_{i}\right) \mathrm{p}\left(m_{i} \mid m_{i}^{*}, \mathbf{c}_{i} \mathbf{c}_{i}^{*}, \Phi_{i}\right) \\
&=\mathrm{p}\left(\mathbf{c}_{i}^{*} \mid \mathbf{Z}_{i}, \alpha, \Sigma\right) \mathrm{p}\left(\mathbf{c}_{i} \mid \mathbf{c}_{i}^{*}\right) \mathrm{p}\left(m_{i}^{*} \mid \mathbf{c}_{i}, \mathbf{c}_{i}^{*}, \mathbf{Z}_{i}, \mathbf{W}, \alpha, \lambda, \delta, \Sigma\right) \mathrm{p}\left(m_{i} \mid m_{i}^{*}\right) \\
&=(2 \pi)^{-J / 2}|\Sigma|^{-1 / 2} \exp \left[-.5\left(\mathbf{c}_{i}^{*}-\mathbf{Z}_{i} \alpha\right)^{\prime} \Sigma^{-1}\left(\mathbf{c}_{i}^{*}-\mathbf{Z}_{i} \alpha\right)\right] \cdot\left[\sum_{j=1}^{J} c_{i j} \prod_{\ell=1}^{J} \chi_{[0, \infty)}\left(c_{i j}^{*}-c_{i \ell}^{*}\right)\right] \\
& \cdot \exp \left\{-.5\left[m_{i}^{*}-\mathbf{u}_{i}^{\prime} \lambda-\left(\mathbf{c}_{i}^{*}-\mathbf{Z}_{i} \alpha\right)^{\prime} \delta\right]^{2}\right\} \cdot\left[m_{i} \chi_{[0, \infty)}\left(m_{i}^{*}\right)+\left(1-m_{i}\right) \chi_{(-\infty, 0)}\left(m_{i}^{*}\right)\right] .
\end{aligned}
$$

Since individuals are independent, the joint distribution of observables and latent variables for all individuals is the product of this expression over $i=1, \ldots, n$.

\section{A2.5 Gibbs sampling algorithm}

The posterior density is proportional to the product of the prior density (A2.1) and the distribution of observables and latent variables (A2.2) over $i=1, \ldots, n$, taking the observables as fixed and the unobserved latent variables and parameters as the arguments of the posterior density. In a Gibbs sampling algorithm (Gelfand and Smith, 1990; Geweke, 1997) the unobservables are grouped and successive drawings are made for each group. Given weak regularity conditions, the unique stationary distribution of these repeated drawings is the 
posterior distribution. In the algorithm described here there are $2 n+2$ groups: $\mathbf{c}_{i}^{*}(i=1, \ldots, n)$, $m_{i}^{*}(i=1, \ldots, n), \alpha$, and $v$. In each case the conditional distribution may be determined by examining the kernel of the posterior density in the vector being drawn.

The latent vectors $\mathbf{c}_{i}^{*}(i=1, \ldots, n)$ are conditionally independent, with $\mathbf{c}_{i}^{*} \sim \mathrm{N}\left(\overline{\mathbf{c}}_{i}, \overline{\mathbf{H}}_{i}^{-1}\right)$ where

$$
\overline{\mathbf{H}}_{i}=\Sigma^{-1}+\delta \delta^{\prime}, \overline{\mathbf{c}}_{i}=\overline{\mathbf{H}}_{i}^{-1}\left[\Sigma^{-1} \mathbf{Z}_{i} \alpha+\delta\left(m_{i}^{*}-\mathbf{u}_{i}^{\prime} \lambda+\delta^{\prime} \mathbf{Z}_{i} \alpha\right)\right],
$$

and subject to $c_{i j}^{*}-c_{i \ell}^{*} \geq 0$ where $j: c_{i j}=1$. While the elements of $\mathbf{c}_{i}^{*}$ can be drawn in succession using the generic algorithm in Geweke (1991), the fixed structure of $\Sigma$ permits a more efficient procedure. Specifically, it can be shown that conditional on all the other parameters and latent variables, the $j$ 'th element of $\mathbf{c}_{i}^{*}$, denoted $c_{i j}^{*}$, is $c_{i j}^{*} \sim \mathrm{N}\left\{\bar{c}_{i j}+\left(1-J^{-1}+\delta_{j}^{2}\right)^{-1}\left[\sum_{\ell \neq j}\left(J^{-1}-\delta_{j} \delta_{\ell}\right)\left(c_{i \ell}^{*}-\bar{c}_{i \ell}\right)\right], \quad\left(1-J^{-1}+\delta_{j}^{2}\right)^{-1}\right\}$,

truncated to the interval $(0, \infty) \cap\left(\max _{\ell \neq j} c_{i \ell}^{*}, \infty\right)$ if $j$ is the observed choice; truncated to the interval $\left(-\infty, c_{i k}^{*}\right)$ if $k(\neq j, J)$ is the observed choice; and to $(-\infty, 0)$ if $k=J$ is the observed choice.

The latent vectors $m_{i}^{*}(i=1, \ldots, n)$ are conditionally independent, with $m_{i}^{*} \sim \mathrm{N}\left[\mathbf{u}_{i}^{\prime} \lambda+\delta^{\prime}\left(c_{i}^{*}-\mathbf{Z}_{i} \alpha\right), 1\right]$ subject to $\left(2 m_{i}-1\right) m_{i}^{*} \geq 0$.

The conditional distribution of $\alpha$ is $\alpha \sim \mathrm{N}\left(\bar{\alpha}, \overline{\mathbf{H}}_{\alpha}^{-1}\right)$ where

$$
\begin{aligned}
& \overline{\mathbf{H}}_{\alpha}=\underline{\mathbf{H}}_{\alpha}+\sum_{i=1}^{n} \mathbf{Z}_{i}^{\prime}\left(\Sigma^{-1}+\delta \delta^{\prime}\right) \mathbf{Z}_{i} \\
& \bar{\alpha}=\underline{\mathbf{H}}_{\alpha}^{-1}\left\{\underline{\mathbf{H}}_{\alpha} \underline{\alpha}+\sum_{i=1}^{n} \mathbf{Z}_{i}^{\prime}\left[\Sigma^{-1} \mathbf{c}_{i}^{*}+\delta\left(\delta^{\prime} \mathbf{c}_{i}^{*}-m_{i}^{*}+\mathbf{u}_{i}^{\prime} \lambda\right)\right]\right\} .
\end{aligned}
$$

Let $v^{\prime}=\left(\lambda^{\prime}, \delta^{\prime}\right)$. The conditional distribution of $v$ is $v \sim \mathrm{N}\left(\bar{v}, \overline{\mathbf{H}}_{v}(\tau)^{-1}\right)$ where

$$
\begin{aligned}
& \overline{\mathbf{H}}_{v}(\tau)=\left[\begin{array}{cc}
\underline{\mathbf{H}}_{\lambda}(\tau) & \mathbf{0} \\
\mathbf{0} & \underline{\mathbf{H}}_{\delta}
\end{array}\right]+\sum_{i=1}^{n}\left[\begin{array}{c}
\mathbf{u}_{i} \\
\mathbf{c}_{i}^{*}-\mathbf{Z}_{i} \alpha
\end{array}\right]\left[\begin{array}{ll}
\mathbf{u}_{i}^{\prime} & \left(\mathbf{c}_{i}^{*}-\mathbf{Z}_{i} \alpha\right)^{\prime}
\end{array}\right], \\
& \bar{v}=\overline{\mathbf{H}}_{v}^{-1}\left[\underline{\mathbf{H}}_{v} \underline{v}+\sum_{i=1}^{n}\left(\begin{array}{c}
\mathbf{u}_{i} \\
\mathbf{c}_{i}^{*}-\mathbf{Z}_{i} \alpha
\end{array}\right) m_{i}^{*}\right] .
\end{aligned}
$$

Finally, 


$$
\bar{s}_{j}^{2} / \tau_{j}^{2} \sim \chi^{2}\left(\bar{v}_{j}\right)(j=p, s, u)
$$

where $\bar{s}_{p}^{2}=\underline{s}_{p}^{2}+\sum_{j=2}^{5} \beta_{j}^{2}, \bar{v}_{p}=\underline{v}_{p}+4, \bar{s}_{s}^{2}=\underline{s}_{s}^{2}+\sum_{j=6}^{9} \beta_{j}^{2}, \bar{v}_{s}=\underline{v}_{s}+4, \bar{s}_{u}^{2}=\underline{s}_{u}^{2}+\sum_{j=10}^{J+9} \beta_{j}^{2}$, and $\bar{v}_{u}=\underline{v}_{u}+J$.

The conditions set forth by Roberts and Smith (1994) for the posterior distribution to be the unique stationary distribution for a Gibbs sampling algorithm, described as Gibbs sampler convergence condition 2 in Geweke (1997) are satisfied. The key technical condition is that the support of the posterior distribution in latent variables and parameters is connected and upper semicontinuous.

\section{A2.6 Computation time}

Using an IBM 332Mhz 604e processor and ESSL matrix computation routines, the computational time per iteration was approximately 6 minutes. This processor is comparable to a Pentium III 600. We then used an IBM SP supercomputer with Silver nodes, each of which has the $604 \mathrm{e}$ processor as its base, in order to compute each iteration in parallel. Two steps were very parallelizable: the $c_{i j}^{*}$ can be computed in parallel for each individual, and the matrix multiplications necessary to compute the conditional posterior of $\alpha$ can also be broken up by individual. We were able to reduce the computation time close to proportionally to the number of processors that we used. For instance, the algorithm took 100 seconds per iteration with 4 processors, 60 seconds per iteration with 8 processors and 33 seconds per iteration with 20 processors. Thus, computation time for 20,000 iterations with 20 processors is roughly 8 days.

\section{Appendix A3: Accuracy of the MCMC approximation to posterior moments}

Collect the parameter vectors in the single vector $\theta^{\prime}=\left(\alpha^{\prime}, \beta^{\prime}, \gamma^{\prime}, \delta^{\prime}\right)$ and the data in the single vector $\mathbf{y}$. A posterior moment can then be expressed $E[g(\theta) \mid \mathbf{y}]$ for the appropriate function of interest $\mathrm{g}$. The Gibbs sampling algorithm produces serially correlated draws $\theta^{(1)}, \ldots, \theta^{(M)}$ from the posterior distribution. Hence $\mathrm{g}\left(\theta^{(1)}\right), \ldots, \mathrm{g}\left(\theta^{(M)}\right)$ is a sequence of draws from the posterior distribution of $\mathrm{g}(\theta)$. The numerical approximation of $\bar{g}=\mathrm{E}[\mathrm{g}(\theta) \mid \mathbf{y}]$ is 
$\bar{g}_{M}=M^{-1} \sum_{m=1}^{M} \mathrm{~g}\left(\theta^{(m)}\right)$. Standard methods for serially correlated time series (Geweke (1999), Section 3.7) then produce a consistent (in $M$ ) approximation of $\tilde{\sigma}^{2}=\lim _{M \rightarrow \infty} M \mathrm{E}\left(\bar{g}^{(M)}-\bar{g}\right)^{2}$. [Expectation in the latter expression is with respect to the Markov chain that defines the Gibbs sampling algorithm.]

The efficiency of any Markov chain Monte Carlo (MCMC) algorithm can be evaluated by comparing $\tilde{\sigma}^{2}$ with the posterior variance of $\mathrm{g}(\theta), \sigma^{2}=\mathrm{E}\left\{[\mathrm{g}(\theta)-\bar{g}]^{2} \mid \mathbf{y}\right\}$. If the algorithm produced iid draws from the posterior distribution, then $\tilde{\sigma}^{2}=\sigma^{2}$. More generally, the relative numerical efficiency of any MCMC algorithm for the function of interest $\operatorname{g}(\theta)$ is $R N E=\sigma^{2} / \tilde{\sigma}^{2}$. Numerical approximations of $\bar{g}$ based on $M$ iterations of the algorithm will have the same accuracy as $R N E \cdot M$ iterations from a hypothetical algorithm that made iid drawings directly from the posterior distribution. The ratio of the standard error of approximation $\left(\tilde{\sigma}^{2} / M\right)^{1 / 2}$, to the posterior standard deviation $\sigma$, is $(R N E \cdot M)^{1 / 2}$. For any given posterior distribution and MCMC algorithm, RNE will be different for different functions of interest.

The results reported in the paper are based on 20,000 iterations of the Gibbs sampler. Visual inspection of parameter draws shows that convergence to the invariant (i.e., posterior) distribution occurs within the first 1,000 iterations, which are discarded. Of the remaining 19,000 , every tenth iteration is used to compute posterior moments. (This reduces the size of the posterior files. Because of the serial correlation in functions of interest over iterations, little information is lost.)

The values of NSE and RNE corresponding to the moments reported in Table 4 are provided in Table A2. (RNE is computed from the 1900 retained iterations.) The Gibbs sampling algorithm for the probit model exhibits no serial correlation, and consequently numerical standard errors are all about $1 / \sqrt{1900} \approx 1 / 44$ of the posterior standard deviation. The degree of serial correlation in the Gibbs sampling algorithm for the selection model varies, depending on the moments. Serial correlation is modest for the demographic and severity coefficients in the mortality probit equation, with all but one RNE greater than 0.2 . For the group quality probits and the coefficients in the multinomial probit hospital selection model serial correlation is greater, with RNEs between 0.004 and 0.014 . Observe that if RNE is 0.01, with 
1900 iterations the variance in the posterior moments due to simulation is $1 / 19$ that of the posterior variance itself: stated less formally, simulation noise inflates the posterior standard deviation by $(20 / 19)^{1 / 2}-1=2.6 \%$.

Table A3 provides similar information about the numerical accuracy of approximations in the Gibbs sampling algorithm for the quality probits $q_{j}$ (selection model) and $q_{j}^{*}$ (probit model) and for $\rho_{j}$, the correlation between the mortality probit equation shock and the shocks to the hospital choice multinomial probit model. The RNEs for $q_{j}^{*}$ in the probit model are centered about 1.0, as was the case for all moments of this model in Table A2. The RNEs of the quality probits $q_{j}$ in the selection model are comparable to those of the group quality probits and $\alpha$ vector in Table A2, while for the correlations $\rho_{j}$ they are somewhat lower.

\section{Appendix A4: Rankings of hospitals}

Table A4 provides rankings for hospitals based on quadratic and absolute value loss functions, using the posterior density from the selection model. Table A5 provides pairwise comparisons: for hospitals at equally spaced quartiles of the posterior quality distribution, the table indicates the posterior probability that the hospital has lower quality than each of the other hospitals in the set. The choice of loss function does not have a large effect on the orderings of relative quality. The majority of hospitals have probability of at least 0.05 of being in any of three quartiles of the distribution. Roughly $10 \%$ of hospitals appear to be either better or worse than average, with posterior probability of at least 95\%. Fairly confident pairwise rankings can be made for the ends of the distribution but not for the majority of hospitals.

Tables A6 and A7 provide the same figures as Tables A4 and A5 respectively, using the posterior density from the probit model. The two sets of tables indicate substantially different orders of rankings, but similar magnitudes of coefficients. In both models, there are 42 hospitals that have quality probit exceeding 0.1 in absolute value. However, the probit model exhibits somewhat more confidence about the rankings. There are only 9 hospitals (as opposed to 21 for the selection model) for which the probability of placement is at least .10 in each quartile, and about $25 \%$ of hospitals appear to be either better or worse than average, with posterior 
probability of at least $95 \%$. The greater confidence in rankings can be ascribed to the restriction of no correlation between shocks to hospital choice and mortality in the probit model.

\section{Appendix A5: Results with alternative prior distributions}

Section 4.4 of the paper describes three alternative priors chosen to study their impact on the results. To recapitulate, variant A effectively eliminates the instruments, by scaling the prior standard deviations of the coefficient vector $\alpha$ in the multinomial hospital assignment model by the factor $10^{-6}$. This leaves only the functional form to identify the hospital-specific parameters in the mortality equation. Variant B scales the prior standard deviations of $\alpha$ in the original selection model downward by a factor of 5 . It does the same for the hospital coefficients $\beta$ in the mortality probit equation, by taking $1.25 \times \frac{1}{5} \times \frac{1}{5} \times\left[\sigma_{\delta}^{2}(J-1)+1\right] / \tau_{j}^{2} \sim \chi^{2}(5)$ rather than $1.25\left[\sigma_{\delta}^{2}(J-1)+1\right] / \tau_{j}^{2} \sim \chi^{2}(5)$. Variant $\mathrm{C}$ is like Variant $\mathrm{B}$ except that prior standard deviations are increased by a factor of 5 relative to the base model. Variants B and C are simply reasonable alternatives to the base prior used in the paper.

Tables 3 and 4 in the paper are reproduced for each of these variants in this appendix: for variant $\mathrm{A}$ in Tables A8 and A9, for variant B in Tables A10 and A11, and for variant C in Tables A12 and A13. Turning first to the variants on Table 3 (i.e. Tables A8, A10, A12), note that there is almost no sensitivity of the covariate coefficients in the mortality equation to the three alternative priors. Given that (1) the priors for these coefficients are the same in all three variants, (2) these priors are independent of the priors for all the other parameters in the model, and (3) that hospital choice and unobserved disease severity are orthogonal to the covariates in the sample, the posterior distribution of the covariate coefficients in the mortality equation would be the same under all three priors. Conditions (1) and (2) are met here; (3) cannot be verified, but it is reasonable as an approximation and is the leading interpretation of the insensitivity of mortality covariate coefficients to priors for hospital quality and the hospital choice multinomial probit model. The posterior distribution of the coefficient vector $\alpha$ in this model is little affected by the alternative priors $\mathrm{B}$ and $\mathrm{C}$, while of course under variant $\mathrm{A}$ these coefficients are much smaller. 
As one would expect, there is substantially more variation in the group hospital quality probits $q_{j}$, across the alternative priors. Table A14 provides the correlation coefficients between the posterior means of the individual hospital quality probits across the 114 hospitals. The correlations between the base selection model and prior variants $\mathrm{B}$ and $\mathrm{C}$ are both 0.80 , whereas correlation between the base model and prior variant $\mathrm{A}$ is 0.34 . These comparisons support the conclusion of the paper (in Section 4.4) that reasonable variations in the prior distribution produce distinct but small effects on the posterior moments of interest, while eliminating the instruments from the selection model produces a substantially larger effect.

This relationship between the alternative priors and the base model is also evident in the posterior probability comparisons of orderings in group quality probits: see the variants on Table 4 in Tables A9, A11 and A13. For the hospital size and ownership group quality probits, the results are clear: the tighter (B) and looser (C) priors produce results close to the base model. By contrast elimination of instruments (prior variant A) produces results entirely dissimilar from the base model. 


\section{Table A1}

Relationship between $\underline{h}_{\delta}^{-1 / 2}$ and severity correlations

\begin{tabular}{|c|c|c|c|c|c|}
\hline$\underline{h}_{\delta}^{-1 / 2}$ & .01 & .08 & .20 & .50 & .80 \\
\hline$E\left(\left|\tilde{\rho}_{j}\right|\right)$ & .008 & .048 & .067 & .067 & .067 \\
\hline $\operatorname{s.d.}\left(\left|\tilde{\rho}_{j}\right|\right)$ & .010 & .050 & .060 & .061 & .061 \\
\hline $\operatorname{corr}\left(\left|\tilde{\rho}_{i}\right|,\left|\tilde{\rho}_{j}\right|\right)$ & .001 & .005 & .005 & .005 & .005 \\
\hline$\tilde{R}^{2}$ & .001 & .060 & .271 & .683 & .838 \\
\hline s.d. $\left(\tilde{R}^{2}\right)$ & .0005 & .025 & .088 & .104 & .070 \\
\hline$E\left(\left|\rho_{j}\right|\right)$ & .008 & .067 & .067 & .067 & .067 \\
\hline $\operatorname{s.d.}\left(\left|\rho_{j}\right|\right)$ & .006 & .051 & .051 & .051 & .051 \\
\hline $\operatorname{corr}\left(\left|\rho_{i}\right|,\left|\rho_{j}\right|\right)$ & .223 & .233 & .233 & .233 & .233 \\
\hline$R^{2}$ & .011 & .421 & .819 & .966 & .986 \\
\hline s.d. $\left(R^{2}\right)$ & .0015 & .032 & .020 & .005 & .002 \\
\hline
\end{tabular}


Table A2

Posterior numerical standard errors and relative numerical efficiencies

\begin{tabular}{|c|c|c|c|}
\hline & Coefficient & \multicolumn{2}{|c|}{ Selection model } \\
\hline & & \multicolumn{2}{|c|}{$\gamma /(\delta \Sigma \delta+1)^{1 / 2}$} \\
\hline \multirow{11}{*}{ 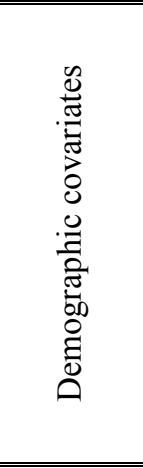 } & Age 70-74 & $-0.009(.024)$ & {$[.0005,1.040]$} \\
\hline & Age 75-79 & $0.065(.023)$ & {$[.0011,0.220]$} \\
\hline & Age $80-84$ & $0.184(.023)$ & {$[.0010,0.296]$} \\
\hline & Age $>84$ & $0.369(.022)$ & {$[.0001,0.269]$} \\
\hline & Female & $-0.087(.013)$ & {$[.0006,0.258]$} \\
\hline & Black & $-0.020(.028)$ & {$[.0021,0.099]$} \\
\hline & Hispanic & $-0.122(.022)$ & {$[.0011,0.210]$} \\
\hline & Native & $0.152(.133)$ & {$[.0039,0.622]$} \\
\hline & Asian & $-0.091(.030)$ & {$[.0010,0.466]$} \\
\hline & Income & $0.222(.021)$ & {$[.0068,0.490]$} \\
\hline & Income ${ }^{\wedge} 2$ & $-0.028(.024)$ & {$[.0008,0.478]$} \\
\hline \multirow{6}{*}{ 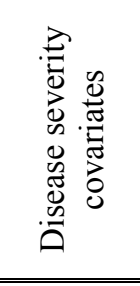 } & & \multicolumn{2}{|c|}{$\gamma /(\delta \Sigma \delta+1)^{1 / 2}$} \\
\hline & Emergency admit & $0.180(.015)$ & {$[\bar{c}[.0006,0.327]$} \\
\hline & Disease stages 1.3-2.3 & $0.089(.028)$ & {$[.0009,0.502]$} \\
\hline & Disease stages 3.1-3.6 & $0.493(.023)$ & {$[.0004,1.849]$} \\
\hline & Disease stage 3.7 & $0.635(.019)$ & {$[.0008,0.292]$} \\
\hline & Disease stage 3.8 & $1.396(.038)$ & {$[.0010,0.704]$} \\
\hline \multirow{9}{*}{ 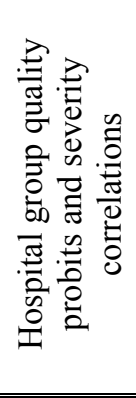 } & & $q_{G}$ & $\rho_{G}$ \\
\hline & 150 beds or less & $0.018(0.021)[0.0053,0.008]$ & $0.001(0.008)[0.0025,0.006]$ \\
\hline & 151 to 200 beds & $-0.069(0.032)[0.0065,0.012]$ & $-0.017(0.003)[0.0032,0.007]$ \\
\hline & 201 to 300 beds & $-0.023(0.027)[0.0052,0.014]$ & $-0.010(0.011)[0.0024,0.010]$ \\
\hline & Over 300 beds & $0.039(0.020)[0.0040,0.013]$ & $0.022(0.008)[0.0022,0.006]$ \\
\hline & Private, not for profit & $0.006(0.018)[0.0041,0.011]$ & $0.003(0.008)[0.0020,0.008]$ \\
\hline & Private, for profit & $0.007(0.015)[0.0039,0.008]$ & $0.008(0.006)[0.002,0.007]$ \\
\hline & Private Teaching & $0.019(0.041)[0.0121,0.006]$ & $0.006(0.014)[0.0045,0.005]$ \\
\hline & Public & $-0.071(0.089)[0.0319,0.004]$ & $-0.017(0.029)[0.0113,0.003]$ \\
\hline \multirow{4}{*}{ 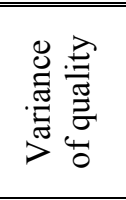 } & & \multicolumn{2}{|c|}{$\tau^{2} /(\delta \Sigma \delta+1)$} \\
\hline & Size & $0.020(0.144)$ & {$[0.0057,0.334]$} \\
\hline & Ownership & $0.020(0.135)$ & {$[0.0042,0.537]$} \\
\hline & Individual Hospital & $0.037(0.006)$ & {$[0.0005,0.099]$} \\
\hline \multirow{6}{*}{ 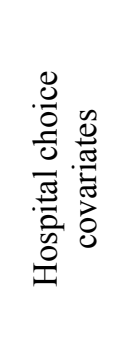 } & & \multicolumn{2}{|c|}{$\alpha$} \\
\hline & Distance & $-13.65(0.15)$ & {$[0.022,0.024]$} \\
\hline & Distance $^{2}$ & $12.43(0.09)$ & {$[0.015,0.015]$} \\
\hline & Distance $\times$ Age & $-0.453(0.025)$ & {$[0.0057,0.010]$} \\
\hline & Distance $\times$ Severity & $-0.311(0.034)$ & {$[0.0066,0.014]$} \\
\hline & $\begin{array}{c}10^{-5} \times \text { Distance } \\
\times \text { Income }\end{array}$ & $-0.974(0.257)$ & {$[0.0256,0.053]$} \\
\hline
\end{tabular}

Notation and definitions are exactly as in Table 3 of the paper. The first two numbers in each entry indicate the posterior mean and standard deviation, respectively. The pair of numbers in brackets, separated by a comma, indicate the numerical standard error (NSE) and relative numerical efficiency (RNE) for the Gibbs sampling approximation of the corresponding posterior mean. 
Table A2 (continued)

Posterior means and standard deviations

\begin{tabular}{|c|c|c|c|}
\hline & Coefficient & \multicolumn{2}{|c|}{ Probit model } \\
\hline & & & \\
\hline \multirow{11}{*}{ 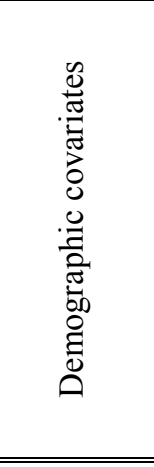 } & Age $70-74$ & $-0.008(0.025)$ & {$[0.0005,1.354]$} \\
\hline & Age $75-79$ & $0.068(0.024)$ & {$[0.0004,1.842]$} \\
\hline & Age 80-84 & $0.187(0.024)$ & {$[0.0005,1.317]$} \\
\hline & Age $>84$ & $0.374(0.022)$ & {$[0.0003,3.669]$} \\
\hline & Female & $-0.087(0.013)$ & {$[0.0003,1.339]$} \\
\hline & Black & $-0.025(0.028)$ & {$[0.0006,1.356]$} \\
\hline & Hispanic & $-0.126(0.023)$ & {$[0.0006,0.712]$} \\
\hline & Native & $0.168(0.134)$ & {$[0.0028,1.168]$} \\
\hline & Asian & $-0.091(0.031)$ & {$[0.0004,3.106]$} \\
\hline & Income & $0.253(0.201)$ & {$[0.0032,2.074]$} \\
\hline & Income $^{\wedge} 2$ & $-0.033(0.024)$ & {$[0.0004,1.549]$} \\
\hline \multirow{6}{*}{ 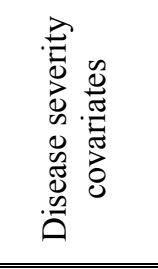 } & & \multicolumn{2}{|c|}{$\gamma$} \\
\hline & Emergency admit & $0.181(0.016)$ & {$[0.0003,1.889]$} \\
\hline & Disease stages 1.3-2.3 & $0.089(0.028)$ & {$[0.0007,0.940]$} \\
\hline & Disease stages 3.1-3.6 & $0.496(0.023)$ & {$[0.0005,1.015]$} \\
\hline & Disease stage 3.7 & $0.640(0.018)$ & {$[0.0004,1.061]$} \\
\hline & Disease stage 3.8 & $1.412(0.037)$ & {$[0.0008,1.239]$} \\
\hline \multirow{9}{*}{ 己 } & & \multicolumn{2}{|c|}{$q_{G}^{*}$} \\
\hline & 150 beds or less & $0.007(0.012)$ & {$[0.0002,1.252]$} \\
\hline & 151 to 200 beds & $-0.034(0.018)$ & {$[0.0006,0.422]$} \\
\hline & 201 to 300 beds & $-0.003(0.013)$ & {$[0.0003,1.418]$} \\
\hline & Over 300 beds & $0.004(0.012)$ & {$[0.0001,3.594]$} \\
\hline & Private, not for profit & $-0.001(0.009)$ & {$[0.0001,2.454]$} \\
\hline & Private, for profit & $-0.008(0.009)$ & {$[0.0002,1.057]$} \\
\hline & Private Teaching & $0.021(0.024)$ & {$[0.0005,1.013]$} \\
\hline & Public & $-0.167(0.042)$ & {$[0.0009,1.077]$} \\
\hline \multirow{4}{*}{ 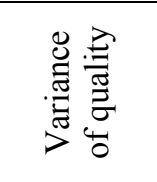 } & & \multicolumn{2}{|c|}{$\tau^{2}$} \\
\hline & Size & $0.209(0.155)$ & {$[0.0028,1.601]$} \\
\hline & Ownership & $0.208(0.155)$ & {$[0.0039,0.841]$} \\
\hline & Individual Hospital & $0.030(0.005)$ & {$[0.0001,1.353]$} \\
\hline
\end{tabular}

Notation and definitions are exactly as in Table 3 of the paper. The pair of numbers in brackets, separated by a comma, indicate the numerical standard error (NSE) and relative numerical efficiency (RNE) for the Gibbs sampling approximation of the corresponding posterior mean. 
Table A3

Some relative numerical efficiencies of the algorithm for hospital-specific parameters

\begin{tabular}{|c||c|c|c|}
\hline Parameter name & $q_{j}$ & $\rho_{j}$ & $q_{j}^{*}$ \\
\hline \hline Average efficiency & .0201 & .0084 & 1.62 \\
\hline Lowest & .0039 & .0036 & 0.27 \\
\hline Third quartile & .0074 & .0051 & 0.91 \\
\hline Median & .0103 & .0064 & 1.23 \\
\hline First quartile & .0215 & .0095 & 2.02 \\
\hline Highest & .1687 & .0723 & 4.86 \\
\hline \hline Number of parameters & 114 & 113 & 114 \\
\hline
\end{tabular}

Posterior moments are computed using every $10^{\text {th }}$ draw of the Gibbs sampling algorithm. Relative numerical efficiency is the ratio of the estimated variance of numerical approximation errors using every $10^{\text {th }}$ draw, to the estimated posterior variance. 
Table A4

Posterior distribution of hospital quality probits, selection model

\begin{tabular}{|c|c|c|c|c|c|c|c|c|}
\hline & \multirow[t]{2}{*}{ Hospital name } & \multirow{2}{*}{$\frac{q_{j}}{2 \text { Mean }}$} & \multicolumn{2}{|l|}{ Rank } & \multicolumn{4}{|c|}{ Quartile probabilities } \\
\hline & & & Mean & Median & & & & \\
\hline 1 & IMONTEREY PARK HOSPITAL & 0.338 & 6.7 & 3 & 0.959 & 0.037 & 0.004 & 0 \\
\hline 2 & ST. JOHNS HOSPITAL AND HEALTH & 0.294 & 7.9 & 5 & 0.964 & 0.034 & 0.003 & 0 \\
\hline 3 & $\begin{array}{l}\text { TERRACE PLAZA MEDICAL CENTER } \\
\end{array}$ & 0.258 & 13.2 & 8 & 0.88 & 0.096 & 0.02 & 0.004 \\
\hline 4 & SAN DIMAS COMMUNITY HOSPITAL & 0.231 & 15.4 & 11 & 0.839 & 0.138 & 0.022 & 0.001 \\
\hline 5 & QUEEN OF ANGELS/HOLLYWOOD PRES & 0.194 & 18.9 & 12 & 0.769 & 0.197 & 0.034 & 0 \\
\hline 6 & DANIEL FREEMAN MARINA HOSPITAL & 0.181 & 22.9 & 15 & 0.691 & 0.223 & 0.077 & 0.009 \\
\hline 7 & EAST LOS ANGELES DOCTORS HOSPI & 0.173 & 24.2 & 16 & 0.685 & 0.206 & 0.089 & 0.019 \\
\hline 8 & COMMUNITY HOSPITAL OF HUNTINGT & 0.183 & 25.4 & 15 & 0.687 & 0.17 & 0.097 & 0.046 \\
\hline 9 & WOODRUFF COMMUNITY HOSPITAL & 0.165 & 26.1 & 19 & 0.646 & 0.235 & 0.099 & 0.02 \\
\hline 10 & LOS ANGELES COMMUNITY HOSPITAL & 0.159 & 27.3 & 19 & 0.633 & 0.229 & 0.106 & 0.032 \\
\hline 11 & LINDA VISTA COMMUNITY HOSPITAL & 0.165 & 27.4 & 19 & 0.632 & 0.221 & 0.113 & 0.034 \\
\hline 12 & KAISER FOUNDATION HOSPITAL - L & 0.15 & 27.7 & 22 & 0.608 & 0.272 & 0.107 & 0.012 \\
\hline 13 & AMI TARZANA REGIONAL MEDICAL C & 0.14 & 28.4 & 21 & 0.597 & 0.277 & 0.102 & 0.024 \\
\hline 14 & MISSION HOSPITAL & 0.146 & 28.8 & 22 & 0.609 & 0.248 & 0.112 & 0.031 \\
\hline 15 & BELLFLOWER DOCTORS HOSPITAL & 0.141 & 30.2 & 25 & 0.555 & 0.295 & 0.126 & 0.024 \\
\hline 16 & CEDARS SINAI MEDICAL CENTER & 0.115 & 30.4 & 29 & 0.486 & 0.456 & 0.058 & 0 \\
\hline 17 & NU MED REGIONAL MED CENTER WES & 0.118 & 31 & 27 & 0.536 & 0.344 & 0.108 & 0.012 \\
\hline 18 & DOCTORS HOSPITAL OF LAKEWOOD - & 0.14 & 31.7 & 22 & 0.574 & 0.222 & 0.154 & 0.051 \\
\hline 19 & WHITE MEMORIAL MEDICAL CENTER & 0.118 & 32.6 & 26 & 0.548 & 0.293 & 0.116 & 0.044 \\
\hline 20 & PRESBYTERIAN INTERCOMMUNITY HO & 0.111 & 34.3 & 24 & 0.565 & 0.206 & 0.174 & 0.055 \\
\hline 21 & CIGNA HOSPITAL OF LOS ANGELES & 0.114 & 34.5 & 28 & 0.502 & 0.3 & 0.152 & 0.047 \\
\hline 22 & ST. MARY MEDICAL CENTER & 0.101 & 34.8 & 30 & 0.457 & 0.385 & 0.139 & 0.018 \\
\hline 23 & ST. VINCENT MEDICAL CENTER & 0.089 & 36.1 & 34 & 0.384 & 0.481 & 0.13 & 0.005 \\
\hline 24 & ANTELOPE VALLEY HOSPITAL MEDIC & 0.092 & 36.1 & 32 & 0.425 & 0.414 & 0.151 & 0.011 \\
\hline 25 & GREATER EL MONTE COMMUNITY HOS & 0.083 & 38.1 & 36 & 0.373 & 0.444 & 0.173 & 0.009 \\
\hline 26 & SANTA MARTA HOSPITAL & 0.081 & 39.1 & 35 & 0.402 & 0.388 & 0.161 & 0.049 \\
\hline 27 & LOS ANGELES CO. USC MEDICAL CE & 0.078 & 39.8 & 36 & 0.376 & 0.395 & 0.193 & 0.037 \\
\hline 28 & SHERMAN OAKS COMMUNITY HOSPITA & 0.076 & 40 & 38 & 0.363 & 0.408 & 0.195 & 0.033 \\
\hline 29 & GLENDALE MEMORIAL HOSPITAL \& $\mathrm{H}$ & 0.074 & 40.9 & 40 & 0.299 & 0.476 & 0.206 & 0.018 \\
\hline 30 & ST. JOSEPH MEDICAL CENTER & 0.068 & 41.4 & 37 & 0.373 & 0.374 & 0.217 & 0.036 \\
\hline 31 & SOUTH BAY HOSPITAL & 0.075 & 41.6 & 37 & 0.385 & 0.337 & 0.197 & 0.081 \\
\hline 32 & PACIFIC ALLIANCE MEDICAL CENTE & 0.071 & 41.8 & 38 & 0.377 & 0.343 & 0.211 & 0.069 \\
\hline 33 & WESTSIDE HOSPITAL & 0.072 & 42.1 & 40 & 0.362 & 0.358 & 0.217 & 0.063 \\
\hline 34 & COVINA VALLEY COMMUNITY HOSPIT & 0.069 & 42.6 & 38 & 0.379 & 0.335 & 0.207 & 0.079 \\
\hline 35 & LITTLE COMPANY OF MARY HOSPITA & 0.061 & 42.7 & 39 & 0.307 & 0.434 & 0.224 & 0.035 \\
\hline 36 & MOTION PICTURE \& TELEVISION HO & 0.073 & 43.5 & 37 & 0.414 & 0.258 & 0.192 & 0.135 \\
\hline 37 & KAISER FOUNDATION HOSPITAL $-\mathrm{P}$ & 0.059 & 43.9 & 41 & 0.309 & 0.397 & 0.241 & 0.053 \\
\hline 38 & HENRY MAYO NEWHALL MEMORIAL HO & 0.047 & 45.8 & 45 & 0.182 & 0.565 & 0.243 & 0.011 \\
\hline 39 & KAISER FOUNDATION HOSPITAL - B & 0.053 & 46.1 & 45 & 0.316 & 0.333 & 0.274 & 0.078 \\
\hline 40 & GLENDALE ADVENTIST MED CENTER & 0.046 & 46.3 & 44 & 0.299 & 0.368 & 0.285 & 0.047 \\
\hline 41 & SANTA MONICA HOSPITAL MEDICAL & 0.048 & 46.3 & 44 & 0.286 & 0.367 & 0.295 & 0.052 \\
\hline 42 & UCLA MEDICAL CENTER & 0.047 & 46.5 & 42 & 0.281 & 0.412 & 0.217 & 0.091 \\
\hline 43 & HOLLYWOOD COMMUNITY HOSPITAL & 0.044 & 48.4 & 44 & 0.317 & 0.301 & 0.233 & 0.149 \\
\hline 44 & ALHAMBRA COMMUNITY HOSPITAL & 0.041 & 48.9 & 48 & 0.26 & 0.353 & 0.301 & 0.086 \\
\hline 45 & HUMANA HOSPITAL WEST HILLS & 0.033 & 49.5 & 48 & 0.207 & 0.419 & 0.312 & 0.062 \\
\hline 46 & VALLEY PRESBYTERIAN HOSPITAL & 0.037 & 49.8 & 49 & 0.227 & 0.373 & 0.328 & 0.072 \\
\hline 47 & CENTINELA HOSPITAL MEDICAL CEN & 0.034 & 49.8 & 48 & 0.259 & 0.345 & 0.298 & 0.097 \\
\hline 48 & BEVERLY HILLS MEDICAL CENTER & 0.035 & 50.6 & 49 & 0.29 & 0.298 & 0.263 & 0.149 \\
\hline 49 & HAWTHORNE HOSPITAL & 0.027 & 51.7 & 50 & 0.241 & 0.342 & 0.293 & 0.124 \\
\hline 50 & KAISER FOUNDATION HOSPITAL - $\mathrm{H}$ & 0.033 & 52 & 53 & 0.314 & 0.223 & 0.282 & 0.182 \\
\hline 51 & SAN PEDRO PENINSULA HOSPITAL & 0.027 & 52 & 53 & 0.222 & 0.329 & 0.364 & 0.085 \\
\hline 52 & LONG BEACH DOCTORS HOSPITAL & 0.016 & 53.8 & 53 & 0.236 & 0.309 & 0.302 & 0.153 \\
\hline 53 & METHODIST HOSPITAL OF SOUTHERN & 0.014 & 53.9 & 51 & 0.181 & 0.396 & 0.314 & 0.109 \\
\hline 54 & SAN FERNANDO COMMUNITY HOSPITA & 0.011 & 55.1 & 56 & 0.243 & 0.279 & 0.291 & 0.187 \\
\hline 55 & INTER COMMUNITY MEDICAL CENTER & 0.009 & 55.7 & 55 & 0.115 & 0.42 & 0.379 & 0.086 \\
\hline 56 & BAY HARBOR HOSPITAL & 0.002 & 57 & 57 & 0.074 & 0.433 & 0.419 & 0.074 \\
\hline 57 & PICO RIVERA COMMUNITY HOSPITAL & -0.003 & 58.2 & 59 & 0.201 & 0.284 & 0.301 & 0.215 \\
\hline 58 & CHARTER SUBURBAN HOSPITAL & -0.008 & 59 & 59 & 0.162 & 0.329 & 0.311 & 0.198 \\
\hline 59 & MONROVIA COMMUNITY HOSPITAL & -0.016 & 59.8 & 58 & 0.225 & 0.267 & 0.234 & 0.273 \\
\hline 60 & BROTMAN MEDICAL CENTER & -0.009 & 60.4 & 62 & 0.13 & 0.311 & 0.383 & 0.177 \\
\hline
\end{tabular}




\begin{tabular}{|c|c|c|c|c|c|c|c|c|}
\hline 61 & CENTURY CITY HOSPITAL & -0.015 & 60.8 & 61 & 0.127 & 0.323 & 0.363 & 0.188 \\
\hline 62 & MEMORIAL MEDICAL CENTER OF LON & -0.014 & 61 & 63 & 0.144 & 0.303 & 0.352 & 0.202 \\
\hline 63 & AMI GLENDORA COMMUNITY HOSPITA & -0.019 & 61 & 61 & 0.164 & 0.301 & 0.288 & 0.246 \\
\hline 64 & LANCASTER COMMUNITY HOSPITAL & -0.018 & 61.9 & 62 & 0.062 & 0.377 & 0.407 & 0.154 \\
\hline 65 & BELLWOOD GENERAL HOSPITAL & -0.02 & 62 & 63 & 0.147 & 0.286 & 0.339 & 0.228 \\
\hline 66 & RIO HONDO MEMORIAL HOSPITAL & -0.023 & 62.1 & 62 & 0.088 & 0.348 & 0.388 & 0.175 \\
\hline 67 & NORTHRIDGE HOSPITAL MEDICAL CE & -0.02 & 62.1 & 62 & 0.059 & 0.362 & 0.435 & 0.144 \\
\hline 68 & QUEEN OF THE VALLEY HOSPITAL - & -0.022 & 62.6 & 64 & 0.074 & 0.322 & 0.453 & 0.152 \\
\hline 69 & PACIFICA HOSPITAL OF THE VALLE & -0.022 & 62.9 & 65 & 0.132 & 0.271 & 0.371 & 0.226 \\
\hline 70 & CHARTER COMMUNITY HOSPITAL & -0.03 & 64.1 & 65 & 0.094 & 0.311 & 0.375 & 0.22 \\
\hline 71 & LOS ANGELES DOCTORS HOSPITAL & -0.035 & 64.7 & 67 & 0.149 & 0.259 & 0.302 & 0.291 \\
\hline 72 & MIDWAY HOSPITAL MEDICAL CENTER & -0.034 & 65.6 & 70 & 0.098 & 0.272 & 0.392 & 0.238 \\
\hline 73 & COMMUNITY HOSPITAL OF GARDENA & -0.043 & 66.7 & 70 & 0.124 & 0.244 & 0.328 & 0.304 \\
\hline 74 & HOLY CROSS MEDICAL CENTER & -0.045 & 68.3 & 71 & 0.047 & 0.271 & 0.445 & 0.237 \\
\hline 75 & BEVERLY HOSPITAL & -0.047 & 68.5 & 73 & 0.105 & 0.218 & 0.361 & 0.316 \\
\hline 76 & ROBERT F. KENNEDY MEDICAL CENT & -0.054 & 68.8 & 71 & 0.088 & 0.259 & 0.335 & 0.317 \\
\hline 77 & TEMPLE COMMUNITY HOSPITAL & -0.055 & 69.2 & 72 & 0.084 & 0.263 & 0.335 & 0.319 \\
\hline 78 & MEDICAL CENTER OF LA MIRADA & -0.056 & 69.2 & 73 & 0.117 & 0.217 & 0.323 & 0.343 \\
\hline 79 & PALMDALE HOSPITAL MEDICAL CENT & -0.049 & 69.3 & 71 & 0.033 & 0.262 & 0.465 & 0.24 \\
\hline 80 & HUNTINGTON MEMORIAL HOSPITAL & -0.051 & 70 & 71 & 0.013 & 0.265 & 0.486 & 0.236 \\
\hline 81 & NORWALK COMMUNITY HOSPITAL & -0.062 & 71.4 & 74 & 0.056 & 0.235 & 0.388 & 0.321 \\
\hline 82 & ST. LUKE MEDICAL CENTER & -0.066 & 71.5 & 74 & 0.054 & 0.254 & 0.357 & 0.335 \\
\hline 83 & LOS ANGELES CO. OLIVE VIEW MED & -0.082 & 74.2 & 79 & 0.081 & 0.197 & 0.319 & 0.403 \\
\hline 84 & TORRANCE MEMORIAL HOSPITAL MED & -0.073 & 74.4 & 77 & 0.024 & 0.223 & 0.398 & 0.355 \\
\hline 85 & DANIEL FREEMAN MEMORIAL HOSPIT & -0.078 & 74.5 & 78 & 0.053 & 0.221 & 0.328 & 0.398 \\
\hline 86 & GARFIELD MEDICAL CENTER & -0.086 & 74.6 & 76 & 0.046 & 0.224 & 0.358 & 0.372 \\
\hline 87 & ST. FRANCIS MEDICAL CENTER & -0.078 & 75.2 & 78 & 0.023 & 0.213 & 0.391 & 0.373 \\
\hline 88 & ENCINO HOSPITAL & -0.086 & 75.5 & 80 & 0.058 & 0.194 & 0.326 & 0.422 \\
\hline 89 & THE HOSPITAL OF THE GOOD SAMAR & -0.085 & 76.3 & 77 & 0.017 & 0.202 & 0.399 & 0.383 \\
\hline 90 & DOWNEY COMMUNITY HOSPITAL & -0.083 & 76.8 & 79 & 0.016 & 0.185 & 0.417 & 0.382 \\
\hline 91 & KAISER FOUNDATION HOSPITAL - W & -0.095 & 77 & 81 & 0.047 & 0.195 & 0.328 & 0.431 \\
\hline 92 & POMONA VALLEY HOSPITAL MEDICAL & -0.085 & 77.6 & 81 & 0.009 & 0.173 & 0.413 & 0.405 \\
\hline 93 & WHITTIER HOSPITAL MEDICAL CENT & -0.106 & 78.2 & 84 & 0.073 & 0.166 & 0.285 & 0.477 \\
\hline 94 & GRANADA HILLS COMMUNITY HOSPIT & -0.094 & 78.3 & 83 & 0.027 & 0.181 & 0.349 & 0.442 \\
\hline 95 & PIONEER HOSPITAL & -0.096 & 79.1 & 85 & 0.043 & 0.141 & 0.346 & 0.471 \\
\hline 96 & PANORAMA COMMUNITY HOSPITAL & -0.114 & 81.3 & 87 & 0.041 & 0.147 & 0.302 & 0.51 \\
\hline 97 & LOS ANGELES CO. MARTIN L. KING & -0.151 & 82.4 & 88 & 0.05 & 0.161 & 0.279 & 0.51 \\
\hline 98 & LONG BEACH COMMUNITY HOSPITAL & -0.122 & 83.6 & 88 & 0.014 & 0.121 & 0.33 & 0.535 \\
\hline 99 & SAN GABRIEL VALLEY MEDICAL CEN & -0.125 & 83.8 & 87 & 0.006 & 0.124 & 0.367 & 0.504 \\
\hline 100 & BURBANK COMMUNITY HOSPITAL & -0.127 & 84.5 & 92 & 0.035 & 0.111 & 0.262 & 0.592 \\
\hline 101 & CALIFORNIA MEDICAL CENTER - LO & -0.142 & 86.1 & 94 & 0.018 & 0.13 & 0.26 & 0.592 \\
\hline 102 & SANTA TERESITA HOSPITAL & -0.141 & 86.7 & 91 & 0.009 & 0.092 & 0.327 & 0.572 \\
\hline 103 & WASHINGTON MEDICAL CENTER & -0.137 & 87 & 92 & 0.008 & 0.088 & 0.315 & 0.589 \\
\hline 104 & DOMINGUEZ MEDICAL CENTER & -0.179 & 91.3 & 98 & 0.018 & 0.079 & 0.212 & 0.691 \\
\hline 105 & VALLEY HOSPITAL MEDICAL CENTER & -0.159 & 91.8 & 96 & 0.001 & 0.044 & 0.254 & 0.702 \\
\hline 106 & MEDICAL CENTER OF NORTH HOLLYW & -0.165 & 92.9 & 97 & 0 & 0.032 & 0.253 & 0.716 \\
\hline 107 & $\begin{array}{l}\text { VERDUGO HILLS HOSPITAL } \\
\end{array}$ & -0.169 & 94.1 & 98 & 0.001 & 0.025 & 0.213 & 0.761 \\
\hline 108 & FOOTHILL PRESBYTERIAN HOSPITAL & -0.169 & 94.3 & 97 & 0.001 & 0.019 & 0.221 & 0.759 \\
\hline 109 & CANOGA PARK HOSPITAL & -0.213 & 96.4 & 103 & 0.005 & 0.05 & 0.165 & 0.779 \\
\hline 110 & COAST PLAZA MEDICAL CENTER & -0.213 & 97.9 & 104 & 0.002 & 0.032 & 0.154 & 0.812 \\
\hline 111 & MEMORIAL HOSPITAL OF GARDENA & -0.277 & 102.1 & 108 & 0 & 0.016 & 0.113 & 0.871 \\
\hline 112 & LOS ANGELES CO. HARBOR/UCLA ME & -0.275 & 103.5 & 108 & 0 & 0.01 & 0.094 & 0.896 \\
\hline 113 & KAISER FOUNDATION HOSPITAL - $W$ & -0.282 & 105 & 108 & 0 & 0.002 & 0.061 & 0.938 \\
\hline 114 & PACIFIC HOSPITAL OF LONG BEACH & -0.333 & 108.8 & 112 & 0 & 0.002 & 0.023 & 0.975 \\
\hline
\end{tabular}


Table A5

Comparison of selected hospital quality probits, selection model

\begin{tabular}{|c|c|c|c|c|c|c|c|c|}
\hline \multicolumn{9}{|c|}{ Posterior probability that hospital with rank in row ranks below hospital with rank in column } \\
\hline & 1 & 15 & 29 & 43 & 57 & 71 & 85 & 99 \\
\hline 15 & 0.886 & 1 & & & & & & \\
\hline 29 & 0.91 & 0.638 & 1 & & & & & \\
\hline 43 & 0.938 & 0.682 & 0.568 & 1 & & & & \\
\hline 57 & 0.972 & 0.775 & 0.658 & 0.604 & 1 & & & \\
\hline 71 & 0.977 & 0.822 & 0.724 & 0.648 & 0.559 & 1 & & \\
\hline 85 & 0.999 & 0.911 & 0.8 & 0.713 & 0.655 & 0.580 & 1 & \\
\hline 99 & 0.992 & 0.947 & 0.888 & 0.822 & 0.751 & 0.677 & 0.634 & 1 \\
\hline 114 & 1 & 0.998 & 1 & 0.985 & 0.969 & 0.957 & 0.968 & 0.887 \\
\hline \multicolumn{9}{|c|}{ Identity of hospital by rank } \\
\hline \multicolumn{2}{|l|}{ Rank } & \multicolumn{7}{|c|}{ Hospital Name } \\
\hline \multicolumn{2}{|l|}{1} & \multicolumn{7}{|c|}{ Monterey Park Hospital } \\
\hline \multicolumn{2}{|l|}{15} & \multicolumn{7}{|c|}{ Bellflower Doctors Hospital } \\
\hline \multicolumn{2}{|l|}{29} & \multicolumn{7}{|c|}{ Glendale Memorial Hospital \& Health Center } \\
\hline \multicolumn{2}{|l|}{43} & \multicolumn{7}{|c|}{ Hollywood Community Hospital } \\
\hline \multicolumn{2}{|l|}{57} & \multicolumn{7}{|c|}{ Pico Rivera Community Hospital } \\
\hline \multicolumn{2}{|l|}{71} & \multicolumn{7}{|c|}{ Los Angeles Doctors Hospital } \\
\hline \multicolumn{2}{|l|}{85} & \multicolumn{7}{|c|}{ Daniel Freeman Memorial Hospital } \\
\hline \multicolumn{2}{|l|}{99} & \multicolumn{7}{|c|}{ San Gabriel Valley Medical Center } \\
\hline \multicolumn{2}{|l|}{114} & \multicolumn{7}{|c|}{ Pacific Hospital of Long Beach } \\
\hline
\end{tabular}


Table A6

\section{Posterior distribution of hospital quality probits, probit model}

\begin{tabular}{|c|c|c|c|c|c|c|c|c|}
\hline & \multirow[t]{2}{*}{ Hospital name } & \multirow{2}{*}{$\frac{q_{j}^{*}}{2 \text { Mean }}$} & \multicolumn{2}{|l|}{ Rank } & \multicolumn{4}{|c|}{ Quartile probabilities } \\
\hline & & & Mean & Median & & & & \\
\hline 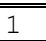 & SANTA MARTA HOSPITAL & 0.331 & 3.1 & 2 & 0.998 & 0.002 & 0 & 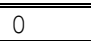 \\
\hline 2 & ST. JOHNS HOSPITAL AND HEALTH & 0.227 & 7.5 & 6 & 0.995 & 0.005 & 0 & 0 \\
\hline 3 & LINDA VISTA COMMUNITY HOSPITAL & 0.24 & 12.4 & 6 & 0.868 & 0.098 & 0.029 & 0.005 \\
\hline 4 & MONTEREY PARK HOSPITAL & 0.187 & 13.9 & 10 & 0.883 & 0.106 & 0.011 & 0 \\
\hline 5 & WOODRUFF COMMUNITY HOSPITAL & 0.199 & 15.7 & 9 & 0.827 & 0.129 & 0.038 & 0.006 \\
\hline 6 & COMMUNITY HOSPITAL OF HUNTINGT & 0.194 & 16.6 & 9 & 0.812 & 0.142 & 0.041 & 0.006 \\
\hline 7 & QUEEN OF ANGELS/HOLLYWOOD PRES & 0.145 & 17.6 & 16 & 0.896 & 0.104 & 0 & 0 \\
\hline 8 & TERRACE PLAZA MEDICAL CENTER & 0.174 & 19.1 & 12 & 0.763 & 0.173 & 0.058 & 0.006 \\
\hline 9 & SAN DIMAS COMMUNITY HOSPITAL & 0.155 & 19.5 & 14 & 0.768 & 0.198 & 0.03 & 0.003 \\
\hline 10 & WHITE MEMORIAL MEDICAL CENTER & 0.141 & 19.7 & 17 & 0.794 & 0.194 & 0.012 & 0 \\
\hline 11 & HENRY MAYO NEWHALL MEMORIAL HO & 0.135 & 20.9 & 18 & 0.763 & 0.217 & 0.019 & 0.001 \\
\hline 12 & BELLFLOWER DOCTORS HOSPITAL & 0.149 & 21.7 & 15 & 0.709 & 0.228 & 0.057 & 0.005 \\
\hline 13 & $\begin{array}{l}\text { SAN PEDRO PENINSULA HOSPITAL } \\
\end{array}$ & 0.123 & 23.6 & 21 & 0.698 & 0.274 & 0.028 & 0 \\
\hline 14 & SOUTH BAY HOSPITAL & 0.135 & 24.1 & 17 & 0.677 & 0.239 & 0.075 & 0.008 \\
\hline 15 & MOTION PICTURE \& TELEVISION HO & 0.152 & 25.2 & 14 & 0.663 & 0.196 & 0.102 & 0.039 \\
\hline 16 & CHARTER SUBURBAN HOSPITAL & 0.113 & 26.4 & 23 & 0.618 & 0.326 & 0.053 & 0.003 \\
\hline 17 & DANIEL FREEMAN MARINA HOSPITAL & 0.116 & 26.5 & 22 & 0.617 & 0.318 & 0.06 & 0.005 \\
\hline 18 & BEVERLY HOSPITAL & 0.098 & 28.5 & 27 & 0.549 & 0.417 & 0.034 & 0 \\
\hline 19 & CEDARS SINAI MEDICAL CENTER & 0.09 & 29.4 & 28 & 0.502 & 0.488 & 0.011 & 0 \\
\hline 20 & INTER COMMUNITY MEDICAL CENTER & 0.088 & 31.5 & 29 & 0.486 & 0.442 & 0.071 & 0.001 \\
\hline 21 & LOS ANGELES CO. USC MEDICAL CE & 0.086 & 32.2 & 30 & 0.46 & 0.464 & 0.075 & 0.002 \\
\hline 22 & COVINA VALLEY COMMUNITY HOSPIT & 0.096 & 32.4 & 27 & 0.519 & 0.321 & 0.134 & 0.026 \\
\hline 23 & LOS ANGELES COMMUNITY HOSPITAL & 0.102 & 33 & 26 & 0.544 & 0.267 & 0.135 & 0.053 \\
\hline 24 & HUMANA HOSPITAL WEST HILLS & 0.084 & 33.6 & 31 & 0.464 & 0.399 & 0.129 & 0.008 \\
\hline 25 & ST. MARY MEDICAL CENTER & 0.081 & 33.6 & 31 & 0.455 & 0.435 & 0.102 & 0.008 \\
\hline 26 & MISSION HOSPITAL & 0.101 & 33.7 & 27 & 0.527 & 0.265 & 0.152 & 0.056 \\
\hline 27 & AMI TARZANA REGIONAL MEDICAL C & 0.081 & 34 & 32 & 0.435 & 0.442 & 0.115 & 0.008 \\
\hline 28 & HOLLYWOOD COMMUNITY HOSPITAL & 0.088 & 34.3 & 29 & 0.492 & 0.332 & 0.146 & 0.03 \\
\hline 29 & GLENDALE MEMORIAL HOSPITAL \& H & 0.073 & 34.4 & 34 & 0.337 & 0.627 & 0.036 & 0 \\
\hline 30 & HAWTHORNE HOSPITAL & 0.09 & 34.8 & 29 & 0.486 & 0.31 & 0.163 & 0.041 \\
\hline 31 & UCLA MEDICAL CENTER & 0.074 & 35.6 & 33 & 0.396 & 0.472 & 0.129 & 0.003 \\
\hline 32 & CENTURY CITY HOSPITAL & 0.072 & 37.1 & 33 & 0.422 & 0.384 & 0.167 & 0.027 \\
\hline 33 & SANTA MONICA HOSPITAL MEDICAL & 0.062 & 38 & 37 & 0.287 & 0.606 & 0.105 & 0.001 \\
\hline 34 & KAISER FOUNDATION HOSPITAL - P & 0.065 & 38 & 36 & 0.347 & 0.487 & 0.157 & 0.009 \\
\hline 35 & KAISER FOUNDATION HOSPITAL - L & 0.061 & 38.4 & 37 & 0.299 & 0.577 & 0.123 & 0.002 \\
\hline 36 & PACIFIC ALLIANCE MEDICAL CENTE & 0.065 & 38.4 & 36 & 0.38 & 0.429 & 0.17 & 0.021 \\
\hline 37 & GREATER EL MONTE COMMUNITY HOS & 0.062 & 38.9 & 37 & 0.344 & 0.465 & 0.182 & 0.009 \\
\hline 38 & CIGNA HOSPITAL OF LOS ANGELES & 0.065 & 40 & 36 & 0.394 & 0.352 & 0.199 & 0.055 \\
\hline 39 & PRESBYTERIAN INTERCOMMUNITY HO & 0.051 & 41.7 & 41 & 0.242 & 0.567 & 0.188 & 0.003 \\
\hline 40 & ALHAMBRA COMMUNITY HOSPITAL & 0.052 & 42.3 & 40 & 0.307 & 0.439 & 0.22 & 0.033 \\
\hline 41 & BELLWOOD GENERAL HOSPITAL & 0.046 & 44.6 & 42 & 0.308 & 0.39 & 0.237 & 0.065 \\
\hline 42 & NORTHRIDGE HOSPITAL MEDICAL CE & 0.041 & 44.8 & 44 & 0.2 & 0.549 & 0.239 & 0.012 \\
\hline 43 & SAN FERNANDO COMMUNITY HOSPITA & 0.05 & 45.1 & 41 & 0.365 & 0.291 & 0.232 & 0.113 \\
\hline 44 & LANCASTER COMMUNITY HOSPITAL & 0.033 & 47.3 & 47 & 0.207 & 0.472 & 0.286 & 0.035 \\
\hline 45 & ST. LUKE MEDICAL CENTER & 0.031 & 47.9 & 47 & 0.203 & 0.46 & 0.303 & 0.034 \\
\hline 46 & WHITTIER HOSPITAL MEDICAL CENT & 0.033 & 48 & 46 & 0.247 & 0.407 & 0.267 & 0.079 \\
\hline 47 & EAST LOS ANGELES DOCTORS HOSPI & 0.031 & 48.2 & 48 & 0.232 & 0.415 & 0.296 & 0.057 \\
\hline 48 & BEVERLY HILLS MEDICAL CENTER & 0.037 & 48.5 & 46 & 0.331 & 0.282 & 0.235 & 0.153 \\
\hline 49 & GRANADA HILLS COMMUNITY HOSPIT & 0.027 & 49.2 & 49 & 0.204 & 0.427 & 0.316 & 0.052 \\
\hline 50 & LITTLE COMPANY OF MARY HOSPITA & 0.02 & 50.9 & 51 & 0.127 & 0.504 & 0.341 & 0.029 \\
\hline 51 & BROTMAN MEDICAL CENTER & 0.019 & 51.2 & 51 & 0.104 & 0.537 & 0.336 & 0.023 \\
\hline 52 & NORWALK COMMUNITY HOSPITAL & 0.017 & 52.6 & 52 & 0.207 & 0.365 & 0.311 & 0.117 \\
\hline 53 & ST. JOSEPH MEDICAL CENTER & 0.012 & 53.2 & 53 & 0.036 & 0.597 & 0.359 & 0.008 \\
\hline 54 & ST. VINCENT MEDICAL CENTER & 0.012 & 53.3 & 53 & 0.11 & 0.474 & 0.365 & 0.051 \\
\hline 55 & ANTELOPE VALLEY HOSPITAL MEDIC & 0.01 & 54.3 & 54 & 0.119 & 0.447 & 0.358 & 0.075 \\
\hline 56 & KAISER FOUNDATION HOSPITAL $-\mathrm{H}$ & 0.007 & 55.1 & 55 & 0.106 & 0.44 & 0.387 & 0.067 \\
\hline 57 & THE HOSPITAL OF THE GOOD SAMAR & 0.005 & 55.6 & 56 & 0.048 & 0.499 & 0.428 & 0.025 \\
\hline 58 & TORRANCE MEMORIAL HOSPITAL MED & 0.004 & 55.9 & 56 & 0.071 & 0.455 & 0.421 & 0.053 \\
\hline 59 & MEMORIAL MEDICAL CENTER OF LON & -0.002 & 57.7 & 58 & 0.051 & 0.443 & 0.454 & 0.052 \\
\hline 60 & LOS ANGELES CO. MARTIN L. KING & -0.003 & 58 & 58 & 0.126 & 0.367 & 0.374 & 0.134 \\
\hline
\end{tabular}




\begin{tabular}{|c|c|c|c|c|c|c|c|c|}
\hline 61 & KAISER FOUNDATION HOSPITAL - B & -0.005 & 58.5 & 59 & 0.067 & 0.398 & 0.449 & 0.085 \\
\hline 62 & LOS ANGELES DOCTORS HOSPITAL & -0.006 & 58.9 & 61 & 0.234 & 0.242 & 0.267 & 0.257 \\
\hline 63 & ROBERT F. KENNEDY MEDICAL CENT & -0.009 & 59.9 & 61 & 0.074 & 0.367 & 0.469 & 0.09 \\
\hline 64 & DOCTORS HOSPITAL OF LAKEWOOD - & -0.009 & 60 & 60 & 0.043 & 0.399 & 0.484 & 0.074 \\
\hline 65 & LONG BEACH DOCTORS HOSPITAL & -0.013 & 60.8 & 61 & 0.144 & 0.314 & 0.326 & 0.216 \\
\hline 66 & SAN GABRIEL VALLEY MEDICAL CEN & -0.018 & 62.6 & 63 & 0.009 & 0.354 & 0.587 & 0.049 \\
\hline 67 & NU MED REGIONAL MED CENTER WES & -0.023 & 63.9 & 65 & 0.051 & 0.325 & 0.467 & 0.157 \\
\hline 68 & AMI GLENDORA COMMUNITY HOSPITA & -0.029 & 64.9 & 67 & 0.116 & 0.283 & 0.349 & 0.253 \\
\hline 69 & LOS ANGELES CO. OLIVE VIEW MED & -0.03 & 65.1 & 66 & 0.123 & 0.283 & 0.308 & 0.286 \\
\hline 70 & HOLY CROSS MEDICAL CENTER & -0.039 & 68.9 & 70 & 0.022 & 0.244 & 0.545 & 0.189 \\
\hline 71 & ENCINO HOSPITAL & -0.041 & 69 & 70 & 0.052 & 0.255 & 0.433 & 0.261 \\
\hline 72 & GLENDALE ADVENTIST MED CENTER & -0.038 & 69.2 & 70 & 0 & 0.183 & 0.736 & 0.081 \\
\hline 73 & SHERMAN OAKS COMMUNITY HOSPITA & -0.045 & 69.8 & 73 & 0.075 & 0.23 & 0.406 & 0.289 \\
\hline 74 & BURBANK COMMUNITY HOSPITAL & -0.046 & 70.1 & 72 & 0.059 & 0.243 & 0.414 & 0.285 \\
\hline 75 & KAISER FOUNDATION HOSPITAL - $\mathrm{W}$ & -0.046 & 70.3 & 72 & 0.048 & 0.242 & 0.433 & 0.277 \\
\hline 76 & CENTINELA HOSPITAL MEDICAL CEN & -0.045 & 70.6 & 73 & 0.032 & 0.228 & 0.488 & 0.251 \\
\hline 77 & VALLEY PRESBYTERIAN HOSPITAL & -0.044 & 70.8 & 72 & 0.006 & 0.216 & 0.602 & 0.176 \\
\hline 78 & $\begin{array}{l}\text { PICO RIVERA COMMUNITY HOSPITAL } \\
\end{array}$ & -0.056 & 71.1 & 76 & 0.123 & 0.215 & 0.276 & 0.387 \\
\hline 79 & WESTSIDE HOSPITAL & -0.053 & 72.4 & 74 & 0.031 & 0.209 & 0.473 & 0.287 \\
\hline 80 & GARFIELD MEDICAL CENTER & -0.049 & 72.5 & 74 & 0.002 & 0.164 & 0.669 & 0.165 \\
\hline 81 & METHODIST HOSPITAL OF SOUTHERN & -0.054 & 73.9 & 75 & 0.001 & 0.135 & 0.676 & 0.188 \\
\hline 82 & MONROVIA COMMUNITY HOSPITAL & -0.061 & 74.1 & 77 & 0.046 & 0.202 & 0.394 & 0.358 \\
\hline 83 & COMMUNITY HOSPITAL OF GARDENA & -0.071 & 75.1 & 81 & 0.092 & 0.184 & 0.292 & 0.432 \\
\hline 84 & PALMDALE HOSPITAL MEDICAL CENT & -0.07 & 76.7 & 79 & 0.025 & 0.168 & 0.418 & 0.388 \\
\hline 85 & WASHINGTON MEDICAL CENTER & -0.076 & 78.7 & 82 & 0.016 & 0.158 & 0.422 & 0.405 \\
\hline 86 & SANTA TERESITA HOSPITAL & -0.086 & 82.5 & 84 & 0.002 & 0.077 & 0.473 & 0.447 \\
\hline 87 & PACIFIC HOSPITAL OF LONG BEACH & -0.088 & 82.6 & 85 & 0.004 & 0.087 & 0.455 & 0.454 \\
\hline 88 & HUNTINGTON MEMORIAL HOSPITAL & -0.088 & 83.9 & 85 & 0.001 & 0.023 & 0.518 & 0.458 \\
\hline 89 & TEMPLE COMMUNITY HOSPITAL & -0.103 & 84.4 & 89 & 0.024 & 0.11 & 0.32 & 0.546 \\
\hline 90 & MEDICAL CENTER OF LA MIRADA & -0.109 & 84.6 & 91 & 0.026 & 0.115 & 0.297 & 0.562 \\
\hline 91 & FOOTHILL PRESBYTERIAN HOSPITAL & -0.095 & 84.7 & 87 & 0.002 & 0.069 & 0.416 & 0.513 \\
\hline 92 & DOWNEY COMMUNITY HOSPITAL & -0.094 & 85.2 & 87 & 0.001 & 0.033 & 0.457 & 0.51 \\
\hline 93 & MEDICAL CENTER OF NORTH HOLLYW & -0.095 & 85.2 & 87 & 0 & 0.049 & 0.429 & 0.522 \\
\hline 94 & VALLEY HOSPITAL MEDICAL CENTER & -0.103 & 86.3 & 89 & 0.004 & 0.066 & 0.362 & 0.568 \\
\hline 95 & BAY HARBOR HOSPITAL & -0.104 & 87.5 & 89 & 0 & 0.025 & 0.389 & 0.586 \\
\hline 96 & MIDWAY HOSPITAL MEDICAL CENTER & -0.105 & 88.3 & 90 & 0 & 0.005 & 0.383 & 0.612 \\
\hline 97 & PANORAMA COMMUNITY HOSPITAL & -0.121 & 89 & 94 & 0.009 & 0.067 & 0.298 & 0.626 \\
\hline 98 & QUEEN OF THE VALLEY HOSPITAL - & -0.109 & 89 & 91 & 0 & 0.019 & 0.359 & 0.622 \\
\hline 99 & PACIFICA HOSPITAL OF THE VALLE & -0.124 & 90.1 & 95 & 0.003 & 0.062 & 0.285 & 0.651 \\
\hline 100 & CHARTER COMMUNITY HOSPITAL & -0.121 & 91 & 94 & 0 & 0.027 & 0.302 & 0.672 \\
\hline 101 & POMONA VALLEY HOSPITAL MEDICAL & -0.12 & 91.8 & 94 & 0 & 0.007 & 0.268 & 0.724 \\
\hline 102 & DANIEL FREEMAN MEMORIAL HOSPIT & -0.127 & 93.1 & 95 & 0 & 0.007 & 0.241 & 0.752 \\
\hline 103 & LONG BEACH COMMUNITY HOSPITAL & -0.13 & 93.3 & 96 & 0 & 0.015 & 0.232 & 0.753 \\
\hline 104 & VERDUGO HILLS HOSPITAL & -0.134 & 94 & 96 & 0 & 0.012 & 0.221 & 0.768 \\
\hline 105 & COAST PLAZA MEDICAL CENTER & -0.161 & 95.5 & 102 & 0.005 & 0.044 & 0.201 & 0.75 \\
\hline 106 & RIO HONDO MEMORIAL HOSPITAL & -0.167 & 98.7 & 103 & 0.001 & 0.017 & 0.136 & 0.847 \\
\hline 107 & DOMINGUEZ MEDICAL CENTER & -0.206 & 100.6 & 107 & 0.004 & 0.031 & 0.126 & 0.839 \\
\hline 108 & PIONEER HOSPITAL & -0.183 & 101.3 & 105 & 0 & 0.009 & 0.1 & 0.891 \\
\hline 109 & KAISER FOUNDATION HOSPITAL - $\mathrm{W}$ & -0.18 & 102 & 105 & 0 & 0.002 & 0.076 & 0.922 \\
\hline 110 & MEMORIAL HOSPITAL OF GARDENA & -0.204 & 104.2 & 107 & 0 & 0.004 & 0.06 & 0.936 \\
\hline 111 & LOS ANGELES CO. HARBOR/UCLA ME & -0.213 & 105.2 & 108 & 0 & 0.002 & 0.045 & 0.954 \\
\hline 112 & ST. FRANCIS MEDICAL CENTER & -0.197 & 105.2 & 107 & 0 & 0 & 0.011 & 0.989 \\
\hline 113 & CANOGA PARK HOSPITAL & -0.276 & 106.8 & 112 & 0.001 & 0.016 & 0.058 & 0.926 \\
\hline 114 & CALIFORNIA MEDICAL CENTER - LO & -0.315 & 112.5 & 113 & 0 & 0 & 0 & 1 \\
\hline
\end{tabular}


Table A7

Comparison of selected hospital quality probits, probit model

\begin{tabular}{|c|c|c|c|c|c|c|c|c|}
\hline \multicolumn{9}{|c|}{ Posterior probability that hospital with rank in row ranks below hospital with rank in column } \\
\hline & 1 & 15 & 29 & 43 & 57 & 71 & 85 & 99 \\
\hline 15 & 0.87 & 1 & & & & & & \\
\hline 29 & 0.995 & 0.708 & 1 & & & & & \\
\hline 43 & 0.975 & 0.724 & 0.574 & 1 & & & & \\
\hline 57 & 1 & 0.843 & 0.864 & 0.636 & 1 & & & \\
\hline 71 & 0.999 & 0.885 & 0.899 & 0.728 & 0.681 & 1 & & \\
\hline 85 & 1 & 0.927 & 0.959 & 0.807 & 0.805 & 0.619 & 1 & \\
\hline 99 & 1 & 0.96 & 0.986 & 0.894 & 0.915 & 0.782 & 0.673 & 1 \\
\hline 114 & 1 & 0.999 & 1 & 0.996 & 1 & 0.997 & 0.991 & 0.974 \\
\hline \multicolumn{9}{|c|}{ Identity of hospital by rank } \\
\hline \multicolumn{2}{|l|}{ Rank } & \multicolumn{7}{|c|}{ Hospital Name } \\
\hline \multicolumn{2}{|l|}{1} & \multicolumn{7}{|c|}{ Santa Marta Hospital } \\
\hline \multicolumn{2}{|l|}{15} & \multicolumn{7}{|c|}{ Motion Picture \& Television Hospital } \\
\hline \multicolumn{2}{|l|}{29} & \multicolumn{7}{|c|}{ Glendale Memorial Hospital \& Health Center } \\
\hline \multicolumn{2}{|l|}{43} & \multicolumn{7}{|c|}{ San Fernando Community Hospital } \\
\hline \multicolumn{2}{|l|}{57} & \multicolumn{7}{|c|}{ The Hospital of the Good Samaritan } \\
\hline \multicolumn{2}{|l|}{71} & \multicolumn{7}{|c|}{ Encino Hospital } \\
\hline \multicolumn{2}{|l|}{85} & \multicolumn{7}{|c|}{ Washington Medical Center } \\
\hline \multicolumn{2}{|l|}{99} & \multicolumn{7}{|c|}{ Pacifica Hospital of the Valley } \\
\hline \multicolumn{2}{|l|}{114} & \multicolumn{7}{|c|}{ California Medical Center - Los Angeles } \\
\hline
\end{tabular}


Table A8

Posterior means and standard deviations

Selection model, prior variant A: instruments eliminated

\begin{tabular}{|c|c|c|c|}
\hline & Coefficient & \multicolumn{2}{|c|}{ Selection model } \\
\hline & & \multicolumn{2}{|c|}{$\gamma /(\delta \Sigma \delta+1)^{1 / 2}$} \\
\hline \multirow{11}{*}{ 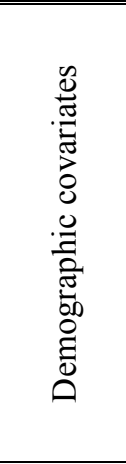 } & Age $70-74$ & -0.006 & $(0.025)$ \\
\hline & Age 75-79 & 0.068 & $(0.024)$ \\
\hline & Age $80-84$ & 0.186 & $(0.024)$ \\
\hline & Age $>84$ & 0.368 & $(0.022)$ \\
\hline & Female & -0.086 & $(0.012)$ \\
\hline & Black & -0.031 & $(0.027)$ \\
\hline & Hispanic & -0.11 & $(0.023)$ \\
\hline & Native & 0.171 & $(0.13)$ \\
\hline & Asian & -0.085 & $(0.031)$ \\
\hline & Income & 0.256 & $(0.197)$ \\
\hline & Income ${ }^{\wedge}$ & -0.029 & $(0.023)$ \\
\hline \multirow{6}{*}{ 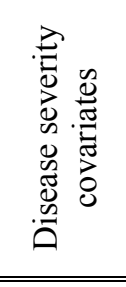 } & & \multicolumn{2}{|c|}{$\gamma /(\delta \Sigma \delta+1)^{1 / 2}$} \\
\hline & Emergency admit & 0.173 & $(0.015)$ \\
\hline & Disease stages 1.3-2.3 & 0.088 & $(0.028)$ \\
\hline & Disease stages 3.1-3.6 & 0.487 & $(0.022)$ \\
\hline & Disease stage 3.7 & 0.630 & $(0.018)$ \\
\hline & Disease stage 3.8 & 1.387 & $(0.036)$ \\
\hline & & $q_{G}$ & $\rho_{G}$ \\
\hline $\bar{\Xi} \cdot \overparen{\Xi}$ & 150 beds or less & $(0.025)$ & $\begin{array}{ll}-0.0002 \quad(0.041) \\
\end{array}$ \\
\hline$\tilde{\sigma} 0 \tilde{0}$ & 151 to 200 beds & $(0.072)$ & $(0.052)$ \\
\hline 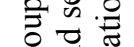 & 201 to 300 beds & $(0.037)$ & $(0.040)$ \\
\hline 茄 & Over 300 beds & $(0.031)$ & $(0.048)$ \\
\hline 馬: 号 & Private, not for profit & $(0.031)$ & $(0.047)$ \\
\hline की & Private, for profit & $(0.038)$ & -0.012 \\
\hline & Private Teaching & $(0.13)$ & $(0.046)$ \\
\hline & Public & $(0.19)$ & $(0.066)$ \\
\hline & & $\tau^{2} /($ & $\delta+1)$ \\
\hline.$\stackrel{\Xi}{\Xi}$ & Size & 0.24 & $(0.18)$ \\
\hline$\overbrace{>}^{\pi} \omega_{0}^{\sigma}$ & Ownership & 0.25 & $(0.18)$ \\
\hline & Individual Hospital & 0.046 & $(0.009)$ \\
\hline & & & \\
\hline & Distance & $-1.39 \times 10^{-6}$ & $\left(6.12 \times 10^{-6}\right)$ \\
\hline 过 & Distance $^{2}$ & $-3.40 \times 10^{-6}$ & $\left(1.17 \times 10^{-6}\right)$ \\
\hline$\stackrel{\vec{\sigma}}{\vec{\sigma}}$ & Distance $\times$ Age & $-2.33 \times 10^{-6}$ & $\left(3.98 \times 10^{-6}\right)$ \\
\hline की & Distance $\times$ Severity & $-1.65 \times 10^{-6}$ & $\left(4.91 \times 10^{-6}\right)$ \\
\hline & $\begin{array}{c}10^{-5} \times \text { Distance } \\
\times \text { Income }\end{array}$ & $-1.58 \times 10^{-6}$ & $\left(1.39 \times 10^{-6}\right)$ \\
\hline
\end{tabular}

Notation and definitions are exactly as for Table 3 of the paper. 


\section{Table A9}

Posterior probability comparisons of group hospital quality probits

Selection model, prior variant A: instruments eliminated

\begin{tabular}{|c|c|c|c|c|}
\hline & \multicolumn{4}{|c|}{ A. Hospitals grouped by size } \\
\hline & $\leq 150$ beds & $151-200$ beds & $201-300$ beds & $>300$ beds \\
\hline$\leq 150$ beds & $0.10(--)$ & $\begin{array}{c}34 \% \\
0.099(0.013)\end{array}$ & $\begin{array}{c}75 \% \\
0.105(0.009)\end{array}$ & $\begin{array}{c}31 \% \\
0.096(0.007)\end{array}$ \\
\hline $151-200$ beds & $\begin{array}{c}66 \% \\
0.103(0.012)\end{array}$ & $0.10(--)$ & $\begin{array}{c}74 \% \\
0.108(0.017)\end{array}$ & $\begin{array}{c}51 \% \\
0.098(0.013)\end{array}$ \\
\hline 201-300 beds & $\begin{array}{c}25 \% \\
0.096(0.009)\end{array}$ & $\begin{array}{c}26 \% \\
0.095(0.018)\end{array}$ & $0.10(--)$ & $\begin{array}{c}13 \% \\
0.092(0.008)\end{array}$ \\
\hline \multirow[t]{3}{*}{$>300$ beds } & $\begin{array}{c}69 \% \\
0.105(0.008)\end{array}$ & $\begin{array}{c}49 \% \\
0.103(0.014)\end{array}$ & $\begin{array}{c}87 \% \\
0.110(0.010)\end{array}$ & $0.10(--)$ \\
\hline & \multicolumn{4}{|c|}{ B. Hospitals grouped by ownership classification } \\
\hline & $\begin{array}{c}\text { Private } \\
\text { not-for-profit }\end{array}$ & $\begin{array}{c}\text { Private } \\
\text { for-profit }\end{array}$ & $\begin{array}{l}\text { Private } \\
\text { teaching }\end{array}$ & Public \\
\hline $\begin{array}{c}\text { Private } \\
\text { not-for-profit }\end{array}$ & $0.10(--)$ & $\begin{array}{c}15 \% \\
0.089(0.011)\end{array}$ & $\begin{array}{c}47 \% \\
0.096(0.020)\end{array}$ & $\begin{array}{c}56 \% \\
0.107(0.034)\end{array}$ \\
\hline $\begin{array}{l}\text { Private } \\
\text { for-profit }\end{array}$ & $\begin{array}{c}85 \% \\
0.114(0.012)\end{array}$ & $0.10(--)$ & $\begin{array}{c}57 \% \\
0.110(0.027)\end{array}$ & $\begin{array}{c}67 \% \\
0.120(0.035)\end{array}$ \\
\hline $\begin{array}{l}\text { Private } \\
\text { teaching }\end{array}$ & $\begin{array}{c}53 \% \\
0.107(0.022)\end{array}$ & $\begin{array}{c}43 \% \\
0.096(0.025)\end{array}$ & $0.10(--)$ & $\begin{array}{c}50 \% \\
0.117(0.053)\end{array}$ \\
\hline Public & $\begin{array}{c}44 \% \\
0.102(0.036)\end{array}$ & $\begin{array}{c}33 \% \\
0.090(0.030)\end{array}$ & $\begin{array}{c}50 \% \\
0.101(0.049)\end{array}$ & $0.10(--)$ \\
\hline
\end{tabular}

Notation and definitions are exactly as for Table 4 of the paper. The first number in each cell is the posterior probability that the group quality probit $q_{G}$ in the column category exceeds $q_{G}$ in the row category, and the second number is the posterior mean probability of mortality in the row category given a $10 \%$ probability of mortality in the column category, with the posterior standard deviation of this statistic in parentheses. 
Table A10

Posterior means and standard deviations

Selection model, prior variant B: tighter prior on $\alpha$ and $\beta$

\begin{tabular}{|c|c|c|c|c|c|}
\hline & Coefficient & \multicolumn{4}{|c|}{ Selection model } \\
\hline & & \multicolumn{4}{|c|}{$\gamma /(\delta \Sigma \delta+1)^{1 / 2}$} \\
\hline \multirow{11}{*}{ 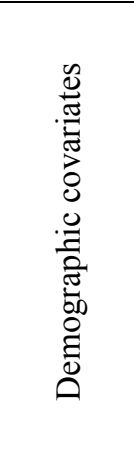 } & Age $70-74$ & \multicolumn{2}{|c|}{-0.008} & \multicolumn{2}{|c|}{ (0.024) } \\
\hline & Age $75-79$ & \multicolumn{2}{|c|}{0.066} & \multicolumn{2}{|c|}{$(0.025)$} \\
\hline & Age $80-84$ & \multicolumn{2}{|c|}{0.185} & \multicolumn{2}{|c|}{$(0.025)$} \\
\hline & Age $>84$ & \multicolumn{2}{|c|}{0.370} & \multicolumn{2}{|c|}{$(0.023)$} \\
\hline & Female & \multicolumn{2}{|c|}{-0.087} & \multicolumn{2}{|c|}{$(0.013)$} \\
\hline & Black & \multicolumn{2}{|c|}{-0.008} & \multicolumn{2}{|c|}{$(0.026)$} \\
\hline & Hispanic & \multicolumn{2}{|c|}{-0.13} & \multicolumn{2}{|c|}{$(0.022)$} \\
\hline & Native & \multicolumn{2}{|c|}{0.177} & \multicolumn{2}{|c|}{$(0.13)$} \\
\hline & Asian & \multicolumn{2}{|c|}{-0.089} & \multicolumn{2}{|c|}{$(0.031)$} \\
\hline & Income & \multicolumn{2}{|c|}{0.262} & \multicolumn{2}{|c|}{ (0.198) } \\
\hline & Income $^{\wedge} 2$ & \multicolumn{2}{|c|}{-0.033} & \multicolumn{2}{|c|}{$(0.024)$} \\
\hline \multirow{6}{*}{ 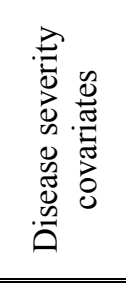 } & & \multicolumn{4}{|c|}{$\gamma /(\delta \Sigma \delta+1)^{1 / 2}$} \\
\hline & Emergency admit & & 183 & & \\
\hline & Disease stages 1.3-2.3 & & 091 & & \\
\hline & Disease stages 3.1-3.6 & & 492 & & \\
\hline & Disease stage 3.7 & & 633 & & \\
\hline & Disease stage 3.8 & & 402 & & \\
\hline & & & $q_{G}$ & & \\
\hline 寻 & 150 beds or less & -0.001 & (0.019) & -0.009 & $(0.021)$ \\
\hline $\bar{\sigma} \bar{D}=$ & 151 to 200 beds & -0.062 & $(0.029)$ & -0.013 & $(0.025)$ \\
\hline 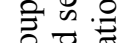 & 201 to 300 beds & 0.013 & $(0.025)$ & 0.004 & $(0.019)$ \\
\hline$\frac{\pi}{0}$ & Over 300 beds & 0.025 & $(0.021)$ & 0.014 & $(0.017)$ \\
\hline 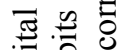 & Private, not for profit & 0.007 & $(0.019)$ & 0.002 & $(0.016)$ \\
\hline की & Private, for profit & 0.003 & $(0.018)$ & 0.007 & $(0.024)$ \\
\hline & Private Teaching & 0.033 & $(0.045)$ & 0.012 & $(0.026)$ \\
\hline & Public & -0.068 & $(0.069)$ & -0.020 & $(0.023)$ \\
\hline & & & $\tau^{2} /(c$ & $8+1)$ & \\
\hline. $\bar{\Xi}$ & Size & & 011 & & \\
\hline $\bar{\Xi}$ & Ownership & & 012 & & \\
\hline & Individual Hospital & & 008 & & 23) \\
\hline & & & & & \\
\hline & Distance & & .47 & & 41) \\
\hline 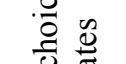 & Distance $^{2}$ & & .35 & & 73) \\
\hline  & Distance $\times$ Age & & 46 & & 25) \\
\hline के & Distance $\times$ Severity & & 36 & & \\
\hline & $\begin{array}{c}10^{-5} \times \text { Distance } \\
\times \text { Income }\end{array}$ & & 979 & $(0$ & 32) \\
\hline
\end{tabular}

Notation and definitions are exactly as for Table 3 of the paper. 
Table A11

Posterior probability comparisons of group hospital quality probits

Selection model, prior variant B: tighter prior on $\alpha$ and $\beta$

\begin{tabular}{|c|c|c|c|c|}
\hline & \multicolumn{4}{|c|}{ A. Hospitals grouped by size } \\
\hline & $\leq 150$ beds & $151-200$ beds & $201-300$ beds & $>300$ beds \\
\hline$\leq 150$ beds & $0.10(--)$ & $\begin{array}{c}2 \% \\
0.090(0.005)\end{array}$ & $\begin{array}{c}68 \% \\
0.103(0.007)\end{array}$ & $\begin{array}{c}76 \% \\
0.104(0.006)\end{array}$ \\
\hline $151-200$ beds & $\begin{array}{c}98 \% \\
0.111(0.006)\end{array}$ & $0.10(--)$ & $\begin{array}{c}94 \% \\
0.114(0.009)\end{array}$ & $\begin{array}{c}98 \% \\
0.112(0.008)\end{array}$ \\
\hline $201-300$ beds & $\begin{array}{c}32 \% \\
0.098(0.007)\end{array}$ & $\begin{array}{c}6 \% \\
0.088(0.008)\end{array}$ & $0.10(--)$ & $\begin{array}{c}66 \% \\
0.102(0.005)\end{array}$ \\
\hline \multirow[t]{3}{*}{$>300$ beds } & $\begin{array}{c}23 \% \\
0.096(0.006)\end{array}$ & $\begin{array}{c}2 \% \\
0.086(0.007)\end{array}$ & $\begin{array}{c}34 \% \\
0.098(0.005)\end{array}$ & $0.10(--)$ \\
\hline & \multicolumn{4}{|c|}{ B. Hospitals grouped by ownership classification } \\
\hline & $\begin{array}{c}\text { Private } \\
\text { not-for-profit }\end{array}$ & $\begin{array}{l}\text { Private } \\
\text { for-profit }\end{array}$ & $\begin{array}{l}\text { Private } \\
\text { teaching }\end{array}$ & Public \\
\hline $\begin{array}{c}\text { Private } \\
\text { not-for-profit }\end{array}$ & $0.10(--)$ & $\begin{array}{c}44 \% \\
0.100(0.006)\end{array}$ & $\begin{array}{c}70 \% \\
0.105(0.009)\end{array}$ & $\begin{array}{c}12 \% \\
0.088(0.011)\end{array}$ \\
\hline $\begin{array}{l}\text { Private } \\
\text { for-profit }\end{array}$ & $\begin{array}{c}56 \% \\
0.101(0.006)\end{array}$ & $0.10(--)$ & $\begin{array}{c}70 \% \\
0.106(0.009)\end{array}$ & $\begin{array}{c}20 \% \\
0.088(0.013)\end{array}$ \\
\hline $\begin{array}{l}\text { Private } \\
\text { teaching }\end{array}$ & $\begin{array}{c}30 \% \\
0.096(0.009)\end{array}$ & $\begin{array}{c}30 \% \\
0.095(0.008)\end{array}$ & $0.10(--)$ & $\begin{array}{c}11 \% \\
0.084(0.017)\end{array}$ \\
\hline Public & $\begin{array}{c}87 \% \\
0.114(0.014)\end{array}$ & $\begin{array}{c}81 \% \\
0.114(0.015)\end{array}$ & $\begin{array}{c}89 \% \\
0.120(0.015)\end{array}$ & $0.10(--)$ \\
\hline
\end{tabular}

Notation and definitions are exactly as for Table 4 of the paper. The first number in each cell is the posterior probability that the group quality probit $q_{G}$ in the column category exceeds $q_{G}$ in the row category, and the second number is the posterior mean probability of mortality in the row category given a $10 \%$ probability of mortality in the column category, with the posterior standard deviation of this statistic in parentheses. 
Table A12

Posterior means and standard deviations

Selection model, prior variant C: looser prior on $\alpha$ and $\beta$

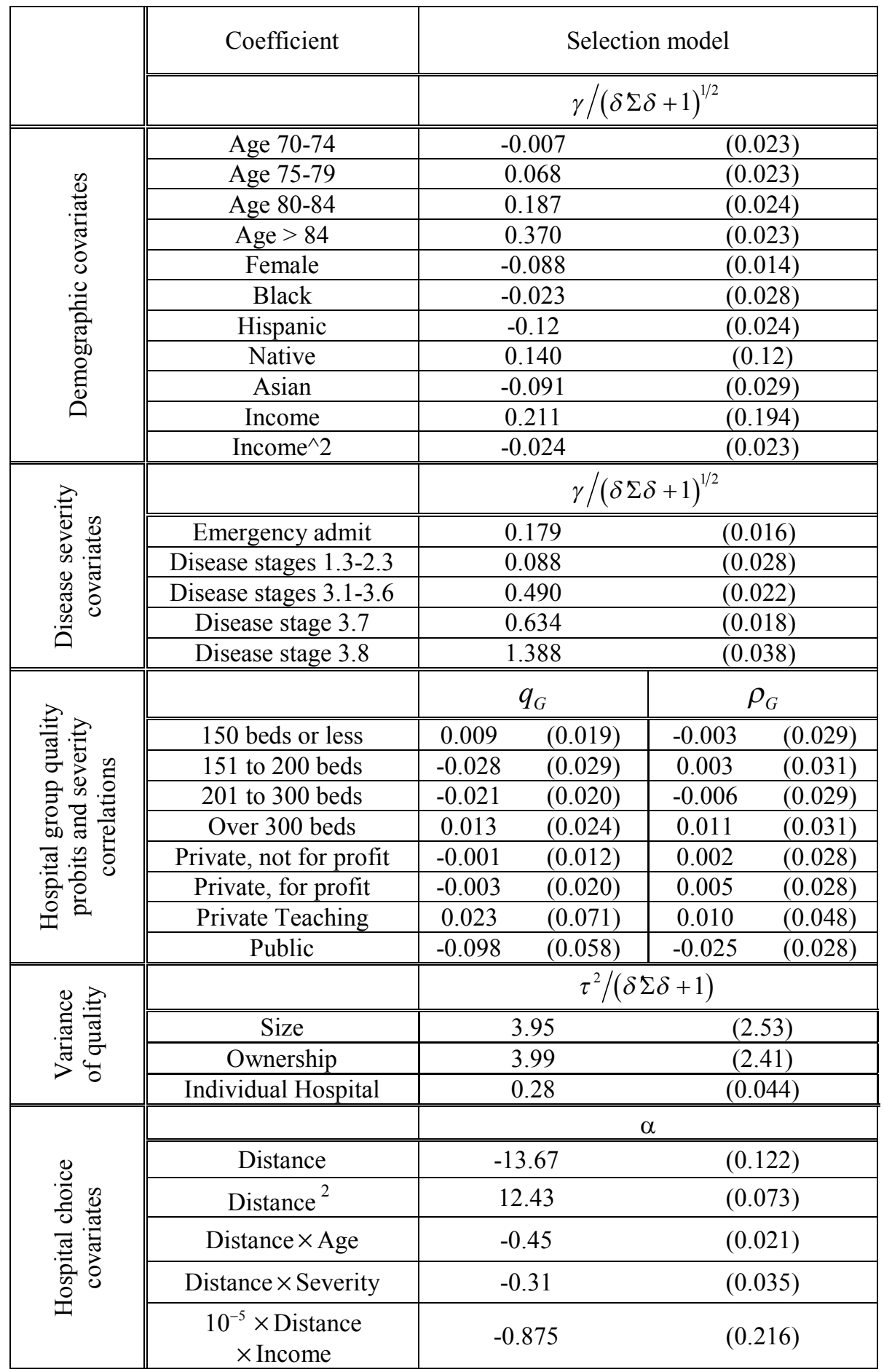

Notation and definitions are exactly as for Table 3 of the paper. 
Table A13

Posterior probability comparisons of group hospital quality probits

Selection model, prior variant C: looser prior on $\alpha$ and $\beta$

\begin{tabular}{|c|c|c|c|c|}
\hline & \multicolumn{4}{|c|}{ A. Hospitals grouped by size } \\
\hline & $\leq 150$ beds & $151-200$ beds & $201-300$ beds & $>300$ beds \\
\hline$\leq 150$ beds & $0.10(--)$ & $\begin{array}{c}9 \% \\
0.094(0.005)\end{array}$ & $\begin{array}{c}13 \% \\
0.095(0.004)\end{array}$ & $\begin{array}{c}50 \% \\
0.101(0.007)\end{array}$ \\
\hline $151-200$ beds & $\begin{array}{c}91 \% \\
0.107(0.006)\end{array}$ & $0.10(--)$ & $\begin{array}{c}59 \% \\
0.102(0.005)\end{array}$ & $\begin{array}{c}77 \% \\
0.108(0.008)\end{array}$ \\
\hline $201-300$ beds & $\begin{array}{c}87 \% \\
0.106(0.005)\end{array}$ & $\begin{array}{c}41 \% \\
0.099(0.005)\end{array}$ & $0.10(--)$ & $\begin{array}{c}81 \% \\
0.106(0.007)\end{array}$ \\
\hline \multirow[t]{3}{*}{$>300$ beds } & $\begin{array}{c}50 \% \\
0.100(0.007)\end{array}$ & $\begin{array}{c}23 \% \\
0.094(0.008)\end{array}$ & $\begin{array}{c}19 \% \\
0.095(0.006)\end{array}$ & $0.10(--)$ \\
\hline & \multicolumn{4}{|c|}{ B. Hospitals grouped by ownership classification } \\
\hline & $\begin{array}{c}\text { Private } \\
\text { not-for-profit }\end{array}$ & $\begin{array}{l}\text { Private } \\
\text { for-profit }\end{array}$ & $\begin{array}{l}\text { Private } \\
\text { teaching }\end{array}$ & Public \\
\hline $\begin{array}{c}\text { Private } \\
\text { not-for-profit }\end{array}$ & $0.10(--)$ & $\begin{array}{c}50 \% \\
0.100(0.004)\end{array}$ & $\begin{array}{c}65 \% \\
0.105(0.013)\end{array}$ & $\begin{array}{c}4 \% \\
0.084(0.009)\end{array}$ \\
\hline $\begin{array}{l}\text { Private } \\
\text { for-profit }\end{array}$ & $\begin{array}{c}50 \% \\
0.100(0.004)\end{array}$ & $0.10^{--}(--)$ & $\begin{array}{c}63 \% \\
0.106(0.015)\end{array}$ & $\begin{array}{c}5 \% \\
0.085(0.010)\end{array}$ \\
\hline $\begin{array}{l}\text { Private } \\
\text { teaching }\end{array}$ & $\begin{array}{c}35 \% \\
0.097(0.013)\end{array}$ & $\begin{array}{c}37 \% \\
0.097(0.014)\end{array}$ & $0.10(--)$ & $\begin{array}{c}11 \% \\
0.082(0.014)\end{array}$ \\
\hline Public & $\begin{array}{c}96 \% \\
0.119(0.011)\end{array}$ & $\begin{array}{c}95 \% \\
0.119(0.012)\end{array}$ & $\begin{array}{c}89 \% \\
0.124(0.020)\end{array}$ & $0.10(--)$ \\
\hline
\end{tabular}

Notation and definitions are exactly as for Table 4 of the paper. The first number in each cell is the posterior probability that the group quality probit $q_{G}$ in the column category exceeds $q_{G}$ in the row category, and the second number is the posterior mean probability of mortality in the row category given a $10 \%$ probability of mortality in the column category, with the posterior standard deviation of this statistic in parentheses. 
Table A14

Correlation between posterior means of hospital quality probits, alternative selection models

\begin{tabular}{|c|c|c|c|}
\hline & Prior variant A & Prior variant B & Prior variant C \\
\hline Base model & .34 & .80 & .80 \\
\hline Prior variant A & -- & .16 & .47 \\
\hline Prior variant B & -- & -- & .66 \\
\hline
\end{tabular}

Table entry indicates correlations between row and column models. 


\section{References (beyond those in the paper)}

Geweke, J., 1991, "Efficient Simulation from the Multivariate Normal and Student- $t$ Distributions Subject to Linear Constraints," in E. M. Keramidas (ed.), Computing Science and Statistics: Proceedings of the 23rd Symposium on the Interface, 571-578. Fairfax, VA: Interface Foundation of North America.

Roberts, G.O., and A.F.M. Smith, 1994, "Simple Conditions for the Convergence of the Gibbs Sampler and Metropolis-Hastings Algorithms," Stochastic Processes and Their Applications 49: 207-216. 